\title{
EFSUMB Guidelines on Interventional Ultrasound (INVUS), Part III Abdominal Treatment Procedures (Long Version)
}

\section{EFSUMB Leitlinien interventioneller Ultraschall (INVUS), Teil III Ultraschall-geführte therapeutische Interventionen (Langversion)}

Authors

Affiliations
C. F. Dietrich ${ }^{1,7}$, T. Lorentzen ${ }^{2}$, L. Appelbaum ${ }^{3}$, E. Buscarini ${ }^{4}$, V. Cantisani ${ }^{5}$, J. M. Correas ${ }^{6}$, X. W. Cui ${ }^{1,7}$, M. D’Onofrio ${ }^{8}$, O. H. Gilja ${ }^{9}$, M. Hocke ${ }^{10}$, A. Ignee ${ }^{1}$, C. Jenssen ${ }^{11}$, A. Kabaalioğlu' ${ }^{12}$, E. Leen ${ }^{13}$, C. Nicolau ${ }^{14}$, C. P. Nolsøe ${ }^{2}$, M. Radzina ${ }^{15}$, C. Serra ${ }^{16}$, P. S. Sidhu ${ }^{17}$, Z. Sparchez ${ }^{18}$, F. Piscaglia ${ }^{19}$

Affiliation addresses are listed at the end of the article.

Key words
guideline
ultrasound guidance
abscess
hepatocellular carcinoma
liver metastases
cysts
radio frequency ablation
drainage
safety

Bibliography

DOI http://dx.doi.org/

10.1055/s-0035-1553917

Published online: December 15, 2015

Ultraschall in Med 2016; 37:

E1-E32 @ Georg Thieme Verlag KG Stuttgart · New York . ISSN 0172-4614

\section{Correspondence}

\section{Prof. Dr. med. Christoph F.}

\section{Dietrich}

Medizinische Klinik 2, Caritas Krankenhaus Bad Mergentheim Uhlandstr. 7

D-97980 Bad Mergentheim Germany

Tel.: ++49/(0)7931/58-22 01/ 2200

Fax: ++ 49/(0)7931/582290

Christoph.dietrich@ckbm.de

\section{Abstract \\ $\nabla$}

The third part of the European Federation of Societies for Ultrasound in Medicine and Biology (EFSUMB) Guidelines on Interventional Ultrasound (INVUS) assesses the evidence for ultrasound-guided and assisted interventions in abdominal treatment procedures. Recommendations for clinical practice are presented covering indications, contraindications, and safe and effective performance of the broad variety of these techniques. In particular, drainage of abscesses and fluid collections, interventional tumor ablation techniques, interventional treatment of symptomatic cysts and echinococcosis, percutaneous transhepatic cholangiography and drainage, percutaneous gastrostomy, urinary bladder drainage, and nephrostomy are addressed (long version).

\section{Introduction}

This is the third of three guidelines (parts I - III) within the framework of the European Federation of Societies for Ultrasound in Medicine and Biology (EFSUMB) Guidelines on Interventional Ultrasound (INVUS) describing ultrasound (US)-guided percutaneous diagnostic and therapeutic interventions of the abdomen. Part III deals with the indications and clinical impact of US-guided therapeutic interventions and gives evidence-based recommendations for the safe and efficient performance of these techniques using the available evidence at the time of manuscript preparation. It is complemented by guidelines on general aspects of US-guided interventions (part I) [1] and US-guided diagnostic interventions (part II) [2]. In addition, EFSUMB also publishes guidelines on the use of diagnostic and therapeutic endoscopic ultrasound interventions

\section{Zusammenfassung \\ $\nabla$}

Der dritte Teil der Leitlinien der European Federation of Societies for Ultrasound in Medicine and Biology (EFSUMB) zur interventionellen Sonografie (INVUS) bewertet die Evidenz für transkutane sonografisch gestützte und assistierte therapeutische Interventionen im Abdomen. Auf der Grundlage publizierter Daten werden zu Indikationen, Kontraindikationen sowie zur sicheren und effizienten Durchführung Empfehlungen für die klinische Praxis gegeben. Berücksichtigung finden die sonografisch geführte Drainage von Abszessen und Flüssigkeitsansammlungen, Tumorablationstechniken, transkutane Zystensklerosierung symptomatischer Zysten und der Echinokokkose, die perkutane transhepatische Cholangiografie und Drainage, die perkutane Gastrostomie, die Harnblasenpunktion und Drainage sowie die Nephrostomie (Langversion).

$[3,4]$ and ultrasound-guided vascular interventions [5].

Methods of guideline development are described in the introduction to the EFSUMB Guidelines on Interventional Ultrasound [6]. Levels of evidence (LoE) and Grades of Recommendations (GoR) have been assigned according to the Oxford Centre for Evidence-based Medicine criteria (March 2009 edition) [http://www.cebm.net/oxford-centre-evidence-based-medicine-levels-evidencemarch-2009].

\section{Local ablative procedures of the liver $\nabla$} Introduction

Local ablative procedures play a key role in the management of patients with malignancies, primarily with hepatocellular carcinoma (HCC), but also with metastases [7-10]. 
The short-term clinical outcome is improved by a multi-modality approach discussed at multidisciplinary team meetings. The reported success rates are multifactorial, and depend upon patient selection and operator experience. The best outcome is delivered when strict clinical criteria are followed and aided by multidisciplinary board discussions.

Most operators use a percutaneous approach, but laparoscopic and laparotomic routes can also be used. Over the last 25 years, different methods have been developed and used clinically. Percutaneous ethanol injection (PEI) was the first widespread technique. Later on, thermal ablative procedures (radiofrequency ablation (RFA), microwave and laser ablation) emerged rapidly. Recently, novel US-guided ablative procedures have become available (interstitial brachytherapy, irreversible electroporation (IRE), and high intensity focused ultrasound (HIFU)) [11 - 15].

\section{Treatment intention}

Local ablative procedures can be classified according to the treatment intention as curative or palliative $[16,17]$.

\section{Curative intention}

Tumor ablation is usually performed with curative intent. This applies mainly to small HCCs ( $\leq 5 \mathrm{~cm})$, as well as to colorectal liver metastases [17-23]. The decision for local ablation over resection should take into account data such as the patient's age, co-morbidities, normal parenchymal reserve and tumor distribution inside the liver, as well as the risks for metachronous tumor growth, and all these should be weighed against the invasiveness of the procedure [16].

\section{Recommendation 1}

HCC ablation should be preferably performed with curative intent (LoE 1a, GoR A). Strong consensus (100\%).

\section{Palliative strategy}

The main indication for palliative treatment of liver tumors is metastatic neuroendocrine tumor load. Other primary [24] and secondary liver tumors may also be treated [16, 25 - 32].

\section{Multi-modal treatment}

With multiple liver metastases (commonly colorectal) not suitable for surgical resection because of their number or location (e. g., proximity of vascular or biliary structures), a combined/ multimodal approach should be considered [33].

Ablation in conjunction with resection is increasingly used as a parenchyma-sparing curative strategy that combines effective ablative treatment of small tumors with resection of large tumors, for which ablation is less effective [34-41]. Similar concepts can be applied to hepatocellular carcinoma (HCC) in a cirrhotic liver, when extensive surgical sacrifice of the parenchyma must be avoided.

\section{Recommendation 2}

Ablation in conjunction with resection may be considered as a parenchyma-sparing curative strategy (LoE 2a, GoR B). Strong consensus (100\%).

\section{Hepatocellular carcinoma (HCC)}

The treatment options for HCC in a cirrhotic liver are transplantation, surgical resection, local ablative therapies, transarterial chemoembolization (TACE), radioembolization with Yttrium90 loaded beads (transarterial radioembolization (TARE), and, in cases of advanced disease, systemic therapy with sorafenib $\left(\right.$ Nexavar $\left.^{\circledR}\right)$. Image-guided percutaneous ablation therapies, such as RFA [42 - 44], PEI [45 - 47] and microwave coagulation [48], have been performed mainly with small HCCs, according to the Milan criteria [49]. These are potentially curative, minimally invasive, and repeatable in case of recurrence [50].

\section{Local ablative treatment techniques for HCC \\ Radiofrequency ablation}

The energy generated by RFA induces coagulation necrosis of the tumor. Different systems have been introduced. Monopolar systems employ a neutral electrode (grounding pad) that is applied to the body surface. The current flows between the ablation probe in the tumor and the neutral electrode generates heat concentrically around the probe. In bipolar RFA systems, both electrodes are mounted close together on the same probe so that all current flow occurs directly between the two electrodes; a neutral electrode is not required. This arrangement has some advantages; ablation can be performed with an active cardiac pacemaker in place, provided that the ablation zone is not close to the pacemaker. Bipolar systems also eliminate the danger of skin burns from the neutral electrode used in monopolar systems. Multipolar systems in which three or more needles can be used simultaneously in an alternating mode are also available $[16,51,52]$. Complete removal of neoplastic tissue (R0) is common after surgical resection, while complete tumor necrosis following RFA is almost $90 \%$ for very small HCCs $<2 \mathrm{~cm}$ and drops to $50 \%$ to $70 \%$ for lesions between $3-5 \mathrm{~cm}$ and lower for larger lesions [44, 53-57] due to the heat loss of perfusion-mediated tissue cooling within the ablated region [44, 53, 55 - 59].

\section{Size of tumors}

As a single RFA needle usually coagulates a region $\leq 2-3 \mathrm{~cm}$ in diameter, potentially non-spherical (depending on the RF system), multiple sequential insertions may be required to achieve a safety margin in lesions $\geq 2-2.5 \mathrm{~cm}$. In one series of 1000 RFA procedures (2140 nodules) in 664 patients, complete ablation was obtained using a mean number of electrode insertions of $1.5,2.3$, 4.2 , and 11.7 for nodules of $\leq 2 \mathrm{~cm}, 2.1-3 \mathrm{~cm}, 3.1-5 \mathrm{~cm}$, and $>5 \mathrm{~cm}$ respectively [59].

To overcome this limitation, multi-needle systems have been introduced for simultaneous ablations and stereotactically guided RFA that produce coagulation zones up to $7-10 \mathrm{~cm}[52,60-$ $62]$. There is no accepted maximum tumor size that can be ablated in a single session but the size is generally in the $4-5 \mathrm{~cm}$ range. Complete response (necrosis) following RFA is $80-90$ percent for tumors $<3 \mathrm{~cm}[43,55,56,63,64]$. Complete necrosis rates are $50-70$ percent for lesions between $3-5 \mathrm{~cm}$ and lower for larger lesions [44, 53-57]. It is difficult to reliably completely treat tumors $>5-6 \mathrm{~cm}$ with current RFA devices. A small study showed that the RFA zone was 3.4-fold larger in patients who received a single dose of pegylated liposomal doxorubicin (20 mg IV) 24 hours prior to planned RFA, as compared to controls (with RFA alone) [65]. This is a promising finding but the evidence is currently inadequate.

The ablated zone should encompass the treated tumor and a circumferential margin of $5-10 \mathrm{~mm}$ around the tumor [66]. Abla- 
tion of giant tumors has been performed using (repeated or single shot large volume) ethanol injection under general anesthesia $[16,17,62]$. However, this technique has significant adverse effects and complete necrosis was difficult to achieve; this technique has been abandoned.

\section{Location of tumors}

HCC tumors in a subcapsular location or adjacent to the gallbladder have a higher likelihood of incomplete ablation [67] or major complications [54, 68, 69]. In a study of 24 explanted livers with RFA-treated HCC prior to liver transplantation, $88 \%$ complete necrosis was achieved for tumors with a non-perivascular location, compared to $47 \%$ complete necrosis for tumors with perivascular locations, the suggested reason being the 'heat sink' phenomenon (blood flow in peritumorally located vessels may carry heat away from the lesions) [58].

To reduce the number of complications, attention must be paid to vulnerable structures close to the tumor or the ablation zone. This applies to the porta hepatis, gallbladder, stomach, small intestine and colon, all of which are particularly sensitive to thermal damage $[70,71]$. In case of subdiaphragmatic lesions, pulmonary, pleural or cardiac heat damage might occur, usually with only minor clinical significance $[72,73]$. Subcapsular or exophytic tumors should be accessed through a portion $(\geq 10 \mathrm{~mm})$ of non-tumoral liver tissue, whenever possible [74], since direct needle insertion into the tumor carries a higher risk of complications, e. g. needletrack seeding or hemorrhage [68]. In selected patients, some operators are prepared to ablate even subscapular tumors [75, 76].

\section{Number of tumors}

The maximum number of tumors that can be ablated in a single procedure is not clearly defined, but ranges from 3 to 5 in most centers [16]. Overall survival is best for patients with solitary tumors, intermediate for those with 2 to 3 tumors, and worst for those with $\geq 3$ tumors [77].

\section{Recommendation 3}

The maximum recommended diameter of HCC lesions treatable with thermal ablation is generally considered below or equal to $5 \mathrm{~cm}$, although optimal results are obtained in lesions $<3 \mathrm{~cm}$ (LoE 2b, GoR B). Strong consensus (100\%).

\section{Recommendation 4}

The ablation zone should aim to extend at least $5 \mathrm{~mm}$ beyond the visible borders (LoE 3a, GoR B). Strong consensus (100\%).

\section{Recommendation 5}

In lesions close to large vessels and heat-sensitive structures, alternative or additional techniques should be considered (LoE 3a, GoR B). Strong consensus (100\%).

\section{Recommendation 6}

Three to five HCCs are the recommended maximum number of lesions in a single session that allows percutaneous ablation with curative intent (LoE 2a, GoR B). Strong consensus (100\%).
RFA versus surgical resection in small HCCs

There is inconclusive evidence as to whether RFA is as effective as surgical resection as the first-line treatment for patients with small, solitary HCCs $[63-71,78]$.

Randomized controlled trials (RCTs) report conflicting results [79-81]. While the first did not identify outcome differences [79], the others suggested survival advantages for surgical resection [80, 81]. Uncontrolled investigations have reported similar outcomes for resection and RFA in early HCC patients [82]. In non-randomized comparative studies, hepatectomy was reported to be better than percutaneous ablation [83], whereas other studies reported no significant difference [84-86]. Higher survival rates were found for resection [87]. A meta-analysis including 11873 patients $(n=6094$ RFA; $n=5779$ hepatic resection) did not find significant differences between groups for 1and 3-year overall survival, recurrence-free survival and disease-free survival. The 5-year overall survival was lower with RFA likely due to higher 3- and 5-year recurrence rates with RFA, but the complication rate and hospital stays were significantly lower for RFA patients [78]. Surgical resection significantly improved the overall survival and disease-free survival rates in comparison with RFA, but still, in a selected group of patients (Child-Pugh class B, multiple HCCs, or in HCCs $\leq 3 \mathrm{~cm}$ ) the two treatments did not show significant differences [87]. This study was not randomized and the surgical and ablation series were obtained in different centers. In a randomized trial resection had better survival and lower recurrence rates than RFA for patients with HCCs using the Milan criteria [80]. This analysis assessed the role of specific tumor size thresholds in early HCC, showing that size had a great impact on the effectiveness of RFA but not of surgery.

A systematic review of 8000 patients [14] with a current Cochrane analysis [88] reported uncertainty regarding the question of the impact of RFA versus surgery. However, a more recent meta-analysis, published after the Cochrane analysis [89], showed that there were differences in age and liver function between patients with early HCC submitted to either RFA or resection. When the analysis was corrected for these parameters, no survival differences were observed between RFA and surgery in single HCCs $<2 \mathrm{~cm}$ or $2-3$ HCC tumors $<3 \mathrm{~cm}$, whereas surgery resulted in a longer survival in the case of single HCCs measuring $2-5 \mathrm{~cm}$ [89]. With RFA, survival rates have been reported to be $39.9-68.5 \%$ at 5 years [59, 82, $90-93]$ and local tumor progression rates to be $2.4-16.9 \%$ [59, 90, 91, 93]. Mortality and morbidity rates of RFA have been reported to be $0-1.5 \%$ and $0.9-7.9 \%$, respectively [59, 82, $91-94]$.

\section{Percutaneous ethanol injection}

PEI was the first ablative procedure, initially reported in the early 1980 s $[45,46,95]$. Under US guidance the tip of a fine needle (20 - 21 gauge) is placed inside the lesion. Ethanol is then injected. It creates a coagulative necrosis as a result of cellular dehydration, protein denaturation, and chemical occlusion of small tumor vessels [12, 83, $96-100]$.

The procedure is inexpensive and safe, with low mortality and morbidity ( $0-3.2 \%$ and $0-0.4 \%$, respectively) [101-103]. Even though RFA has replaced PEI because of superior and predictable ablative results, the two methods are equally effective in small tumors $(<2 \mathrm{~cm})[43,104,105]$. PEI can be offered in small HCCs, mainly those for which RFA is not feasible due to tumor location (e.g. adjacent to the gallbladder, hepatic hilum, or large vessels) [106]. 
Another chemical ablation technique, percutaneous acetic acid injection (PAI), has not offered substantial advantages over PEI [107].

\section{RFA versus PEI}

In comparison with PEI, the necrotic area in RFA is predictable and must include a peritumoral safety margin $\geq 5 \mathrm{~mm}$ of necrosis. This will ablate satellite tumors and minimize local recurrence.

Randomized controlled trials comparing RFA with PEI demonstrate that RFA is superior to ethanol injection in terms of treatment response, number of sessions, recurrences, and overall survival (2-year local recurrence rate: 2 - $18 \%$ versus 11 - $45 \%$ ) [104, $105,108-112]$ as further supported by meta-analyses $[88,111$, 113].

A meta-analysis of six RCTs comparing RFA with PEI and enrolling patients with a tumor size of $\leq 5 \mathrm{~cm}$ found RFA significantly superior to PEI with overall survival (HR 1.64, 95\% CI 1.31 to 2.07), and lack of local progression (HR 2.44, 95\% CI 1.71 - 3.49) [88].

The efficacy of the methods is similar for tumors $\leq 2 \mathrm{~cm}[43,104$, 105, 114]. Meta-analyses, including RCTs, confirmed that treatment with RFA offers a survival benefit as compared to PEI in tumors $>2 \mathrm{~cm}[111-113,115,116]$. RFA has a slightly higher rate of major complications ( $4 \%$; $95 \% \mathrm{CI}, 1.8-6.4 \%$ ) as compared to PEI (2.7\%; $95 \%$ CI, $0.4-5.1 \%)$ [54, 108, 110, 116]. The best results obtained in series of HCC patients treated by RFA provided 5 -year survival rates of $40-70 \%$ or higher in select groups of patients $[60,91,117]$. The best outcomes have been reported in Child-Pugh A patients with small $(<2 \mathrm{~cm})$ single tumors [82, 118]. Independent predictors of survival with RFA are initial complete response, Child-Pugh score, number or size of nodules, and baseline alpha-fetoprotein levels [87].

Child-Pugh A patients with small tumors - that are expected to achieve complete response - are the ideal candidates for RFA, with few patients being more suitable for PEI [119].

\section{Other procedures}

Percutaneous microwave ablation (MWA), produced by dielectric heat from microwave energy emitted from an inserted bipolar electrode, was introduced into clinical practice in the $1990 \mathrm{~s}[48,56,120-125]$. The technique is reported to improve local tumor control [48], with complete response rates of 89 $95 \%$ and three-year survival rates of $51-81 \%[48,56,123$, 126 - 128]. An RCT demonstrated that the number of treatment sessions was fewer with RFA than with microwave coagulation [129], although the rates of complete therapeutic effect, major complications, and local tumor progression were not statistically different between the two therapies. Although requiring electrode needles of a larger diameter than with RFA, MWA has been shown to be safe [130]. Differences in ablative capability with different MWA needle types working at different frequencies of emission are recognized, although no formal comparison has been reported. This is at variance with RFA, where different devices tend to produce similar ablation volumes [131]. An RCT comparing MWA with RFA for HCCs $<4 \mathrm{~cm}$, showed $89 \%$ and $96 \%$ complete response rates, respectively, and $24 \%$ and $12 \%$ for two-year local recurrence rates, respectively (differences not statistically significant). The incidence of residual foci of untreated disease was significantly different (17.4\% for MWA, and $8.3 \%$ for RFA) [129]. Laser thermal ablation is a further alternative, and is useful for HCCs $<4 \mathrm{~cm}[11,132-135]$. This approach is mainly used in Europe with experience from single centers $[11,133,134]$. No trial was found for RFA versus placebo or for transplantation.

\section{Selection of ablation technique}

With PEI, local response is related to tumor size. PEI has yielded very favorable results for small encapsulated HCCs $(<2 \mathrm{~cm})$ [17, 95]. Complete ablation can be achieved in $90-100 \%$ of tumors $<2 \mathrm{~cm}$, the percent of complete ablation is $70-80 \%$ for larger tumors of $2-3 \mathrm{~cm}$ in size, and $50-60 \%$ for lesions larger than $3 \mathrm{~cm}$ $[119,136]$. HCC encapsulation by a cirrhotic liver prevents satellite nodules from being reached, leading to higher rates of local recurrence in comparison to RFA (10-33\% in tumors smaller than $3 \mathrm{~cm}$ and $44-50 \%$ in larger tumors [100, $137-139])$. The targeting of the necrosis only to intra-nodular tissue avoids possible damage to surrounding structures.

\section{Recommendation 7}

Percutaneous ethanol injection with curative intent is an alternative to thermal ablation in encapsulated HCCs $<20 \mathrm{~mm}$ (LoE 2a, GoR B). Broad agreement (95\%).

\section{Recommendation 8}

Percutaneous ethanol injection can be an alternative in case of contraindications to thermal ablation (LoE 3b, GoR B). Broad agreement (79\%).

\section{Selection of imaging modality (ultrasound, CT, MRI)}

US is the first-line imaging modality for local ablative procedures in the liver (except for intraoperative cryoablation). CT guidance can be an alternative, particularly when US guidance is not feasible anatomically or with US imaging of occult lesions [140, 141]. MRI guidance is possible but with limited availability. Local expertise and personal experience determine the modality of choice. Contrast-enhanced imaging must be available during the interventional procedure to confirm the completeness of necrosis. Fusion imaging is an alternative technique that can be used for the guidance of the procedure [16].

\section{Planning and monitoring ablation treatment}

Imaging plays an important role before, during and after ablation procedures. Assessment of tissue perfusion is crucial to differentiate necrotic areas from viable residual tumor. With US- and CT-guided RFA, this requires evaluation with contrast-enhanced imaging during and immediately after ablation. CEUS can provide important information for assessment during and immediately after ablation [142, 143]:

- assessment of the lesions to be treated by ablation (number, size, degree and homogeneity of lesion enhancement, presence of feeding vessels, to define the eligibility for treatment and the best ablation strategy)

- depiction of previously undetectable lesions with the support of fusion imaging, enabling needle/probe guidance to occult lesions

- detection of viable tumor persistence following loco-regional treatment [66]

CEUS is the most effective method to define local recurrence in a treated nodule because of its real-time capability, the intra-vas- 
cular characteristic of the contrast agent and the near-total differentiation between the displayed contrast and background information of current imaging methods [8]. CT and MRI (3 D reconstruction) provide better overviews of the liver and adjacent organs, which are necessary for pretreatment staging and useful to detect distant intra- and extra-hepatic tumor recurrence.

\section{Contraindications}

Contraindications to local ablation are identical to the general contraindications to interventional procedures, based on the risk and benefit for each individual patient and with particular attention to the age, co-morbidity, and desires of the patient [144-146]. Local ablative strategies are contraindicated in patients with significant ascites, uncorrectable coagulopathy, and obstructive jaundice (because of the risk of bile peritonitis). A predicted safe needle track must be confirmed.

\section{Complications}

Studies have established that RFA is a low-risk procedure [147 $150]$, with a mortality of $0.1-0.8 \%$ and few adverse events. Major complications occur in $2.2-11 \%$ of RFA-treated patients [ 94 , 147,151 - 153]. Bleeding, infection, fistula formation, bile duct damage, and tumor seeding are possible complications of local ablative therapy $[16,17,23,146]$. Tumor seeding is reported only for percutaneous procedures and is observed in $0-12.5 \%$ (median 0.9\%) [154], mainly in PEI [74, 155-160]. Larger needle diameters, multiple punctures, subcapsular tumor locations, and combination with biopsies are associated with a higher risk [152].

Thermal track ablation should be performed at the conclusion of any thermal ablation, as it reduces the likelihood of tumor seeding to below $1 \%[74,156-158]$.

\section{Guidelines including RFA for HCC}

European guidelines on HCC

EASL-EORTC Clinical Practice Guidelines: Management of $\mathrm{HCC}^{1}$

According to the European Association for the Study of the Liver (EASL) and the European Organisation for Research and Treatment of Cancer (EORTC) 2012 guidelines, local ablative procedures for focal liver lesions (FLLs) are indicated for the following situations [161]:

- RFA or PEI as the standard of care for patients with tumors stage 0-A according to the Barcelona-Clinic Liver Cancer (BCLC) staging system [162, 163], when not suitable for surgery [Evidence 2A; Recommendation 1B].

- RFA is preferred over PEI, in order to assure better control of the disease, corresponding to complete response with a safety margin [Evidence 1 D, Recommendation 1A]. PEI can be used in $10-15 \%$ where RFA is not technically feasible but PEI is practicable.

- RFA or PEI is equally acceptable for small tumors $<2 \mathrm{~cm}$ classified as stage 0 tumors according to BCLC classification, with proof that more than $90 \%$ of cases will have a complete re- sponse and a good long-term outcome [Evidence 1A, Recommendation $1 \mathrm{C}]$.

ESMO-ESDO Clinical Practice Guidelines for diagnosis, treatment and follow-up of $\mathrm{HCC}^{2}$

According to the European Society for Medical Oncology (ESMO) and The European Society of Digestive Oncology (ESDO) guidelines [164], indications are:

- Local ablative techniques, including RFA and PEI as alternatives to resection for treatment of small HCC nodules $(<2 \mathrm{~cm})[\mathrm{LoE}$ 3, GoR B].

- RFA is recommended over PEI whenever it is available and feasible, as it provides better local control, especially in HCCs $>2 \mathrm{~cm}$ [LoE 2, GoR A] [13].

- For RFA treatment, the number and diameter of lesions to be treated should not exceed 5 and $5 \mathrm{~cm}$, respectively [LoE 3, GoR B].

- Dynamic CT and MRI examinations every 3 months for the first 2 years and surveillance every 6 months thereafter are recommended and should be used in accordance with the clinical setting to detect early recurrence [LoE 3, GoR A].

- Patients with recurrences following curative therapy may still be considered for attempts at curative therapy.

\section{American Guidelines on HCC}

AASLD Management of HCC: An Update ${ }^{3}$

According to the American Association for the Study of Liver Diseases (AASLD) updated guidelines [http://www.aasld.org/sites/ default/files/guideline_documents/HCCUpdate2010.pdf], indications are:

- Resection as the first option for patients with the optimal profile according to BCLC staging system (Level of evidence II)

- Liver transplantation or ablation in patients with advanced disease (Level of evidence II)

- Local ablation for patients who cannot undergo resection, or as a bridge to transplantation (level of evidence II).

- Alcohol injection and radiofrequency are equally effective for tumors $<2 \mathrm{~cm}$. However, the necrotic effect of radiofrequency ablation is more predictable in all tumor sizes and in addition, its efficacy is clearly superior to that of alcohol injection in larger tumors (level of evidence I).

- For very early HCC, confirmation of the completeness of ablation by RFA therapy is needed to prove the efficacy of the method.

National Cancer Institute (NCI) of American Guidelines for HCC

The NCI recommends loco-regional ablative procedures to be considered in patients who are not liver transplant candidates. There are no strict indications and the risk and benefits are to be compared with alternative treatment strategies [http://www. cancer.gov/types/liver/hp/adult-liver-treatment-pdq].

\footnotetext{
2 In this guideline, levels of evidence and grades of recommendation are rated according to the adapted Infectious Diseases Society of AmericanUnited States Public Health Service Grading System for ranking recommendations in clinical guidelines (quality of evidence I-III; Strength of Recommendation $\mathrm{A}-\mathrm{C}$ ).

${ }^{3}$ For classification of evidence an own grading system (I, II-1, II-2, II-3, III)
} was used.

\footnotetext{
${ }^{1}$ In this guideline, the classification of evidence was performed according to the National Cancer Institute: PDQ Levels of Evidence for Adult and Pediatric Cancer Treatment Studies. Bethesda, MD: National Cancer Institute (http:// cancer.gov/cancertopics/pdq/levels-evidence-adult-treatment/HealthProfessional). The strength of recommendations was rated using a modified GRADE system (level of evidence: A: high, B: moderate, C: low/very low quality; grade of recommendation: 1 = strong recommendation and $2=$ weaker recommendation).
} 


\section{Asian Guidelines on $\mathrm{HCC}^{4}$}

Asian Pacific Association for the Study of the Liver (APASL) consensus recommendations on HCC

According to the APASL, the recommendations are [50]:

- Local ablation is an acceptable alternative to resection for small HCCs $(<3 \mathrm{~cm})$ in Child-Pugh class A cirrhosis [LOE 2b, GOR B].

- Local ablation is a first-line treatment of unresectable, small HCCs with $\leq 3$ nodules in Child-Pugh class A or B cirrhosis [LOE 2b, GOR B].

In the clinical guidelines (EASL, AASLD, APASL [50, 161, 165]), RFA is considered a second-line treatment after surgery, without documented evidence, knowing that patients treated with RFA tend to be sicker, and have more advanced liver disease [166, 167]. An expert position paper from the Barcelona group suggested using RFA as the first-line treatment for BCLC-0 patients, corresponding to a tumor bulk of a single $\mathrm{HCC}<2 \mathrm{~cm}$ [168]. In case of single tumors $>3 \mathrm{~cm}$, the rates of complete response with RFA alone decrease progressively [55]. Under these circumstances, a combination of percutaneous ablation with transarterial chemoembolization has provided better recurrence-free survival, but a significantly better survival rate was not demonstrated in comparison to individual treatments $[169,170]$. Three meta-analyses concluded that a combination of TACE plus RFA is associated with a higher survival rate than each procedure alone [171 - 173]. The quality of the evidence was thought to be low [171] and none of the analyses considered the toxicity of combined therapy.

The presence of multiple tumors represented the most frequent indication for RFA [21, 79, 87, $174-180]$. An advantage of ablation is parenchyma sparing, a major benefit in HCC patients, most of whom have a poorly functioning cirrhotic liver. Decision making should always be a multidisciplinary exercise.

Initially, patients should be assessed for possible transplantation. Those who are not transplant candidates are considered for alternative treatments, taking into account that the present interventional ultrasound recommendations are specifically designed for HCCs in liver cirrhosis and are considered only after liver transplantation has been excluded.

\section{Recommendation 9}

A multidisciplinary approach to assess patients with HCC in liver cirrhosis for possible transplantation is recommended prior to alternative treatments (LoE 5, GoR D). Strong consensus (100\%).

\section{Recommendation 10}

RFA with curative intent is an alternative, more cost-effective technique in comparison to surgery in early HCC BCLC-0 (HCC $<2 \mathrm{~cm}$ ) (LoE 2a, GoR B). Strong consensus (100\%).

\section{Recommendation 11}

RFA with curative intent should be considered as a secondline treatment in single HCCs $2-5 \mathrm{~cm}$ in Child-Pugh A patients, after the patient has been evaluated for surgical resection (LoE 2b, GoR B). Strong consensus (100\%).

\footnotetext{
${ }^{4}$ The APASL guidelines used the Oxford Centre for Evidence-based Medicine classification (LoE 1-5; GoR A-D; May 2010) [http://www.cebm.net/oxford-centre-evidence-based-medicine-levels-evidence-march-2009].
}

\section{Recommendation 12}

RFA with curative intent should be considered as the first-line treatment in Child-Pugh B patients with single HCCs $<5 \mathrm{~cm}$ or in patients with 2 or $3 \mathrm{HCCs}<3 \mathrm{~cm}$ (LoE $2 \mathrm{~b}$, GoR B). Strong consensus (100\%).

\section{Recommendation 13}

Solitary HCCs $>3 \mathrm{~cm}$ not suitable for surgery should be considered for combined loco-regional treatments (LoE 4, GoR C). Broad agreement (95\%).

\section{Recurrence and adjuvant therapy}

The benefits of local ablative techniques are limited by disease recurrence, which varies between $4-60 \%$ depending on the size of the ablated tumor and the approach used. Local tumor progression after PEI has been reported to be between 6 - $43 \%$, depending on the tumor size. This limits the value of the procedure in lesions $>3 \mathrm{~cm}$, where higher local recurrence rates are documented $[101,102,137,138,181]$.

In various clinical studies, combinations of RFA with other treatment modalities (TACE followed by RFA [182] or hepatic arterial balloon occlusion during RFA [183]) have been attempted to increase the ablated volume by reducing the cooling effect of the blood flow. Although extension of the necrotic zone was achieved, it is uncertain whether these combined treatments improve the prognosis.

The long-term prognosis following surgical resection or RFA for HCC remains disappointing, with a high recurrence rate (5-year rate $>70 \%$ ), mainly a consequence of ineffective adjuvant therapy [50, 184-188]. The results of the STORM trial, a phase III randomized, double-blind, placebo-controlled trial of 1114 patients evaluating adjuvant sorafenib after resection or ablation, showed no differences in recurrence-free survival, time to recurrence or overall survival [189].

\section{Colorectal cancer liver metastases}

It is estimated that $50-60 \%$ of patients with colorectal cancer (CRC) will develop liver metastases [190]. Estimates for five-year survival after diagnosis of liver metastases vary between 17 $48 \%$. The most successful treatment for hepatic metastases is surgical resection [9, 10, 36, 77, $191-197]$. When CRC metastases are confined to the liver, liver resection is indicated as a potentially curative treatment whenever an $\mathrm{RO}$ resection (curative resection) of all metastases is technically feasible [34, 35, 198]. However, approximately $50-70 \%$ of these patients will develop recurrence [199].

Local ablative procedures with curative intent have a role in the management of CRC liver metastases [9, 10]. Depending on the size of the lesions, RFA may be performed alone or combined with resection [200]. Several studies have demonstrated that RFA achieved permanent local ablation of liver metastases and a 5year survival of $24 \%$ to $43 \%$ [ $201-205$ ]. These results are comparable to surgery $[36,77,191-197]$. This is noteworthy as RFA patients generally have a poorer prognosis, partly as a result of higher comorbidity than surgical candidates [31]. Local recurrence occurs more frequently after ablation than with resection $[9,10,206]$. In a study comparing RFA and surgery in 482 patients with CRC liver metastases, the overall survival (OS) and disease-free survival (DFS) did not differ between the two groups in 226 patients with 
a single metastatic tumor $<3 \mathrm{~cm}$ (RFA group 99 patients, resection group 127 patients): the five-year OS and DFS rates were $51.1 \%$ and $33.6 \%$, respectively, in the RFA group and $51.2 \%$ and $31.6 \%$, respectively, in the resection group. In the 70 patients with a solitary metastasis $\geq 3 \mathrm{~cm}$ (RFA group: 14 patients; resection group: 56 patients), the DFS rates were significantly lower in the RFA group (RFA group: $23.1 \%$; resection group: $36.6 \% ; \mathrm{P}=0.01$ ) [207]. Two meta-analyses confirmed that surgery is superior to RFA with regard to survival outcomes in patients with resectable CRC liver metastases [208, 209]. However, an imbalance between characteristics of patients allocated to both treatments makes it difficult to draw definitive conclusions [210].

The first RCT on the efficacy of RFA combined with chemotherapy versus chemotherapy alone was underpowered; RFA plus systemic treatment resulted in significantly longer progression-free survival (PFS) compared with chemotherapy alone [211].

Combination therapy resulted in an excellent overall survival of 30 months, also achieved in systemic chemotherapy alone (control arm) [211]. There are no prospective, controlled, randomized studies comparing resection and local ablative procedures.

\section{Recommendation 14}

Percutaneous thermal ablation with curative intent is a second-line alternative to surgery in patients with colorectal liver metastases (LoE 2a, GoR B). Strong consensus (100\%).

\section{Recommendation 15}

The maximum diameter of metastatic lesions treatable with thermal ablation is generally considered $\leq 4 \mathrm{~cm}$, although better results are obtained in lesions $<3 \mathrm{~cm}$ (LoE 5, GoR D). Strong consensus (100\%).

\section{Recommendation 16}

The ablation zone should aim to extend at least $10 \mathrm{~mm}$ beyond the visible borders (LoE 5, GoR D). Broad agreement (94\%).

\section{Other liver metastases}

Percutaneous thermal ablation or PEI may be a therapeutic option for neuroendocrine liver metastases [28, 29].

\section{Renal malignancies treated with local ablative therapy Introduction}

The incidence and detection of asymptomatic renal masses has increased over the previous 25 years, essentially as a consequence of improved imaging technology and the improved understanding of the clinical-pathological behavior of renal cell carcinoma (RCC) [212-216]. The survival rate has improved as a result of earlier diagnosis [213, $217-219]$. Currently most renal masses (61\%) are incidental findings [220].

Possible treatment options for RCC are [221]:

- Surgery, either nephrectomy or nephron-sparing (open or laparoscopic)

- Local ablative procedures (percutaneous or laparoscopic)

cryoablation

- radiofrequency ablation

$\checkmark$ microwave ablation (MWA)

- Active surveillance
Treatment options for RCCs are appraised below with regard to age and performance status, history of previous partial nephrectomy, comorbidity factors, renal function, and staging.

\section{Small masses}

Standard therapy for small RCCs is nephron-sparing surgery. Local ablative techniques have evolved into alternative procedures, showing excellent results [222]. Active surveillance, an alternative option, can be suggested in poor surgical candidates, as histologically confirmed small RCCs have a growth rate of $4 \mathrm{~mm}$ per year [223]. Active surveillance is currently not a standard option. Tumors $<4 \mathrm{~cm}$ in diameter are ideal candidates for ablative techniques. The volume to be treated should include a $5-10 \mathrm{~mm}$ safety margin [224]. Most tumors $<3 \mathrm{~cm}$ can be treated in a single ablation session. Tumors between $3-4 \mathrm{~cm}$ in diameter can also be successfully treated, although multiple ablation sessions may be required [225 - 233].

\section{Recommendation 17}

Patients with RCCs $<3 \mathrm{~cm}$ with significant surgical risk or requirement for nephron-sparing strategy should be considered for local ablative therapy (LoE 2b, GoR B). Strong consensus (100\%).

RCTs comparing surgery and local ablative therapy have not been performed [221, 234]. Cancer-specific survival is similar for both methods [235, 236]. The European and American Urological Associations recommend thermal ablation as a treatment option for patients with a T1 renal mass [237].

US techniques are recommended as the ideal imaging guide for RFA [237].

Possible advantages of local ablative procedures are: (1) treatment option for surgically unfit patients, (2) lower morbidity and mortality, (3) shorter hospitalization time, (4) better parenchymal sparing.

The presence of viable tumor in core biopsies following RFA in about $47 \%$ of cases has been suggested [238], but others found no viable tumor on biopsy after one year [239]. This remains controversial, probably resulting from histological uncertainty in defining viability in core specimens, suggesting that frequent imaging follow-up is necessary. Cryotherapy was performed laparoscopically (75\%) and RFA was mainly performed percutaneously (84\%) [240], making comparison difficult.

Local recurrence-free survival following image-guided tumor ablation is $87 \%$ [241]. The local recurrence of percutaneously performed RFA is estimated at $2.5-14 \%$ [242]. Cancer-specific survival of patients treated with RFA is comparable to patients treated with surgery [227, 237, 243]. Both cryotherapy and RFA had a higher risk of recurrence compared to partial nephrectomy [244], but re-intervention is straightforward [227].

The rate of major complications for cryotherapy is $5 \%$, which is lower than for surgery [237], the most common complication being hemorrhage [213] with $2 \%$ developing distant metastases $[237,243]$. Post-procedural ureteric strictures have also been documented [237]. Cryotherapy is preferred over RFA in central tumors in contact with the renal hilum or the ureter [245].

Systemic therapy for advanced RCC is increasingly used. Imaging does not always accurately differentiate benign from malignant disease [246]. Up to $25 \%$ of small $(<3 \mathrm{~cm})$ kidney lesions are benign [247], and as such, based on established oncologic standards, histological confirmation is necessary prior to treatment with a de- 
structive technique. This standard is not always followed. In a meta-analysis the rate of unknown histology was reported at $40 \%$ (before RFA) and 24\% (before cryotherapy) [248].

\section{Recommendation 18}

RCC histology should be obtained prior to ablation (LoE 4, GoR C). Broad agreement (81\%).

Contrast-enhanced US (CEUS) can be used for surveillance after RFA of RCCs in order to detect local recurrence and to assess for liver metastases [249]. CT of the thorax and abdomen is necessary to exclude metachronous extrahepatic metastases. No RCTs have been performed [250-252].

Recommendation 19

Contrast-enhanced ultrasound or CT or MRI should be performed in the follow-up after RCC ablation, unless contraindicated (LoE 4, GoR C). Strong consensus (100\%).

\section{Pancreas}

At present, radical resection is the only option capable of improving long-term survival in the case of pancreatic cancer. This is possible in $20-30 \%$, and after resection, the 5-year survival rate, even in high-volume surgical centers and in combination with adjuvant therapy, does not exceed $30 \%$ [253]. Neoadjuvant strategies are under evaluation. RFA of pancreatic ductal adenocarcinoma is based on encouraging experiences in other organs [241, 254 ], and is intended to be palliative for unresectable locally advanced adenocarcinoma [255 - 259].

RFA is performed under intraoperative US guidance during laparotomy [255]. Following RFA, there are controversial patient survival reports. In pancreas centers, RFA has become a palliative treatment for tumor cytoreduction in a multimodality treatment approach [257, 259-261]. A systematic review concludes that RFA has a positive impact on survival [259]. A pretreatment biopsy is required [246].

\section{Abscess drainage \\ $\nabla$}

US-guided percutaneous drainage of abdominal abscesses is a well-established interventional procedure first described in 1974 [262] and is currently the first-line treatment approach for abdominal abscesses.

\section{Definition and classification}

Differentiation between phlegmonous inflammation and abscesses is of importance for treatment guidance. Antibiotic treatment is indicated for phlegmonous inflammation and for abscesses $<1-3 \mathrm{~cm}$, although the "minimal drainage size" of abdominal abscesses is not established. An abscess is a pus-containing confined collection, most often caused by bacteria. To be termed an abscess, the fluid has to be viscous and surrounded by an inflammatory wall that develops as a result of effective host defense [263]. Free contaminated or infected peritoneal fluid or loculated collections represent a phase in the continuum of peritoneal contamination/infection/empyema and are not termed an abscess [264]. A classification of abdominal abscesses has been proposed [॰ Table 1] [265]:
Table 1 Classification of abdominal abscesses.

\begin{tabular}{|ll}
\hline classification & examples \\
\hline visceral versus non-visceral & hepatic versus subphrenic \\
\hline primary versus secondary & splenic versus appendiceal \\
\hline $\begin{array}{l}\text { spontaneous versus } \\
\text { postoperative }\end{array}$ & diverticular versus \\
intra-peritoneal versus & peri-anastomotic \\
retroperitoneal & tubo-ovarian versus psoas \\
\hline simple versus complex & complex: \\
& - multiple (liver) \\
& - multiloculated \\
& - communication with bowel \\
& (e. g. leaking anastomosis) \\
& - associated with necrotic tissue \\
& (pancreatic) \\
& - associated with cancer \\
& subphrenic, subhepatic, lesser \\
& sac, paracolic, pelvic, interloop, \\
\hline anatomical & perirenal, psoas \\
\hline
\end{tabular}

Recommendation 20

Phlegmonous infections and small abscesses should be treated with antibiotics and require no drainage (LoE: 5; GoR: D). Strong consensus: $100 \%$.

\section{Postoperative fluid collection}

Fluid collections present on postoperative imaging, localized or generalized ("free fluid"), are common and nonspecific which may represent different pathological entities such as hematoma, exudate, seroma, bilioma, lymphocele or an abscess. Fluid seen on imaging is often not characteristic; any patient with a clinical suspicion of an abdominal abscess should have a diagnostic aspiration to guide further management. Sterile fluid collections can become infected postoperatively, requiring diagnostic aspiration and eventually therapeutic drainage.

\section{Ultrasound (US)}

US imaging is often the initial modality used in abscess delineation as it allows dynamic evaluation and real-time guidance of needling. Depending on the contents, an abscess can be anechoic, hypoechoic and even hyperechoic. CEUS can be helpful in differentiating vascularized from avascular areas [266, 267].

\section{Computed tomography (CT) and magnetic resonance imaging (MRI)}

CT is indicated in technically limited US examinations or inconclusive results. CT often gives better anatomic details (exact location, size, shape, organ relations) of fluid collections than US, although there is no evidence to support this. An enhancing thickened wall and the presence of gas indicates abscess formation.

Magnetic resonance cholangiopancreatography (MRCP) is indicated in patients with biliary tree obstruction and leakage, e.g. after surgery, but is not used as the initial investigation in the detection of abdominal abscesses.

\section{Diagnostic aspiration}

A US-guided diagnostic puncture of a fluid collection with a fine needle or a larger needle (dependent on the viscosity) can distinguish an abscess from a non-infected fluid collection. 
The aspirate should be examined for pus and consistency (thick or liquid) and for debris, in order to guide further drainage strategy. The aspirate should be sent for bacterial culture.

\section{Recommendation 2}

Diagnostic aspiration of a suspected infected fluid collection is recommended (LoE 5, GoR D). Strong consensus (100\%).

\section{Puncture and drainage}

The fundamentals of image-guided (percutaneous) treatment of abscesses include drainage with a needle or catheter, plus lavage. A description of the procedure can be found in text-books [268] and in the EFSUMB Course Book [(www.efsumb.org/ecb/ecb-01. asp)].

\section{Catheter drainage versus needle aspiration}

A meta-analysis of 5 RCTs comparing catheter drainage and repeated needle aspirations of liver abscesses demonstrated catheter drainage to be more effective, with higher success and shorter time to achieve clinical improvement [269]. Studies of abdominal abscesses of various etiology have shown good results with repeated needle aspiration in simple abscesses $<5 \mathrm{~cm}$. In larger abscesses catheter drainage performed better than repeat needle aspiration [270 - 274].

With regard to the organs involved, an abscess of $5 \mathrm{~cm}$ in the liver is small in comparison with a $5 \mathrm{~cm}$ abscess in the kidney or spleen. Needle aspiration should be the initial approach, as this is simple, causes less patient discomfort and avoids problems related to drainage catheter care. This technique is preferred if bowel loops need to be traversed for drainage. Catheter drainage is indicated if needle aspiration fails after $2-3$ attempts [270, 275]. Needle aspiration may still be performed after catheter displacement.

\section{Recommendation 22}

Abscesses less than $5 \mathrm{~cm}$ in diameter can be treated with needle aspiration (LoE 2b, GoR B). Strong consensus (100\%).

\section{Recommendation 23}

Catheter drainage is more effective than needle aspiration in abscesses larger than $5 \mathrm{~cm}$ in diameter (LoE 1a, GoR A). Broad agreement ( $89 \%)$.

\section{Small or large catheters}

Large bore $12-14 \mathrm{~F}$ catheters were favored for abscess drainage early in the development of this clinical application, but with experience [276], a typical abscess catheter is now $7-10 F$. No difference in outcome was seen in a study of intra-abdominal abscesses treated with 7F pigtail catheters and 14F sump drain catheters [277].

This reduction in catheter size can be attributed to: 1 . The early interventionalist was influenced by surgical traditions, where large catheters were common; 2 . Developments in catheter material and construction allowing a larger inner diameter and improved surface structure. Currently large catheters $(>10 \mathrm{~F})$ should be reserved for complex abscesses containing thick pus and debris.

\section{Recommendation 24}

Catheters of 7-10F in size are recommended for the treatment of most abscesses, regardless of abscess dimensions (LoE 4, GoR C). Broad agreement (90\%).

\section{Recommendation 25}

Large catheters ( $>10 \mathrm{~F}$ ) should be reserved for complex abscesses with thick contents (LoE, 5, GoR D). Broad agreement (90\%).

Catheter introduction techniques: Trocar versus Seldinger Two techniques are used for the insertion of a drainage catheter: the trocar (one-step) technique and the Seldinger (two-step) technique. Both have advantages and disadvantages and can be performed with either a free-hand or needle-guided technique, depending on the preference and experience of the operator. There are no studies comparing the two techniques, probably because the methods are complementary rather than competitive [o Table 2].

\section{Recommendation 26}

The trocar technique is suitable in most circumstances using catheters $\leq 10 \mathrm{~F}$ (LoE 5, GoR D). Broad agreement (93\%).

\section{Recommendation 27}

The Seldinger technique is recommended when access is difficult, for large catheters, and for catheter replacement ( $\operatorname{LoE} 5$, GoR D). Broad agreement (86\%).

Single versus double lumen

Double lumen catheters are not recommended since they combine the negative features of large diameters and relatively small lumens.

\section{Recommendation 28}

Double lumen catheters are not recommended (LoE 5, GoR D). Broad agreement (94\%).

\begin{tabular}{|c|c|c|}
\hline & $\begin{array}{l}\text { trocar tech- } \\
\text { nique }\end{array}$ & seldinger technique \\
\hline advantages & $\begin{array}{l}\text { - fast and } \\
\text { simple }\end{array}$ & $\begin{array}{l}\text { - preferred when access is difficult } \\
\text { - introduction guided by transrectal } \\
\text { or trans-vaginal probes possible } \\
\text { - preferred when track dilatation and } \\
\text { catheter exchange is needed } \\
\text { - preferred technique for large } \\
\text { catheters } \\
\text { - preferred for cases in which } \\
\text { insertion is difficult }\end{array}$ \\
\hline $\begin{array}{l}\text { disadvan- } \\
\text { tages and } \\
\text { limitations }\end{array}$ & $\begin{array}{l}\text { - not suitable } \\
\text { for large } \\
\text { catheters }\end{array}$ & $\begin{array}{l}\text { - fluoroscopy may be necessary to } \\
\text { monitor the procedure } \\
\text { - time-consuming and complex }\end{array}$ \\
\hline
\end{tabular}


Abscess cavity extension and complexity, fistula, and contrast injection (X-ray, CEUS)

Treatment planning requires careful assessment of the size, shape, content and extent of the abscess, including identification of associated fistulas. Fistulography (or abscessography, sinography) with intracavitary injection of iodinated contrast media under CT or fluoroscopic guidance has been the recommended technique. Direct injection of US contrast agent through the needle or catheter has been reported to facilitate confirmation of correct needle or catheter position and allows evaluation of any communication between cavities in complex abscesses at the bedside [278 - 280].

\section{Recommendation 29}

Intracavitary CEUS may add value regarding needle and catheter position, cavity morphology and presence of fistulas (LoE 4 , GoR C). Strong consensus ( $100 \%$.

\section{Specific organs and locations}

With respect to the specific location of intra-abdominal abscesses (organ or cavity), a dedicated management strategy should be considered, but the basis for all percutaneous drainage remains identical: puncture, aspiration and irrigation.

\section{Liver abscess}

Pyogenic liver abscesses are often the result of biliary obstruction caused by benign or malignant diseases with consequent cholangitis. Abscess formation may also occur following microbe entry into the liver via the portal vein (pyophlebitis) secondary to GI tract infections (diverticulitis, appendicitis, chronic inflammatory bowel disease, or post-operative infections). The microbes may also enter the liver via the arterial system e.g. in osteomyelitis or endocarditis. For percutaneous drainage, a transhepatic access route is preferred for direct puncture to avoid spillage of pus into the peritoneal cavity. Further imaging with US, endoscopic ultrasound (EUS), CT, or MRI is indicated to ascertain the cause of the biliary obstruction. Intracavitary contrast injection (X-ray or CEUS) into a hepatic abscess can demonstrate communication between the abscess and the biliary tree, which might alter management strategy. Small amebic abscesses generally respond to conservative treatment and do not require drainage, but large amebic abscesses may need drainage [281].

Recommendation 30

The origin of liver abscesses should be investigated to search for an underlying cause (LoE 5, GoR D). Strong consensus $(100 \%)$

\section{Recommendation 31}

A transhepatic access route is recommended for the percutaneous drainage of hepatic abscesses (LoE 5, GoR D). Strong consensus (100\%).

\section{Splenic abscess}

Splenic abscesses are rare, except in immunocompromised patients. There are no studies of percutaneous drainage versus surgical treatment (splenectomy). The outcomes of percutaneous drainage are conflicting; a meta-analysis [282] reported that per- cutaneous drainage and needle aspiration had low success rates ( $51 \%$ and $65 \%$, respectively). Other studies reported a higher success rate of percutaneous drainage [271, 283-289], which is recommended as the first-line treatment. Percutaneous treatment allows preservation of the spleen. Splenic puncture or biopsy is relatively safe as documented in a meta-analysis [290].

\section{Recommendation 32}

Percutaneous splenic abscess drainage should be the first-line treatment and surgery should be performed in the case of treatment failure (LoE 4, GoR C). Broad agreement (89\%).

\section{Pancreatic abscess}

Percutaneous drainage of pancreatic abscesses is often prolonged and may require multiple catheters. A study has reported success in $86 \%$ of patients [291, 292]. Typically pancreatic abscesses appear after acute pancreatitis. Fistulas can be problematic. The percutaneous approach has the advantage of being quick and offering treatment access for severely ill patients. As a second stage procedure, conversion to internal drainage (double pigtail plastic stent or self-expanding metal stents) via an EUS approach should be considered [293]. However, this approach remains controversial [294].

\section{Recommendation 33}

Pancreatic abscess management is complex and often prolonged. EUS and percutaneous procedures should be considered (LoE 4, GoR C). Broad agreement (89\%).

\section{Enteric abscess}

Abscesses are frequent complications of Crohn's disease, diverticulitis and appendicitis. In Crohn's disease, there is no study comparing percutaneous and surgical drainage of abscesses. Percutaneous drainage of Crohn's-related abscesses has a high success rate, demonstrated in several studies and is the first-line treatment [295, 296]. With early percutaneous drainage, (non-elective) surgery can often be avoided ( $14-85 \%$ of patients) [296 - 300].

Several studies suggest that percutaneous drainage of Crohn'srelated abscesses is less effective when there are associated bowel (macro) fistulas [295]. A fistula should be suspected when the drainage catheter produces a persistently high volume of fluid ( $>50 \mathrm{~mL}$ of fluid per day). Contrast injection (X-ray or CEUS) into the abscess (fistulography) should be performed.

Abscesses can be detected in $15 \%$ of patients with acute diverticulitis [301, 302]. Antibiotics successfully treat smaller abscesses $(<3 \mathrm{~cm})[301,303,304]$, but larger abscesses $(>3 \mathrm{~cm})$ require percutaneous drainage $[305,306]$. In peridiverticular abscesses, suspected fistulas need to be confirmed or refuted as this may require surgery. Peri-appendicular abscesses can occur either as a result of rupture of an infected appendix or post-operatively. Despite the frequency of peri-appendicular abscesses, no studies have investigated percutaneous treatment.

It is generally accepted that a peri-appendicular abscess will respond to percutaneous treatment. A pitfall with presumed periappendiceal and peri-diverticular abscesses is an infected, necrotic tumor. This may be drained successfully but requires subsequent colonoscopy to determine if an underlying tumor is present. Leakage of enteric contents at an anastomosis may lead to abscess for- 
mation which most often requires reconstructive surgery. Sometimes, a non-surgical approach is preferred with usage of longterm percutaneous drainage with large catheters.

\section{Recommendation 34}

Abscesses in Crohn's disease, diverticulitis and appendicitis may benefit from percutaneous drainage as the first-line strategy (LoE 4, GoR C). Broad agreement (89\%).

\section{Abscess in the lower abdomen and pelvis}

Abscesses located in the lower abdomen and pelvis represent a challenge primarily because of overlying bowel loops, making the traditional transabdominal puncture route difficult. For these deep pelvic abscesses, alternative puncture routes are available. Transrectal, transvaginal, transperineal and transgluteal accesses have all been shown to be useful and safe [272, 293, 307, 308]. The transrectal route provides direct access to perirectal and presacral fluid collections whereas the transvaginal route accesses gynecologic and midpelvic collections. The development of dedicated endoprobes with needle guides has established transvaginal and transrectal US-guided abscess drainage procedures [293] but comparative studies are missing. Different drainage techniques are possible (needle aspiration or catheter drainage) and catheters can be introduced using a one-step trocar technique or preferably using a Seldinger technique $[272,307,308]$.

\section{Recommendation 35}

US-guided drainage by transrectal, transperineal or transvaginal access is associated with a low risk of complications and should be considered for deep pelvic abscesses (LoE 4, GoR C). Strong consensus (100\%).

\section{Catheter management and patient care during abscess drainage}

There is a paucity of evidence for the management of abscess catheters and this mainly depends on clinical judgment and local practice. Daily catheter care, including routine irrigation, and observation of output is mandatory for successful abscess drainage. There is general agreement regarding catheter management:

- An abscess catheter should be connected to a drainage bag.

- Routine irrigation should be performed at least 3 times a day.

- Irrigation with $10-20 \mathrm{~mL}$ of saline solution until the aspirate is clear is often sufficient; over-distension should be avoided.

- A persistently high output ( $>50 \mathrm{~mL}$ of fluid per day) may indicate connection to a fistula.

- Re-evaluation with US, CT or fluoroscopy is indicated in cases of catheter dysfunction or insufficient drainage.

- Repeated catheter clogging indicates a change (over guide wire) to a new and possibly larger catheter.

- Simple abscesses are typically alleviated after 5-7 days of treatment indicated by a decreased output $(<10 \mathrm{~mL}$ of fluid per day) and clinical improvement.

\section{Use of fibrinolytics (plasminogen activator or streptoki-} nase) in viscous fluid collections or complex abscesses Two studies suggest that routine catheter flushing using fibrinolytics instead of saline solution decreases the total time to abscess resolution, length of hospital stay, and total cost of care [309,
310]. No improvement after streptokinase in the treatment of pleural infections was reported [311].

\section{Recommendation 36}

Use of intracavitary fibrinolytics is not routinely recommended (LoE 5, GoR D). Broad agreement (94\%).

\section{Microbiology and antibiotics}

Intra-abdominal abscesses are often polymicrobial (mixed aerobic and anaerobic) reflecting mixed gut flora [312 - 314], whereas liver and splenic abscesses tend to be monomicrobial. These abscesses generally require a combination of drainage (percutaneous/ surgical) with antibiotics for complete cure, since antibiotics do not reach sufficient concentrations within the abscess cavity, as evidenced in an experimental study [315]. Antibiotics are recommended for patients who present with clinical signs of bacteremia (e.g., fever and leukocytosis). Antibiotic treatment should (when indicated) be targeted according to the culture results and antibiotic sensitivities. If required, broad-spectrum antibiotic agents are recommended as initial treatment, accounting for the polymicrobial nature of abdominal abscesses. Further refinement of antibiotics should be based on culture data including sensitivity testing $[313,316]$.

\section{Intracavitary antibiotic treatment}

Intracavitary antibiotic treatment is not recommended in the treatment of abdominal abscesses.

\section{Peri-interventional antibiotic treatment}

Peri-interventional use of antibiotics should be reserved for patients who present with clinical signs of septicemia at the time of the drainage procedure [313]. There is no evidence for the prophylactic use of antibiotics.

\section{Specimen collection}

It is good clinical practice to collect pus/aspirate material prior to antibiotic treatment, to ensure sufficient samples for chemical, cytological, and microbiological tests.

\section{Ultrasound-guided paracentesis \\ $\nabla$}

\section{Background}

Fluid collection within the peritoneal cavity is multi-factorial: hypersecretion of serous fluid by the peritoneum with impaired fluid absorption (e.g. peritonitis), injury to fluid-containing structures and pressure alterations in the venous system (e.g. right heart failure, portal hypertension) [268].

Paracentesis is performed either as a diagnostic or as a therapeutic procedure, in the presence of ascites or suspected bacterial peritonitis. Therapeutic paracentesis provides almost immediate symptomatic relief and is usually well tolerated.

\section{Technical issues}

Ascites drainage is usually easily and safely performed by inserting a $14-18$ gauge needle (including paracentesis-specific devices) or as a one-step catheter under US guidance. Catheters can be pig-tail, they can have an internal string for internal loop fixation, or an internal balloon fixation can be used. A small bore catheter (between $5 \mathrm{~F}$ and $\mathrm{7F}$ ) is usually adequate. 
One-step catheters are excellent for drainage but are difficult to introduce as they will not penetrate tissue as easily as a $21-23$ gauge needle, particularly if the tissue is fibrous or firm. Conversion of the procedure to a Seldinger technique using a lumbar needle with the catheter being placed over a guidewire as the final step is possible. Once positioned correctly, the catheter should be secured and left in place for several hours to allow fluid drainage [268].

US guidance offers real-time imaging of the needle tip and surroundings during the procedure, making it safe and effective. In most instances, US assistance (i.e., US utilized to select the best access point prior to blind needle insertion) is as safe as US guidance [317].

US helps to reduce the risk of injury to vessels that run along the inner abdominal wall (e.g. inferior epigastric vessels, distended paraumbilical veins) and to minimize failed aspirations due to malposition of the needle tip. It adds more options to the traditional puncture site in the lower left quadrant of the abdomen (reverse McBurney point). The needle may be inserted anywhere; the operator should choose the shortest possible route that avoids obstacles such as blood vessels, the omentum, and the bowel. The ability to use it as a bedside procedure is an important additional advantage [318].

\section{Complications}

Paracentesis is considered a safe procedure, carrying a $1 \%$ risk of overall complications, which include leakage of ascitic fluid, local infection, abdominal wall hematomas, intraperitoneal hemorrhage, and intestinal perforation [319]. It is recommended to follow strict antiseptic practices in all patients [320]. Ultrasound guidance can reduce the risk of complications after paracentesis, such as pneumothorax and bleeding, thus improving safety [317, 321].

\section{Cytology, microbiology tests}

Fluid can be sent for relevant chemical, cytological, and microbiological tests. The ideal volume for Gram stain is $0.5 \mathrm{~mL}$ and $2 \mathrm{~mL}$ for most cultures. A culture for mycobacteria requires a larger volume of approximately $10 \mathrm{~mL}$. A sterile tube (or even the aspiration syringe itself) is sufficient for dispatch to the microbiology laboratory, when the transportation time is $<2$ hours. If the transport time will exceed 2 hours, a suitable transport medium must be used. If collected specimens cannot be submitted immediately, the fluid should be stored at $4{ }^{\circ} \mathrm{C}$ to prevent specimen contamination or overgrowth by fast-growing organisms [268].

\section{Recommendation 37}

Ultrasound-guided or assisted paracentesis is a low-risk and effective procedure (LoE 4, GoR C). Strong consensus (100\%).

\section{Specific considerations}

\section{Cirrhosis}

Ascites is the most common complication of cirrhosis leading to hospital admission. $12 \%$ of hospitalized patients who present with decompensated cirrhosis and ascites have spontaneous bacterial peritonitis (SBP). Early paracentesis is recommended for all hospitalized patients with cirrhosis with a large amount of ascites of recent onset or worsening ascites not responding to diuretic therapy or, when there is fever or abdominal pain, to rule out SBP even when the ascites is scanty. To demonstrate SBP, the white blood cell count in the fluid ( $>500$ leucocytes/nL or $>250$ granulocytes/nL) and/or microbiologic testing positive for bacteria can be used [322].

\section{Albumin administration}

Large-volume paracentesis ( $>5 \mathrm{~L}$ ) is generally an effective and safe procedure, but it does carry a risk of "postparacentesis circulatory dysfunction" (PCD). Even before paracentesis, patients with ascites are subject to marked circulatory dysfunction. In the majority of patients not receiving adjunctive treatment, removal of large volumes of ascites by reducing intra-abdominal pressure increases venous return, which increases cardiac output but also favors further transfer of circulating fluid into the peritoneal cavity. However, because of the drop in peripheral vascular resistance and increase in fluid accumulation in the peritoneal cavity, the effective circulating volume declines, leading to a reduction in arterial pressure and activation of the renin-angiotensin-aldosterone pathway. This complication is associated with a high rate of re-accumulation of ascites, development of hepatorenal syndrome, dilutional hyponatremia, and a decrease in survival. To alleviate PCD, albumin should be administered intravenously in an amount of 6-8 gr for each liter of ascites fluid removed, at least for paracentesis exceeding 5 liters in volume [323].

\section{Recommendation 38}

Administration of albumin is mandatory in large-volume $(>5$ liters) paracentesis (LoE 1a, GoR A). Strong consensus (100\%).

\section{Hemorrhagic complications}

Bleeding complications after paracentesis are rare. Signs and symptoms of hemorrhage typically become evident immediately to 24 hours after the procedure. Renal dysfunction was the most prevalent metabolic derangement, occurring in $70 \%$ of patients with bleeding, compared to coagulopathy and thrombocytopenia ( $59 \%$ and $8 \%$, respectively) [319]. There is no recommendation for the administration of coagulation factors or platelets. If blood is found on diagnostic paracentesis, an abdominal CT or US examination should be performed to evaluate for abdominal wall hematoma or intra-abdominal bleeding. Patients with risk factors for hemoperitoneum may benefit from either a lower-volume paracentesis, slower drainage of ascites, or concurrent administration of albumin [324].

\section{Recommendation 39}

There are no established preprocedural threshold coagulation levels that preclude paracentesis (LoE 5, GoR D). Broad agreement (94\%).

\section{Palliative paracentesis for malignant ascites}

Malignant ascites accounts for around $10 \%$ of cases and occurs with a variety of neoplasms, particularly breast, bronchus, ovary, stomach, pancreas and colon [325]. Large amounts of ascites can cause increased abdominal pressure with pain, dyspnea, loss of appetite, nausea, and reduced mobility. Long-term paracentesis is indicated for patients with symptoms of increased intraabdominal pressure caused by recurring malignant ascites despite repeated paracentesis. 
There is no consensus on the speed of fluid withdrawal, and concurrent intravenous hydration is not well standardized [326]. Tunneled or non-tunneled or peritoneal catheters may be placed under US and fluoroscopic guidance. The use of non-tunneled drainage catheters is associated with increased infection (35\%), blockage (30\%) and leakage (20\%) and should be considered in patients with a short life expectancy [327, 328]. Several studies have described successful and safe placement of tunneled peritoneal catheters as well as the Pleur $\mathrm{X}^{\mathrm{TM}}$ catheter in patients with malignant ascites and a longer life expectancy [329-335]. A study comparing 40 patients with abdominal catheters and 67 patients who underwent repeated large-volume paracenteses over a 41 -month period found similar complication rates. Patient satisfaction with the catheter was high [336]. A systematic review shows that the peritoneal catheter drainage system is clinically effective in patients with malignant ascites, has low complication rates, improves quality of life and is less costly than repeated inpatient paracentesis. A National Institute for Health and Care Excellence (NICE) guideline recommended consideration of a peritoneal catheter drainage system in patients with treatment-resistant, recurrent malignant ascites [337].

\section{Recommendation 40}

Permanent catheter drainage should be considered for terminally ill patients with refractory ascites (LoE 4, GoR C). Broad agreement (94\%).

\section{Sclerotherapy of non-parasitic cysts}

$\nabla$

\section{Hepatic cysts}

Hepatic cysts have a prevalence of $2.5-7 \%$. Most are asymptomatic and do not need treatment [338]. Percutaneous treatment, consisting of aspiration of cystic fluid followed by injection of a sclerosing agent, is usually performed with US guidance, as a minimally invasive option for large or symptomatic cysts.

\section{Indications}

Large cysts $(>6-10 \mathrm{~cm})$ which are symptomatic (pain or infected), causing space-occupying effects (abdominal distension, obstructive jaundice or both), require treatment. Other less established indications include symptomatic small sub-capsular cysts located at sites exposed to mechanical stress (beneath the ribs or sternum) [339]. In polycystic liver disease, any dominant cysts may be treated if causing symptoms or to avoid complications (e.g., rupture, bleeding) [340 - 345].

\section{Recommendation 41}

With symptomatic or compressive hepatic cysts, percutaneous sclerotherapy or surgery should be considered (LoE 4, GoR C). Broad agreement (96\%).

\section{Contraindications}

Caution is required when treating hydatid cysts; the nature of a cyst may not be known prior to aspiration [339]. When there is communication with the biliary tree, cysts are usually decompressed and not distended. A relative contraindication is he- morrhagic cysts [346] though they can be treated with similar results once infection or malignancy has been excluded [342]. Ascites and planned liver transplantation are other relative contraindications.

\section{Other imaging modalities in the work-up (CT/MR/CEUS)}

CT-guided puncture can also be performed but this is rarely necessary as US-guided drainage is usually successful. Before sclerotherapy is attempted, communication with the biliary tree should be investigated using fluoroscopy or intracavitary administration of a US contrast agent [347, 348].

\section{Multidisciplinary decision making}

Multidisciplinary decision (gastroenterologists, surgeons, interventional radiologists) for the procedure is obligatory as other options include open surgery and laparoscopic deroofing which are effective treatments. These treatments are associated with substantial morbidity and mortality and require expertise [349, 350]. Percutaneous treatments have similar efficacy, allowing surgery to be reserved for complicated cases or if percutaneous sclerotherapy fails [341, 351].

\section{Sclerotherapy versus surgery (fenestration)}

No randomized prospective study comparing fenestration and sclerotherapy has been published. In most centers, sclerotherapy is attempted first as a noninvasive option, and laparoscopic fenestration is indicated in refractory cases [351].

\section{Recommendation 42}

Percutaneous ethanol sclerotherapy is a good alternative to laparoscopic deroofing with similar efficacy and lower complication rates (LoE 4, GoR C). Broad agreement (96\%).

\section{Prognosis}

The majority of patients who undergo percutaneous sclerotherapy are symptomatically improved immediately following the procedure, but only $20 \%$ will have partial or full regression of the dominant and symptomatic cyst [350]. In polycystic liver disease both sclerotherapy and surgery are disappointing (77 $100 \%$ recurrence rate) [9].

\section{Materials and technical issues}

The treatment consists of evacuation of the cystic contents (either by aspiration or drainage via a catheter) followed by sclerotherapy of the inner epithelium using standard agents (ethanol, polidocanol, tetracycline chloride, minocycline chloride, hypertonic saline solution and ethanolamine oleate) [352356]. Following local anesthesia, a Chiba needle ( $18-20$ gauge) is introduced into the cyst under US guidance and advanced into the distal third of the cyst. One aliquot should be aspirated for cytologic analysis, white blood cell count, microbiology, and bilirubin level. If the fluid is clear or amber-colored, biliary tree communication is unlikely, thus allowing aspiration and sclerotherapy to proceed. A yellowish or dark-greenish color suggests a biliary communication; these cysts should first be aspirated and drained [339]. A radiopaque contrast medium or US contrast agent should be instilled into the cyst to exclude a connection with the biliary tree [347]. If contrast medium enters the bile ducts, sclerotherapy is contraindicated. 
Ethanol sclerotherapy

Ethanol is most commonly used for sclerotherapy of hepatic cysts (95-98\% concentration) [357 - 359]. Single or multiple sessions may be needed with evacuation of the fluid content performed using 6 - 8F catheters or a Chiba needle ( 18 - 20 gauge) [357 - 359]. Catheters may be introduced directly using the trocar technique with low complications. Prolonged catheter drainage with negative pressure and single-session alcohol sclerotherapy had similar results in hepatic cysts. Performing sclerotherapy in one session might be less effective for destroying the entire epithelium in comparison with prolonged drainage [338]. In ethanol sclerotherapy, different volumes (10-50\% (as a rule "30\%") of the cyst volume, total volume $<200 \mathrm{ml}$ ), different ethanol concentrations (95 - 99\%) were used and the sclerosing agent exposure time varied from 10 minutes (as a rule "30 minutes") to 4 hours [352, 360]. The longer the sclerosing time (retention time, reinjections), the lower the recurrence rate but the higher the complication rate. After ethanol sclerotherapy, an $80-100 \%$ reduction of cyst volume may be achieved [338, 341, 352, 357, 359, 360].

The main complications during ethanol sclerotherapy are pain, ethanol-induced fever or hyperthermia, intoxication, intra-cystic bleeding and iatrogenic pleurisy or peritonitis [342, 353]. Active bleeding can be controlled by repeat injection of the sclerosing agent [339]. Ethanol intoxication and even ethanol-induced coma are serious events that may occur when a large volume of ethanol is injected into large cysts or when the exposure time to ethanol is $>60$ minutes, i. e., the time interval that is optimal for a sclerosing effect $[338,342]$. Patients are often hospitalized for $24 \mathrm{~h}$ and sedation may be necessary.

\section{Recommendation 43}

With percutaneous ethanol sclerotherapy of large liver cysts, the use of small catheters instead of needles should be considered to achieve a longer ethanol exposure time (LoE 4, GoR C). Broad agreement (95\%).

\section{Sclerotherapy using other substances}

Several other substances with better safety profiles, ease of use and low cost have been tested with good results and few complications [352-356]. Polidocanol 1-3\% (aethoxysklerol) may be preferred for its local anesthetic properties (it is less painful than alcohol) and its slight bactericidal activity [339].

The technique usually consists of evacuation of part of the cyst contents, followed by instillation of the sclerosing agent, which is left in situ for various time periods. The intra-cystic distribution of the sclerosing agent may be enhanced by using foam sclerosants (liquid sclerosants mixed with air). The advantage of foam sclerotherapy with polidocanol $(10 \mathrm{~mL}$ of $3 \%)$ has been demonstrated with hepatic cysts $[347,361]$.

\section{Recommendation 44}

Percutaneous sclerotherapy using other substances is an alternative to ethanol (LoE 4, GoR C). Broad agreement (90\%).

\section{Ultrasonographic follow-up}

In polidocanol therapy maximum volume reduction occurred 1 year after the procedure [347]. Follow-up examinations may only be necessary in symptomatic patients.

\section{Renal cysts}

Indications

Simple renal cysts are mostly asymptomatic and do not require treatment. In $2-4 \%$ the cyst may become symptomatic because it enlarges or develops complications such as hemorrhage, infection, rupture or compression [362]. Cysts that develop adjacent to the renal hilum may obstruct the urinary tract [363]. Spontaneous, iatrogenic or traumatic rupture of a large renal cyst may cause hematuria or pain. US-guided cyst aspiration with or without sclerosing therapy is a minimally invasive, simple, safe and low-cost procedure [363].

\section{Recommendation 45}

Symptomatic simple renal cysts should be considered for treatment. (LoE 4, GoR C). Broad agreement (94\%).

\section{Multidisciplinary decision making}

A multidisciplinary decision regarding procedure choice is recommended as surgical excision via open, percutaneous, laparoscopic or robotic surgery is effective but more invasive. Laparoscopic deroofing achieves better results than percutaneous sclerotherapy (PS) [362, 363]. Surgery carries a higher morbidity and longer hospital stay, and is reserved for PS failures or for atypical cysts. An RCT of 40 symptomatic renal cysts found percutaneous aspiration and sclerotherapy with polidocanol equal in efficacy with lower morbidity and shorter hospital stay in comparison with laparoscopic deroofing [364], supporting results from retrospective studies [365]. Percutaneous therapy is indicated in nearly all symptomatic patients, with the exception of suspected malignancy.

\section{Recommendation 46}

The decision on treatment modality should consider that percutaneous sclerotherapy is less invasive and associated with lower risks than laparoscopic deroofing, but has lower efficacy (LoE 2b, GoR B). Broad agreement (88\%).

\section{Contraindications}

Contraindications of renal cyst sclerotherapy are uncorrectable coagulopathy, lack of a safe percutaneous access route, atypical cystic masses where tumor is a possibility and communication with the urinary tract that should be investigated with a contrast study, either CEUS or with X-ray contrast material.

\section{Other imaging modalities in the work-up (CT/CEUS)}

Safe guidance of sclerotherapy of renal cysts may be performed with contrast-enhanced CT [366] or US guidance combined with fluoroscopy or CEUS [279]. Preconditions are:

- the possibility to assess any communication between the cyst and the pelvicalyceal system by filling the cyst with contrast medium (for US guidance this will be performed using fluoroscopy or intracavitary CEUS),

- to exclude any leakage from the puncture site into the retroperitoneal cavity [366].

\section{Materials and technical aspects}

A variety of substances are used for sclerotherapy of the urothelium [356, $367-376]$ as described for liver cysts. Sclerotherapy is 
contraindicated if the contrast medium enters the collecting system. To prevent pain, an anesthetic may be injected into the cyst prior to the instillation of the sclerosing agent [377].

\section{Simple cyst drainage without sclerotherapy}

After simple aspiration, the recurrence ranges from $30-80 \%$ $[274,377]$.

\section{Recommendation 47}

Simple aspiration should not be used in the treatment of renal cysts because recurrence is frequent (LoE 4, GoR C). Broad agreement (93\%).

\section{Ethanol sclerotherapy}

The most common sclerotherapy agent for renal cysts is ethanol [372-376]. A concentration of 95-99\% destroys the secreting cells of the cyst wall without affecting the renal parenchyma [362]. Single or multiple sessions have been used, with better results but with higher complications for multiple sessions [363, $366,373-377$ ]. The time of exposure (in-dwell time) to ethanol varies from 3 minutes to 4 hours, most often around 20 minutes $[352,363,373,375,377,378]$. The volume of ethanol injected following aspiration varies from $20-50 \%$ of the cyst volume and the maximum dose from $75-200 \mathrm{~mL}$. Most studies use $<100 \mathrm{~mL}$ of ethanol [362]. Several techniques have been evaluated to deliver a higher ethanol concentration along the entire cyst wall (limiting recurrence): use of a three-way tube to prevent air from entering the renal cyst, repetition of fluid aspiration to reduce the presence of debris adherent to the cyst wall [379], continuous-negative pressure catheter drainage [338], continuous drainage of the cyst for $24 \mathrm{~h}$ before therapy [380] and no drainage of the agent after finishing the procedure [381]. The results are better for smaller cysts, for two or more injection techniques and for continuous drainage [363, 372 - 374].

The main complications that may occur during ethanol sclerotherapy are pain, fever, and systemic reactions [362]. Alcohol intoxication is a rare complication, occurring after large volume injections. Other complications include extravasation of the sclerosing agent and bleeding, the latter being encountered more frequently after rapid percutaneous drainage [362].

\section{Recommendation 48}

Multiple sessions and/or prolonged drainage should be used to reduce recurrence in symptomatic large renal cysts treated with ethanol sclerotherapy (LoE 4, GoR B). Broad agreement (87\%).

\section{Ultrasonographic follow-up}

Follow-up examinations may only be necessary in symptomatic patients.

\section{Abdominal echinococcal cysts, puncture, aspiration, injection and re-aspiration (PAIR)}

\section{Introduction}

Echinococcosis is a chronic, complex and neglected zoonosis with widespread global distribution. $70 \%$ of cases of cystic echinococco- sis (CE) are located in the liver [382]. US has an important role in the diagnosis, staging and follow-up of abdominal CE and is established in the interventional treatment of abdominal CE [383, 384].

\section{Classification}

The WHO echinococcal cyst classification $[385,386]$ is US-based and was introduced to guide treatment options and to predict prognosis [387]. Type CE1 and CE2 are the typical active cysts. Type CE1 is unilocular, whereas CE2 is multilocular with daughter cysts. The Gharbi classification is still widely used [388]. However, only $28.8 \%$ of publications included in a systematic review used one of the standardized ultrasound classifications [389].

\section{Diagnosis and differential diagnosis}

Determining whether a cystic lesion is a "hydatid cyst" depends on the presence of a thick wall or when membrane detachment is obvious. Simple or minimally complex cysts, as well as biliary cystadenocarcinomas or abscesses may have these features and have to be considered in the differential diagnosis.

\section{Imaging}

US is the imaging modality most appropriate for diagnosis and differential diagnosis [386], while US guidance is usually used for intervention [390, 391]. CT is indicated when US is unsatisfactory (obese patients, difficulty in imaging due to gas/bone) [392]. MRI is usually not indicated as a guidance method for intervention but is preferred to $\mathrm{CT}$ for pretreatment assessment because it characterizes the internal structures of CE better [383, 393, 394].

\section{Serological tests}

Serological tests for echinococcosis should be obtained, where available, before the procedure $[395,396]$.

\section{PAIR indication}

PAIR is most appropriate for Gharbi type I and II cysts (CE1 and CE3(A) according to the WHO classification) [396, 397].

\section{Relative contraindications}

Hydatid cysts with multiple daughter cysts and solid components (Gharbi Type III-IV and WHO CE2-CE3b) are not suitable for PAIR [384, 397, 398]. It is reported that aggressive percutaneous evacuation for these complex cysts is useful, but is not widely accepted.

\section{Pretreatment procedures}

As with any interventional procedure, before the PAIR procedure, the patient should be carefully evaluated. Albendazole should be started one week (or at least one day) prior to the procedure for prophylaxis against abdominal contamination [399], and thereafter continued for at least one month [384, 400]. In one small RCT, adjuvant albendazole treatment decreased the recurrence rate in CE patients treated with PAIR [399].

\section{Procedure, puncture and drainage}

The procedure consists of puncture, aspiration, injection and re-aspiration [268, 387, 401] using a 20-gauge fine needle [402, 403]. The cyst should not be punctured directly but via intervening liver parenchyma to prevent spillage of the contents into the peritoneum. Hydatid fluid is usually transparent. However, in aged or infected cysts, the color may be dark yellow and the material viscous. The aspirated fluid should be analyzed microbiologically, and also cytologically if there is suspicion of a neoplastic cystic 
mass [384]. Following aspiration of the cyst fluid, a scolicidal agent such as $96 \%$ ethanol [404] or hypertonic saline (20\%) [405] is injected into the cavity. The amount should not exceed $1 / 3$ of the initial cyst volume. For cysts $>600 \mathrm{~mL}$, a maximum amount of $200 \mathrm{~mL}$ is advised [384]. After a period of 5-20 minutes, the fluid is re-aspirated [384]. With the potential for anaphylactic reactions, patients should have IV access during the procedure and vital parameters should be monitored [406]. The incidence of severe anaphylaxis is $1-2 \%$ [407]. It is crucial to exclude possible biliary communication of the cyst. Bilirubin in the aspirate can immediately be evaluated with commercially available dip-sticks. Cystography may be performed by injecting contrast material into the cyst cavity to ascertain if the cyst has a connection with the biliary system. It is suggested that if the aspirate is not clear or colorless, but contains bile, then scolicidal agents should not be administered [268]. A counter-suggestion indicates that hypertonic saline may be given with caution, with no biliary damage related to PAIR being reported [396].

\section{Outcome}

RCTs showed PAIR to be superior to albendazole alone [408] and to surgical treatment $[387,409]$. A meta-analysis comparing the clinical outcomes for 769 patients with hepatic CE treated with PAIR plus albendazole or mebendazole with 952 matched historical controls undergoing surgical treatment alone. PAIR combined with albendazole was more effective than surgery and was associated with a lower rate of adverse events and a shorter hospital stay. Clinical and parasitologic cure occurred in $95.8 \%$ of patients undergoing PAIR and in $89.8 \%$ of surgical controls and disease recurrence occurred in $1.6 \%$ and $6.3 \%$, respectively [407]. Retrospective studies favor PAIR over surgery in Gharbi type I and II cysts and found surgical treatment most appropriate in the other Gharbi types [401, 410].

A meta-analysis reported severe adverse events (anaphylaxis, cyst infection, abscess, sepsis, biliary fistula) in $7.9 \%$ of patients treated with PAIR plus albendazole compared to $25.1 \%$ of surgically treated patients. Minor adverse events have been observed in $13.1 \%$ of patients treated with Pair plus albendazole versus $33 \%$ of surgically treated patients [407].

\section{Recommendation 49}

US-guided PAIR is the most appropriate treatment for Gharbi type I and II or WHO CE1 and CE3(A) abdominal hydatid cysts (LoE 2b, GoR B). Strong consensus (100\%).

\section{Recommendation 50}

PAIR should always be accompanied by measures to manage possible anaphylaxis (LoE 5, GoR D). Broad agreement (93\%).

\section{Recommendation 51}

Albendazole should be started prior to PAIR (LoE 2b, GoR B). Strong consensus (100\%).

\section{Post-procedure care}

After the PAIR procedure, the patient should be turned onto the side of puncture, and kept in this position for at least 30 minutes; this may help to avoid leakage from the puncture site. The patient should be hospitalized for one night and observed for late allergic reactions and pain. The following day, after US examination, the patient may be discharged [396].

\section{Follow-up}

Follow-up may be scheduled at one week, one month, three months, six months after PAIR and then annually. CT may be necessary during follow-up, to better depict multiple cysts and calcification $[401,409]$.

\section{Percutaneous transhepatic cholangiodrainage (PTCD) $\nabla$}

\section{Introduction}

Percutaneous transhepatic cholangiography and drainage (PTCD) is a commonly used procedure for the diagnosis and treatment of benign and malignant biliary diseases [411, 412]. PTCD also allows therapeutic interventions, such as placement of a stent across a malignant stricture, dilatation of benign biliary strictures and extraction of biliary tract stones [413].

Endoscopic retrograde cholangiography versus PTCD versus endoscopic ultrasound-guided cholangiodrainage

Endoscopic retrograde cholangiography (ERC) is the method of choice for patients with indications for (therapeutic) biliary access $[414,415]$. The following surgically altered anatomical situations have a high likelihood for ERC failure: Roux-en-Y with gastric bypass, Kausch-Whipple resection, pylorus-preserving Whipple resection, Roux-en-Y with hepaticojejunostomy, choledochojejunostomy, and pancreaticojejunostomy [416]. Patients with a previously performed surgical Billroth I and II gastrectomy were not a problem for conventional ERC.

Alternative methods are PTCD, endoscopic ultrasound (EUS)-guided interventions (EUS cholangiodrainage, EUS-CD) [293] and balloon-assisted enteroscopy (BAE). BAE is only of use if the papilla or the biliary-enteric anastomosis is not reached by conventional endoscopic methods. PTCD and EUS-CD can be useful in these situations as well, if papilla cannulation or passage over a stenosis fails. Here, either method can be used for a rendezvous maneuver with ERC or as the definite procedure [417]. The role of PTCD is not clearly defined in guidelines issued by other professional societies. In malignant hilar strictures, the European Society of Gastrointestinal Endoscopy (ESGE) recommends that the choice between ERC and PTCD is based on local expertise [418] but refers to level 1 evidence for fewer infectious complications with PTCD compared to ERC. They recognize that combined expertise is not available in many centers. PTCD access is not mentioned for patients with common bile duct (CBD) strictures. The American Society of Gastrointestinal Endoscopy (ASGE) guideline for ERCP in diseases of the biliary tract and the pancreas does not mention either PTCD or EUS-guided techniques [414]. The American Society for Gastrointestinal Endoscopy (ASGE) guideline for the role of endoscopy in the evaluation and treatment of patients with biliary neoplasia [419] refers to EUS-guided or percutaneous techniques in case of failure of ERC without further information. The 2013 Tokyo guidelines on the diagnosis and treatment of cholangitis refer to PTCD as the second choice treatment in patients with cholangitis. These guidelines state that EUS-guided techniques are not well established and recommend their use only if ERC or PTCD fails [415]. EUS-guided techniques are well established as a safe and effective alternative to PTCD when ERCP fails [293]. 
Special problems

PTCD: Left versus right lobe

Typically right-sided procedures are preferred, but left-sided PTCD is feasible, both with and without US guidance [420]. A review of conventional PTCD procedures reported a non-significant increase in significant hemobilia of $1.5-5.2 \%$ if the left approach was chosen [421].

\section{Ultrasound guidance versus fluoroscopic guidance}

A blind percutaneous puncture of peripherally located intrahepatic bile ducts has limitations especially with non-dilated bile ducts [422, 423]. Real-time imaging with US is useful for the guidance of PTCD (US-PTCD), especially in patients with non-dilated ducts and for left-sided PTCD [420, 424, 425]. Fluoroscopy delivers significant irradiation both to the patient and to the interventional team. The "As Low As Reasonably Achievable" (ALARA) principle should be applied [426].

A study comparing US-PTCD with fluoroscopy-guided PTCD [427] shows advantages for US guidance regarding intervention success and complications. The Society of Interventional Radiology guidelines does not refer to the use of US guidance for PTCD [428]. Other studies focus on feasibility, technical details or subgroups $[420,424,425]$. No prospective comparative studies are available, but authors recommend US guidance during the puncture procedure as an extrapolation from other interventional procedures where US is effective, efficient and safe in comparison to a "blind" technique, e. g. placement of central venous catheters and nerve blocks $[429,430]$. CEUS has been successfully used to facilitate the efficacy of US-guided PTCD and for the detection of catheter dislodgement and other complications [431 - 434].

\section{Recommendation 52}

For initial puncture in PTCD ultrasound guidance should be considered (LoE 4, GoR C). Strong consensus (100\%).

\section{Level of obstruction}

US can be of advantage in patients with hilar obstruction to identify and allow puncture of peripheral ducts to facilitate a sufficient bile duct length for Seldinger maneuvers.

\section{Presence of obstruction}

Patients with biliary leakage and non-dilated ducts are problematic if ERC fails. US allows targeting of certain areas in which the bile duct lumen may be seen even in the absence of duct dilatation [424].

\section{Percutaneous cholecystostomy \\ $\nabla$}

\section{Introduction}

Acute calculous cholecystitis (ACC) is a common cause of acute surgical admission. Early cholecystectomy (CCE) is a widely accepted method of treatment [435]. Laparoscopic cholecystectomy (LCCE) in acute cases has minimal morbidity [436]. In highrisk patients morbidity and mortality increase to $14-46 \%$ [437]. Alternatively, percutaneous cholecystostomy (PC) is a bridging process, especially in otherwise healthy patients (e.g. ASA I and II) who are severely septic and may become fit in due course for semi-elective surgery [438].
US-guided percutaneous cholecystostomy (USPC), first reported in 1979 [439], was further developed [440] and has become established as a minimally invasive alternative in patients not considered fit for cholecystectomy.

\section{Clinical efficacy}

A meta-analysis of 53 studies ( $\mathrm{n}=1918$ patients) showed no study comparing the outcomes of PC and CCE [441]. Successful PC was reported for $85.6 \%$ of patients. Catheter displacement was reported in $8.57 \%$ (98/1144 patients, 35 papers), and adverse events of all types, most frequently pneumonia, were seen in $6.3 \%$ (44 papers). A mortality of $15 \%$ was reported for PC, defined as 30-day mortality or in-hospital death. The mortality rate caused by biliary infection was 3.6\% (64/1768 patients, 47 papers). Procedure-related mortality rate of PC was $0.4 \%$ (7/1861 patients, 51 papers). The mortality after elective CCE following USPC was $15.4 \%$ [441]. A decrease in mortality from $22 \%$ in 1996 to $13.3 \%$ in later studies is recorded [442 - 446].

Most studies lack comparative data so the conclusions are subjective, preventing valid comparison of success, morbidity, mortality and adverse events [447]. A comparative study of USCP followed by LCCE and primary LCCE in two matched groups of high-risk patients found USCP combined with LCCE superior to LCCE alone with regard to duration of operation, conversion rate to open CCE, length of postoperative hospital stay, and adverse events [448]. A retrospective study comparing outcomes of USCP followed by LCCE compared with LCCE alone in elderly high-risk patients with acute cholecystitis reported a significantly lower rate of conversion to open CCE for patients treated with USCP followed by LCCE. Perioperative mortality and postoperative morbidity did not differ between the two treatment strategies [449]. Examination of outcomes of PC and CCE in patients with acute cholecystitis ( $n=248229$ calculous and 58518 acalculous acute cholecystitis patients) found patients receiving PC were more likely to be older with additional comorbidities. Patients treated with PC had lower complication rates compared with patients treated by CCE. However, patients who received PC had a higher mortality and longer length of stay [450].

Patients with grade III acute CC [451] defined as having cardiovascular dysfunction (hypotension requiring catecholamine therapy), neurological dysfunction (reduction of consciousness), respiratory dysfunction, renal dysfunction, hepatic or hematological dysfunction (platelets below $100000 / \mu \mathrm{L}$ ) are thought to be candidates for the interventional approach. In pregnant women with failure of conservative treatment [452], USPC has been suggested particularly during the $1^{\text {st }}$ and $3^{\text {rd }}$ trimester. Multi-disciplinary discussion between the surgeon, the gynecologist and the interventionalist is necessary in these patients.

With high-risk hemodialysis patients, allocating patients unfit for surgery to USPC, USPC patients had a worse outcome than CCE patients. This may be attributed to the different risk assessment of both groups rather than to a higher risk of USPC [453].

Poor candidates for surgery due to chronic illnesses can also be treated conservatively, and USPC can be reserved for patients not recovering after 3 days. This approach cannot be used in patients with severe sepsis, who should be treated as soon as possible [454]. Evaluation of US-guided PC (USPC) for patients with acute acalculous cholecystitis (AAC) is more difficult because it is normally a complication of serious medical and surgical illnesses $[455,456]$. A study compared clinical efficacy and adverse events of PC and CCE in a large group of severely ill patients with AAC and showed PC to be a safe and cost-effective bridging treatment strategy, 
with perioperative outcomes superior to those of open CCE. Compared with open or laparascopic CCE $(n=1021)$, PC $(n=704)$ was superior in terms of morbidity, intensive-care unit admissions, length of hospital stay, and costs [457]. Two studies showed that in seriously ill patients with AAC, PC is an effective procedure and a good alternative for patients unfit to undergo immediate surgery because of severe sepsis or an underlying comorbidity, and may be regarded as a definite treatment option in the majority of patients $[444,445]$.

In severely ill patients with suspected AAC, USPC should not be performed before diagnostic assessment has confirmed the diagnosis, with USPC being preferable to surgery in severely ill patients. A study comparing USPC with gallbladder aspiration in patients with acute cholecystitis showed superiority of USPC in terms of clinical outcome, but similar complication rates [458]. A comparison of both methods suggested similar clinical efficacy, but reported lower complications for gallbladder aspiration [459].

Data is limited with respect to the duration of gallbladder drainage. Before removal of the drain, laboratory and clinical data should confirm resolution of sepsis [460]. Patients should be re-evaluated following recovery to assess fitness for elective surgery. Cholecystitis recurrence of $10-30 \%$ is reported, and should be weighed against the mortality and morbidity risk in the individual patient. In severely chronically ill patients, recovery is rarely achievable and USPC may be regarded as the definitive treatment. If cohorts treated with both methods are compared, patients with USPC typically have a higher morbidity and mortality than CCE patients, explained by the difference in the patient's acute or chronic health status. According to a meta-analysis of the available data, elective surgery was performed in $38 \%$ (681/1787, 48 papers) [441] and emergency surgery in $4.5 \%$ (77/1724; 47 papers).

\section{Recommendation 53}

Percutaneous ultrasound-guided gallbladder drainage may be considered in patients with acute calculous cholecystitis assessed to be unfit for surgery (LoE 3b, GoR B). Strong consensus $(100 \%)$.

\section{Recommendation 54}

In patients with acute acalculous cholecystitis unfit for surgery, percutaneous ultrasound-guided gallbladder drainage should be considered after diagnostic puncture (LoE 2c, GoR B). Strong consensus (100\%).

\section{Drainage route}

The transhepatic route has advantages regarding tract formation and the avoiding of peritonitis $[442,461]$. The transperitoneal approach has been reported to be no different in relation to complications, but formation of a mature tract without leakage as a precondition for catheter removal is significantly delayed compared with the transhepatic approach [461 - 463]. EUS-guided transmural gallbladder drainage may be performed as an alternative to USPC [293].

\section{Recommendation 55}

Ultrasound-guided percutaneous gallbladder drainage should be performed transhepatically (LoE $2 b$, GoR B). Strong consensus $(100 \%)$.

\section{Percutaneous gastrostomy} $\boldsymbol{\nabla}$

\section{Introduction}

Gastrostomy can be offered when oral food uptake is temporarily or permanently compromised. Gastrostomy may be used in patients with neurological disorders (e.g., neurological degeneration) and advanced (oncological) diseases, e.g. in gastrointestinal stenosis with intractable vomiting where surgical treatment is not feasible or is declined. The endoscopic approach (percutaneous endoscopic gastrostomy, PEG) with the "pull" technique is the most common technique. An alternative is the introducer technique ("push" technique). There is evidence that the introducer technique causes fewer peristomal infections [464, 465].

Image-guided percutaneous gastrostomy (without endoscopic access)

The percutaneous approach (image-guided percutaneous gastrostomy, PG) can be performed under fluoroscopy (radiologically inserted gastrostomy, RIG) or US guidance (USPG). A multicenter survey of RIG with 684 patients in 17 centers found a mortality of $1 \%$ and a complication rate of $5 \%$ [466]. With PEG, a prospective study $(n=484)$ reported a high incidence of complications at 2 and 8 weeks of $39 \%$ and $27 \%$, respectively [467]. A retrospective study [468] compared PEG and RIG insertions and found PEG to be superior with regard to early mortality, mainly from pneumonia.

US guidance in experienced hands allows the identification of the position of (a) the stomach, (b) the liver, and (c) in most instances, the transverse colon. Usually the stomach is filled with water by a nasogastric tube, but if US is used to assist endoscopy, air distension is sufficient.

US may be used in the following situations:

- In cases of anticipated difficulty locating the stomach (scars, advanced gastric cancer, obesity, surgically altered stomach anatomy).

- In endoscopic approach when transillumination fails.

- In cases without access to the upper gastrointestinal tract (complete esophageal obstruction).

In 15 patients with failure of endoscopy, all but one eventually had successful USPG. The reasons for the failure of PEG were scar formation, unusual stomach location, obesity, tumor infiltration and peritoneal carcinosis [469]. It is reported that US together with fluoroscopy after filling the stomach with water via a nasogastric tube is a feasible technique [470]. 154 patients underwent USguided stomach puncture using this water-filled stomach method and T-fastener insertion was possible in all patients. The authors then switched to fluoroscopy and placed a $14 \mathrm{~F}$ feeding tube. Mortality was $2 \%$ and major complications occurred in $3 \%$ [471]. Following failed endoscopy in 11 patients, a new gastropexy device had a $100 \%$ success rate [472]. If USPG is performed, the procedure should include gastropexy (via T-fasteners or anchors) to prevent catheter dislodgement.

\section{Recommendation 56}

In cases in which conventional endoscopically guided gastric puncture fails, ultrasound-assisted gastric puncture may make it possible to accomplish percutaneous gastrostomy (LoE 4, GoR C). Broad agreement (76\%).

The use of US guidance for PEG in patients in whom the conventional technique with a nasogastric tube was not possible (upper 


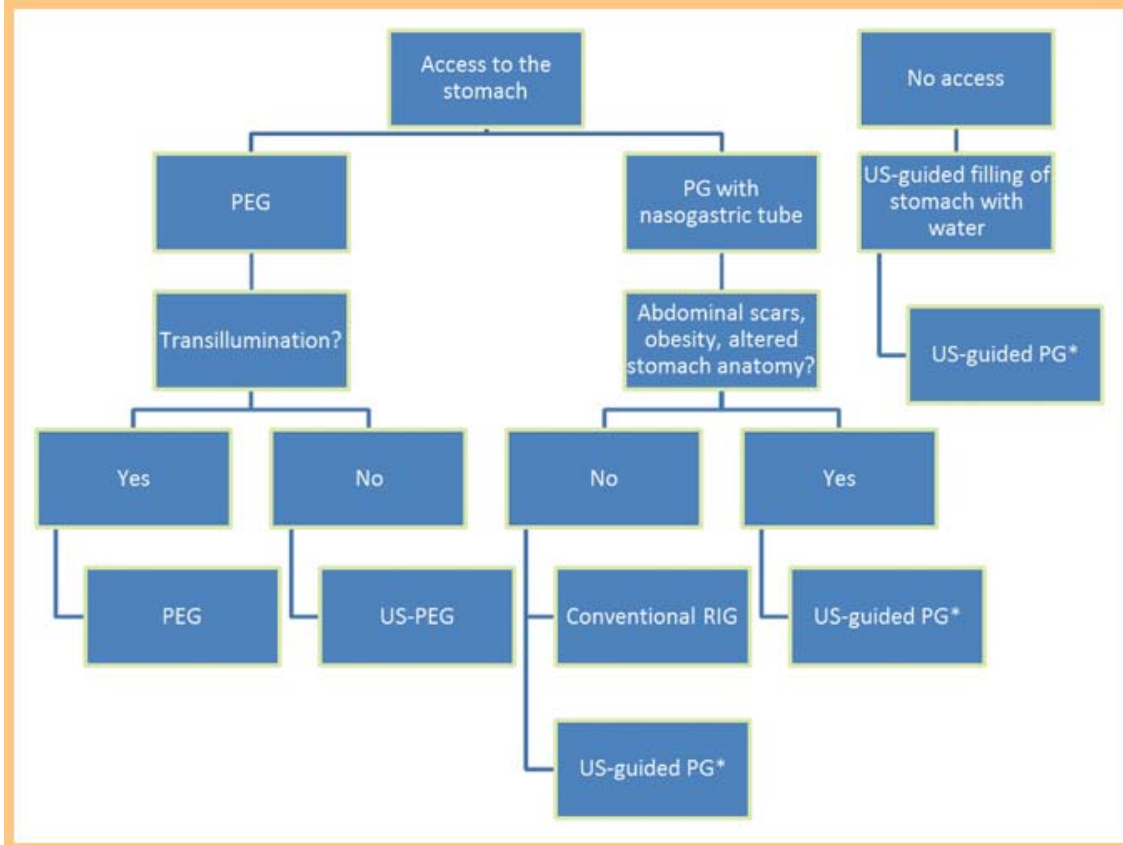

Fig. 1 Ways to perform percutaneous gastrostomy, focusing on the use of ultrasound guidance. * Most investigators use ultrasound for puncture and filling of the stomach and switch to fluoroscopy to guide the wire and dilatator and to perform tube maneuvers.

gastrointestinal tract obstruction) and prevented air filling of the stomach has been reported. In 26/27 patients a stomach puncture under US guidance with a 22 gauge needle was possible to allow air insufflation [473]. Similar success was reported in 7/9 patients with the same technique [474].

\section{Recommendation 57}

When placing a nasogastric tube is not possible, the stomach can be punctured under ultrasound guidance and distended with air or water to facilitate percutaneous image-guided gastrostomy (LoE 4, GoR C). Broad agreement (86\%).

Antibiotic prophylaxis is mandatory for PEG using the pull technique for prevention of peristomal infection. For introducer techniques, antibiotic prophylaxis is not necessary. The database for antibiotic prophylaxis in PEG is comprehensive [475]. There is data for RIG showing no wound infections [466]. In general, the introducer technique has a lower infection rate [465]. Data from US-guided techniques are not available but may be extrapolated from data for RIG. ( $\bullet$ Fig. 1 )

\section{Percutaneous nephrostomy}

$\nabla$

\section{Introduction}

Percutaneous nephrostomy (PCN) remains the procedure of choice for temporary drainage of the obstructed collecting system when the transureteral (or retrograde) approach is not indicated or feasible $[476,477]$. PCN is also used for urinary diversion and to gain access to the urinary tract for subsequent interventional urologic procedures. PCN can be successfully performed in $95-98 \%$ of patients who have a dilated renal collecting system [268].

Nephrostomy placement can potentially injure the five surrounding structures: the pleura, the diaphragm, the colon, the spleen and the liver. In practice, pleural and diaphragm injuries are by far the most common, with colon injury occasionally reported and spleen or liver injury rarely reported. The risk of pleural transgression or diaphragmatic injury is minimized when nephrostomy placement is below the 12 th rib [478]. Approximately $5 \%$ of patients lying prone have a retrorenal colon at the level of the lower renal poles $[479,480]$.

\section{Indications and contraindications}

Indications

PCN may be performed for diagnostic or therapeutic purposes $[481,482]$.

- Relief of urinary obstruction related to malignancy, urinary stones or iatrogenic causes [482].

- Pyonephrosis and obstructive acute pyelonephritis.

- Urinary diversion in patients with urinary fistula, leakage or hemorrhagic cystitis $[478,483]$.

- Access for endourologic procedures, such as nephrolithotomy and removal of urinary stones, dilation or stenting of a ureteral stricture [481].

- Diagnostic testing, such as antegrade pyelography, ureteral perfusion (Whitaker test) [478].

- Specific situations, e.g., uroenteric diversion.

- Treatment of urolithiasis in transplanted kidneys and external malignant obstruction [484-487].

\section{Contraindications}

There is no absolute contraindication for PCN, but the benefits and risks must be weighed for each individual [481, 482]. Relative contraindications are:

- Renal vascular malformations such as an arterial aneurysm [478],

- Severe life-threatening electrolyte imbalances such as hyperkalemia, or severe metabolic acidosis [481],

- Severe coagulopathy [488].

\section{Imaging modalities}

The optimal imaging methods to guide PCN vary at individual centers. The procedure can be performed with the guidance of fluoroscopy, US, CT, and various combinations of those techniques [489-491]. 


\section{Fluoroscopy}

Radiological methods may be necessary to determine whether the puncture needle and PCN catheter have been successfully inserted into the renal pelvis and to determine the site and degree of obstruction [492, 493].

\section{Ultrasound guidance}

US-guided puncture of the collecting system with subsequent placement of the drainage tube under fluoroscopic control is regarded as the standard technique for PCN, particularly in the absence of dilatation of the urinary tract [ $478,494,495]$. US is helpful to identify the most appropriate calyx for puncture and the presence of stones or blood clots or other intraluminal filling defects and to avoid damage to surrounding organs [496]. In addition, it is an ideal method for patient follow-up [496].

\section{Recommendation 58}

Percutaneous nephrostomy can be effectively performed under ultrasound guidance (LoE 2b, GoR B). Strong consensus (100\%).

Injection of US contrast agents via a needle or catheter can also confirm whether the needle or PCN catheter have been correctly inserted in the renal pelvis, with reduction in radiation exposure which may be especially important in the first trimester of pregnancy [492]. Fluoroscopy is recommended to determine the position of the needle and guidewire. The catheter can be visualized by injecting diluted US contrast agent.

\section{Pre-procedure preparation}

Hyperkalemia and coagulopathy should be corrected prior to the procedure [482]. Prophylactic antibiotics are widely used in preparing patients for PCN [497], but are not recommended if the urine is sterile. Antibiotic cover is mandatory in pyonephrosis. Other aspects of patient preparation are identical to those of other interventional procedures; adequate fasting is required if conscious sedation is planned [481].

\section{Technical aspects and indications \\ Methods \\ Positioning}

The risk of adjacent organ injury during percutaneous nephrostomy is minimized when the nephrostomy is inserted below the 12 th rib. Catheter placement through a calyx, rather than through an infundibulum or directly into the renal pelvis, has the lowest risk of vascular injury. Attempts should be made to achieve catheter placement through a calyx, particularly if percutaneous nephrolithotomy or other large-bore catheter placement is considered [478]. A $22-20$ gauge needle is recommended for ultrasound-guided PCN if the Seldinger technique is used to introduce the 0.018 inch guidewire. The introducer is then inserted and provides access to the standard 0.035 inch guidewire.

\section{Seldinger or trocar technique}

Several direct and wire-guided (Seldinger) methods of PCN tube placement have been described. US-guided PCN tube placement has a success rate of $92-94 \%[498,499]$. The trocar and Seldinger techniques are equally effective [500].

Size

The catheter size depends on the purpose of the nephrostomy. A $6-10 \mathrm{~F}$ catheter is recommended for PCN while simple urine drain- age can be achieved with a $5-8 \mathrm{~F}$ catheter. If the collecting system is punctured for further procedures (e.g., tumor or stone removal) or in procedures complicated by gross hematuria, a larger catheter may be considered (14-22F).

The smaller tubes are less traumatic and easier to insert but do not drain the kidney as effectively as larger tubes and are less effective in decompressing the urinary tract. Larger tubes cause more trauma and are slightly more difficult to insert but offer better drainage of the kidney and decompression of the urinary tract. Malecot-type catheters require a skin suture, while balloon catheters do not. Catheters that are indwelling in the renal pelvis are more secure than nephro-stent-type tubes [501].

\section{Recommendation 59}

In percutaneous nephrostomy, access via the posterior-inferior calyces should be attempted to reduce the risk of pleural and vascular injury (LoE 5, GoR D). Strong consensus (100\%).

Post-procedure catheter management and patient care Vital signs should be monitored during initial recovery ( $>24$ hours) [481]. Urinary output should be charted. Urine will be blood-tinged initially but prolonged hematuria ( $>24-48$ hours) should serve as an alert to persistent bleeding from vascular injury [481, 502]. If bleeding occurs, the catheter should be clamped off to tamponade the collecting system. If there is a low risk of infection, antibiotics may be discontinued. However, intravenous antibiotic therapy continues for patients with pyonephrosis, fever and chills. The catheter should be routinely flushed with normal saline and aspirated to reduce blockage [268]. Long-term indwelling catheters should be changed every $4-6$ weeks [268].

\section{Complications}

Major complications can be classified into three types: Severe bleeding (hemorrhage) [482, 502 - 504], injury to adjacent structures (such as pleural involvement, colonic perforation) [482, $502,505]$ and severe infection/sepsis $[481,506,507]$. The incidence of major complications ranges from $0-8 \%[476,491,508$, 509]. Minor complications occur in $2-38 \%$ [476, 491, 508, 509]. Transient gross hematuria is usually present. Other minor complications that may be seen include urine leakage, pain, fever and catheter-related complications (obstruction or dislodgement).

\section{Suprapubic puncture of the bladder}

\section{Introduction}

Suprapubic puncture of the bladder is a safe and reliable method to drain the bladder, while avoiding urethral catheterization [510]. US guidance improves the success rate [511 - 514]. A study reported a success rate of $95.8 \%$ for catheter insertions using US guidance in 24 patients where insertion of a suprapubic catheter without image guidance had failed [515], and the British Association of Urological Surgeons (BAUS) guidelines have recommended US guidance whenever possible [516].

US is recommended to assess the position and volume of the bladder, and to avoid the inadvertent puncture of other structures $[517,518]$. 


\section{Recommendation 60}

Puncture and drainage of the urinary bladder should be performed under ultrasound guidance (LoE 1b, GoR B). Strong consensus $(100 \%)$.

\section{Main indications}

Suprapubic puncture of the bladder is indicated in pathological conditions of the bladder, prostate or urethra that require temporary or permanent drainage of the bladder when urethral catheterization is not possible or is contraindicated.

\section{Contraindications to percutaneous US-guided procedure}

- Absence of visualization of the bladder on US.

- Uncorrected coagulopathy.

- Other relative contraindications are those secondary to complex anatomy due to congenital disorders, habitus, previous surgery or infiltrative pelvic cancer.

Suprapubic puncture can be performed using CT guidance if the bladder is seen on US and if the bladder contains large amounts of air (e.g. in patients with an indwelling urethral catheter) as well as in cases of pelvic trauma, congenital disorders or previous complicated surgery [514].

\section{Materials and technical problems}

The procedure is performed under sterile conditions after the administration of local anesthesia. Sedation may be useful in selected cases. The bladder is filled by transurethral catheter or, when urethral catheterization is not possible, a US-guided suprapubic approach is used to instill saline. The position and volume of the bladder are identified by US and US is helpful for real-time guidance of the percutaneous puncture $[517,518]$. Both needleguide and free-hand techniques may be used, and fluoroscopy or US contrast agent administration can guide final placement of the catheter after voiding. Different suprapubic techniques have been described. Catheters are placed by either the Seldinger (the safest way) or the trocar technique, with dilation of the percutaneous track when necessary. At the end of the procedure, the catheter must be fixed to the abdominal wall. Catheters of $10 \mathrm{~F}$ are large enough to relieve acute urinary retention. Large catheters $(>16 \mathrm{~F})$ are recommended in patients who require prolonged drainage of the bladder in circumstances such as bladder rupture or complicated urethral stricture [510]. Smaller catheter (5 - 7F) can be used for suprapubic cystography in order to fill the bladder with diluted iodinated contrast agents.

\section{Complications}

US guidance can decrease the complication rate of suprapubic puncture $[510,514,519]$. Major complications are rare and include perforation of intestinal loops [520]. Minor complications include pain, infection, hemorrhage, blockage, hematuria and catheter misplacement, all of which are less common when US guidance is performed $[514,519,521]$.

\section{Palliative care}

Palliative care patients often have alterations in locoregional anatomy, vascular patterns and coagulation factors. Therefore, for any invasive procedure it is recommended to consider US guidance to improve safety and help minimize complications and patient dis- comfort. There are no contraindications of US-guided procedures in palliative care [522]. The management of cancer complications indicates potential roles for home-performed US and US-guided procedures at the end of life [523].

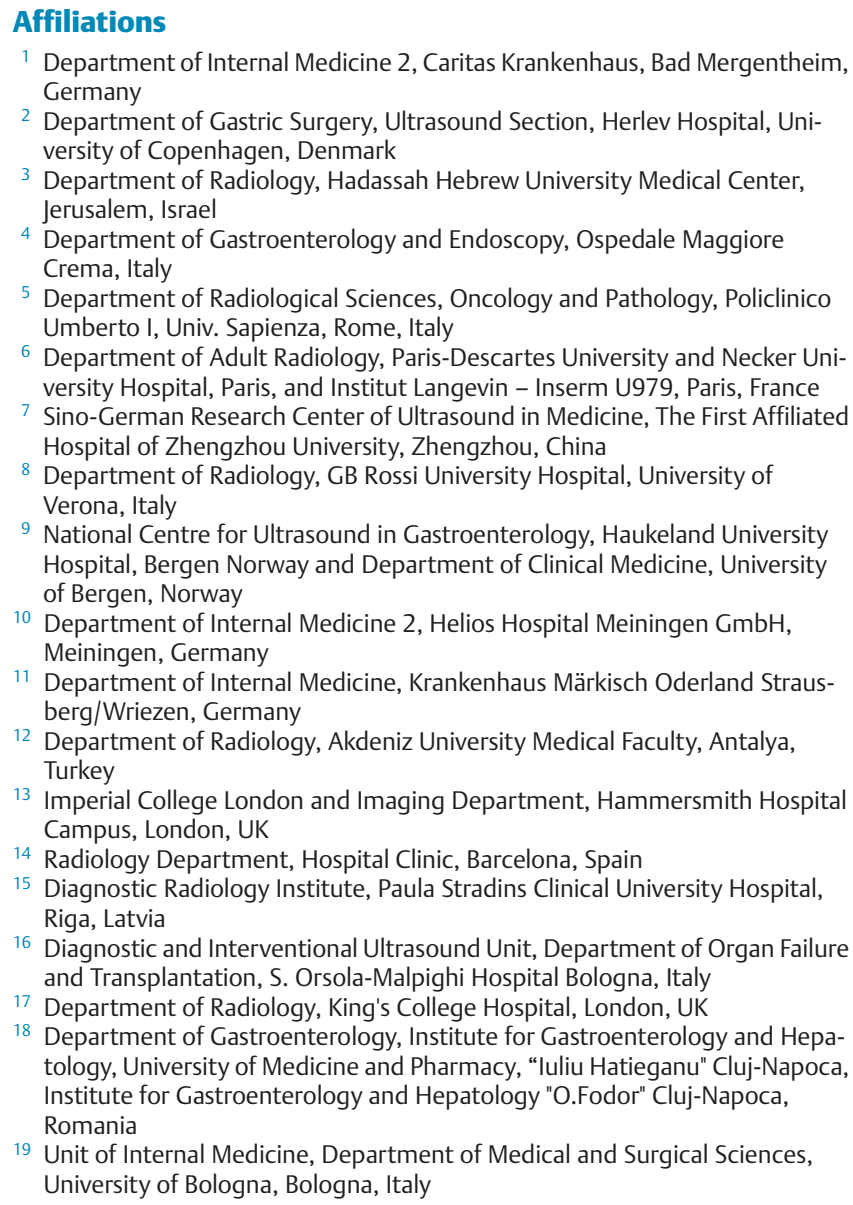

\section{Acknowledgement}

$\nabla$

The authors kindly thank David Cosgrove (UK), Barbara Braden (UK), Liliana Chiorean (France), Franca Meloni (Italy), Andrej Potthoff (Germany), Klaus Schlottmann (Germany), Wolf B. Schwerk (Germany), and Trygve Syversveen (Norway). We would like to acknowledge the endless support and advice from Lynne Rudd, EFSUMB general secretary.

\section{References}

1 Lorentzen T, Nolsoe CP, Ewertsen C et al. EFSUMB Guidelines on Interventional Ultrasound, Part I: General Aspects. Ultraschall in Med 2015; 36 : $464-472$

2 Sidhu PS, Brabrand K, Cantisani V et al. EFSUMB Guidelines on Interventional Ultrasound (INVUS), Part II: Diagnostic Ultrasound Guided Interventional Procedures. Ultraschall in Med 2015, in press

3 Jenssen $C$, Hocke M, Fusaroli $P$ et al. EFSUMB Guidelines on Interventional Ultrasound (INVUS), Part IV: EUS-guided Interventions: General Aspects and EUS-guided Sampling. Ultraschall in Med 2015, in press

4 Fusaroli $P$, Jenssen $C$, Hocke $M$ et al. EFSUMB INVUS Guidelines, Part V: EUS-guided Therapeutic Interventions. Ultraschall in Med 2015, in press 
5 Jenssen $C$, Brkljacic B, Hocke $M$ et al. EFSUMB Guidelines on Interventional Ultrasound (INVUS), Part VI: Ultrasound-Guided Vascular Interventions. Ultraschall in Med 2015, in press

6 Dietrich CF, Lorentzen T, Sidhu PS et al. An introduction into the EFSUMB guidelines on interventional ultrasound. Ultraschall in Med 2015; 36: 460-463

7 Claudon M, Dietrich CF, Choi BI et al. Guidelines and good clinical practice recommendations for contrast enhanced ultrasound (CEUS) in the liver-update 2012: a WFUMB-EFSUMB initiative in cooperation with representatives of AFSUMB, AIUM, ASUM, FLAUS and ICUS. Ultraschall in Med 2013; 34: 11 - 29

8 Claudon M, Dietrich CF, Choi BI et al. Guidelines and good clinical practice recommendations for Contrast Enhanced Ultrasound (CEUS) in the liver - update 2012: A WFUMB-EFSUMB initiative in cooperation with representatives of AFSUMB, AIUM, ASUM, FLAUS and ICUS. Ultrasound Med Biol 2013; 39: 187-210

9 Dietrich CF, Cui XW, Chiorean L et al. Local ablative procedures of the liver. Z Gastroenterol 2015; 53: 579-590

10 Gillams A, Goldberg N, Ahmed M et al. Thermal ablation of colorectal liver metastases: a position paper by an international panel of ablation experts, the interventional oncology sans frontieres meeting 2013. Eur Radiol 2015

11 Pacella CM, Francica G, Di Lascio FM et al. Long-term outcome of cirrhotic patients with early hepatocellular carcinoma treated with ultrasound-guided percutaneous laser ablation: a retrospective analysis. J Clin Oncol 2009; 27: 2615-2621

12 Livraghi T, Bolondi L, Lazzaroni S et al. Percutaneous ethanol injection in the treatment of hepatocellular carcinoma in cirrhosis. A study on 207 patients. Cancer 1992; 69: 925 - 929

13 Lencioni R. Loco-regional treatment of hepatocellular carcinoma. Hepatology 2010; 52: $762-773$

14 Cucchetti A, Piscaglia F, Cescon $M$ et al. Systematic review of surgical resection vs radiofrequency ablation for hepatocellular carcinoma. World J Gastroenterol 2013; 19: 4106-4118

15 Ahmed M, Solbiati L, Brace CL et al. Image-guided tumor ablation: standardization of terminology and reporting criteria-a 10-year update. Radiology 2014; 273: 241 - 260

16 Dietrich CF, Albrecht T, Bernatik T et al. Lokal ablative Verfahren von Lebertumoren; Radiofrequenzablation (RFA). In: Dietrich CF, Nurnberg D eds. Interventionelle Sonographie. Thieme Verlag; 2011: 264-282

17 Dietrich CF, Braden B, Hocke M. Lokal ablative Verfahren, Perkutane Alkoholinjektion. In: Dietrich CF, Nurnberg D eds. Interventionelle Sonographie. Thieme Verlag; 2011: 257-263

18 Ebert MP, Auernhammer C, Caca K et al. Gastrointestinal oncology therapy update 2008 / 2009. Z Gastroenterol 2009; 47: 296 - 306

19 Greten TF, Malek NP, Schmidt S et al. Diagnosis of and therapy for hepatocellular carcinoma. Z Gastroenterol 2013; 51: 1269-1326

20 Abi-Jaoudeh N, Duffy AG, Greten TF et al. Personalized oncology in interventional radiology. J Vasc Interv Radiol 2013; 24: 1083-1092

21 Vivarelli M, Guglielmi A, Ruzzenente A et al. Surgical resection versus percutaneous radiofrequency ablation in the treatment of hepatocellular carcinoma on cirrhotic liver. Ann Surg 2004; 240: 102 - 107

22 Ruzzenente A, Guglielmi A, Sandri M et al. Surgical resection versus local ablation for HCC on cirrhosis: results from a propensity case-matched study. J Gastrointest Surg 2012; 16: 301 - 311

23 Dietrich $C F$, Braden B. Perkutane Zystensklerosierung. In: Dietrich $C F$, Nuernberg D eds. Interventionelle Sonographie. Thieme; 2011: 233 239

24 Carrafiello G, Lagana D, Cotta E et al. Radiofrequency ablation of intrahepatic cholangiocarcinoma: preliminary experience. Cardiovasc Intervent Radiol 2010; 33: 835-839

25 Mazziotti A, Grazi GL, Gardini A et al. An appraisal of percutaneous treatment of liver metastases. Liver Transpl Surg 1998; 4: 271-275

26 Ploeckinger U, Kloeppel G, Wiedenmann B et al. The German NET-registry: an audit on the diagnosis and therapy of neuroendocrine tumors. Neuroendocrinology 2009; 90: 349-363

27 Auernhammer CJ, Jauch KW, Hoffmann JN. [Liver metastases from neuroendocrine tumours of the gastroenteropancreatic system-therapeutic strategies]. Zentralbl Chir 2009; 134: 410-417

28 Atwell TD, Charboneau JW, Que FG et al. Treatment of neuroendocrine cancer metastatic to the liver: the role of ablative techniques. Cardiovasc Intervent Radiol 2005; 28: 409-421

29 Siperstein $A E$, Berber E. Cryoablation, percutaneous alcohol injection, and radiofrequency ablation for treatment of neuroendocrine liver metastases. World J Surg 2001; 25: 693-696
30 Illing $R$, Gillams A. Radiofrequency ablation in the treatment of breast cancer liver metastases. Clin Oncol (R Coll Radiol) 2010; 22: 781 - 784

31 Solbiati L, Ahmed M, Cova $L$ et al. Small liver colorectal metastases treated with percutaneous radiofrequency ablation: local response rate and long-term survival with up to 10 -year follow-up. Radiology 2012; 265: 958-968

32 Meloni MF, Andreano A, Laeseke PF et al. Breast cancer liver metastases: US-guided percutaneous radiofrequency ablation-intermediate and long-term survival rates. Radiology 2009; 253: 861 - 869

33 Nikfarjam M, Shereef S, Kimchi ET et al. Survival outcomes of patients with colorectal liver metastases following hepatic resection or ablation in the era of effective chemotherapy. Ann Surg Oncol 2009; 16: $1860-1867$

34 Pox C, Schmiegel W, Reinacher-Schick A. Colorectal carcinoma: what's new? Dtsch Med Wochenschr 2012; 137: 2577-2580

35 Pox C, Aretz S, Bischoff SC et al. S3-guideline colorectal cancer version 1.0. Z Gastroenterol 2013; 51: $753-854$

36 Miller G, Biernacki P, Kemeny NE et al. Outcomes after resection of synchronous or metachronous hepatic and pulmonary colorectal metastases. J Am Coll Surg 2007; 205: 231 - 238

37 Adam R, Avisar E, Ariche A et al. Five-year survival following hepatic resection after neoadjuvant therapy for nonresectable colorectal. Ann Surg Oncol 2001; 8: 347-353

38 Abdalla EK, Vauthey JN. Chemotherapy prior to hepatic resection for colorectal liver metastases: helpful until harmful? Dig Surg 2008; 25 : $421-429$

39 Abdalla EK. Commentary: Radiofrequency ablation for colorectal liver metastases: do not blame the biology when it is the technology. Am J Surg 2009; 197: 737-739

40 Evrard S, Poston G, Kissmeyer-Nielsen P et al. Combined Ablation and Resection (CARe) as an Effective Parenchymal Sparing Treatment for Extensive Colorectal Liver Metastases. PLoS One 2014; 9: e114404

41 Livraghi T, Solbiati L, Meloni F et al. Percutaneous radiofrequency ablation of liver metastases in potential candidates for resection: the "testof-time approach". Cancer 2003; 97: 3027-3035

42 Rossi S, Di Stasi M, Buscarini E et al. Percutaneous radiofrequency interstitial thermal ablation in the treatment of small hepatocellular carcinoma. Cancer J Sci Am 1995; 1: 73 - 81

43 Livraghi T, Goldberg SN, Lazzaroni S et al. Small hepatocellular carcinoma: treatment with radio-frequency ablation versus ethanol injection. Radiology 1999; 210: 655-661

44 Shiina S, Teratani T, Obi S et al. Nonsurgical treatment of hepatocellular carcinoma: from percutaneous ethanol injection therapy and percutaneous microwave coagulation therapy to radiofrequency ablation. Oncology 2002; 62: 64-68

45 Sugiura N, Takara K, Ohto $M$ et al. Percutaneous intratumoral injection of ethanol under ultrasound imaging for treatment of small hepatocellular carcinoma. Acta Hepatol Jpn 1983; 24: 920

46 Livraghi T, Festi D, Monti F et al. US-guided percutaneous alcohol injection of small hepatic and abdominal tumors. Radiology 1986; 161: $309-312$

47 Shiina S, Tagawa K, Niwa $Y$ et al. Percutaneous ethanol injection therapy for hepatocellular carcinoma: results in 146 patients. Am J Roentgenol 1993; 160: 1023-1028

48 Seki T, Wakabayashi M, Nakagawa T et al. Ultrasonically guided percutaneous microwave coagulation therapy for small hepatocellular carcinoma. Cancer 1994; 74: 817-825

49 Mazzaferro V, Regalia E, Doci R et al. Liver transplantation for the treatment of small hepatocellular carcinomas in patients with cirrhosis. N Engl J Med 1996; 334: 693 - 699

50 Omata M, Lesmana LA, Tateishi R et al. Asian Pacific Association for the Study of the Liver consensus recommendations on hepatocellular carcinoma. Hepatol Int 2010; 4: 439-474

51 Clasen S, Geng A, Herberts $T$ et al. Internally cooled bipolar radiofrequency ablation: is a lower power output more effective? Rofo 2007; 179: $282-288$

52 Seror 0 , N'Kontchou G, Ibraheem $M$ et al. Large (>or=5.0-cm) HCCs: multipolar RF ablation with three internally cooled bipolar electrodes-initial experience in 26 patients. Radiology 2008; 248: 288-296

53 Curley SA, Izzo F, Ellis LM et al. Radiofrequency ablation of hepatocellular cancer in 110 patients with cirrhosis. Ann Surg 2000; 232: 381 391

54 Imamura J, Tateishi R, Shiina $S$ et al. Neoplastic seeding after radiofrequency ablation for hepatocellular carcinoma. Am J Gastroenterol 2008; 103: 3057-3062 
55 Livraghi T, Goldberg SN, Lazzaroni S et al. Hepatocellular carcinoma: radio-frequency ablation of medium and large lesions. Radiology 2000; 214: $761-768$

56 Yin XY, Xie XY, Lu MD et al. Percutaneous thermal ablation of medium and large hepatocellular carcinoma: long-term outcome and prognostic factors. Cancer 2009; 115: $1914-1923$

57 Buscarini L, Buscarini E, Di Stasi M et al. Percutaneous radiofrequency ablation of small hepatocellular carcinoma: long-term results. Eur Radiol 2001; 11: 914-921

$58 \mathrm{Lu}$ DS, Yu NC, Raman SS et al. Radiofrequency ablation of hepatocellular carcinoma: treatment success as defined by histologic examination of the explanted liver. Radiology 2005; 234: 954-960

59 Tateishi $R$, Shiina $S$, Teratani T et al. Percutaneous radiofrequency ablation for hepatocellular carcinoma. An analysis of 1000 cases. Cancer 2005; 103: 1201 - 1209

60 N'Kontchou G, Mahamoudi A, Aout M et al. Radiofrequency ablation of hepatocellular carcinoma: long-term results and prognostic factors in 235 Western patients with cirrhosis. Hepatology 2009; 50: 1475 1483

61 Chen $M H$, Yang W, Yan K et al. Large liver tumors: protocol for radiofrequency ablation and its clinical application in 110 patients-mathematic model, overlapping mode, and electrode placement process. Radiology 2004; 232: $260-271$

62 Bale R, Widmann G, Haidu M. Stereotactic Radiofrequency Ablation. Cardiovasc Intervent Radiol 2010

63 Rossi S, Buscarini E, Garbagnati F et al. Percutaneous treatment of small hepatic tumors by an expandable RF needle electrode. Am J Roentgenol 1998; 170: 1015-1022

64 Shirato K, Morimoto M, Tomita N et al. Small hepatocellular carcinoma: therapeutic effectiveness of percutaneous radio frequency ablation therapy with a LeVeen needle electrode. J Ultrasound Med 2002; 21: $67-76$

65 Goldberg SN, Kamel IR, Kruskal JB et al. Radiofrequency ablation of hepatic tumors: increased tumor destruction with adjuvant liposomal doxorubicin therapy. Am J Roentgenol 2002; 179: 93 -101

66 Sainani NI, Gervais DA, Mueller PR et al. Imaging after percutaneous radiofrequency ablation of hepatic tumors: Part 1, Normal findings. Am J Roentgenol 2013; 200: 184-193

67 Komorizono Y, Oketani M, Sako K et al. Risk factors for local recurrence of small hepatocellular carcinoma tumors after a single session, single application of percutaneous radiofrequency ablation. Cancer 2003; 97 : $1253-1262$

68 Llovet JM, Vilana $R, B r u C$ et al. Increased risk of tumor seeding after percutaneous radiofrequency ablation for single hepatocellular carcinoma. Hepatology 2001; 33: 1124-1129

69 Teratani $T$, Yoshida $H$, Shiina $S$ et al. Radiofrequency ablation for hepatocellular carcinoma in so-called high-risk locations. Hepatology 2006; 43: 1101 - 1108

70 Ritz JP, Lehmann K, Isbert C et al. Effectivity of laser-induced thermotherapy: in vivo comparison of arterial microembolization and complete hepatic inflow occlusion. Lasers Surg Med 2005; 36: 238 - 244

71 Kim SW, Rhim H, Park M et al. Percutaneous radiofrequency ablation of hepatocellular carcinomas adjacent to the gallbladder with internally cooled electrodes: assessment of safety and therapeutic efficacy. Korean J Radiol 2009; 10: 366-376

72 Kang TW, Rhim H, Kim EY et al. Percutaneous radiofrequency ablation for the hepatocellular carcinoma abutting the diaphragm: assessment of safety and therapeutic efficacy. Korean J Radiol 2009; 10: 34-42

73 Head HW, Dodd GD III, Dalrymple NC et al. Percutaneous radiofrequency ablation of hepatic tumors against the diaphragm: frequency of diaphragmatic injury. Radiology 2007; 243: 877-884

74 Bolondi L, Gaiani S, Celli $N$ et al. Tumor dissemination after radiofrequency ablation of hepatocellular carcinoma. Hepatology 2001; 34: $608-610$

$75 \mathrm{Kim}$ YJ, Raman SS, Yu NC et al. Radiofrequency ablation of hepatocellular carcinoma: can subcapsular tumors be safely ablated? Am J Roentgenol 2008; 190: 1029-1034

76 Sartori S, Tombesi P, Macario F et al. Subcapsular liver tumors treated with percutaneous radiofrequency ablation: a prospective comparison with nonsubcapsular liver tumors for safety and effectiveness. Radiology 2008; 248: 670-679

77 Abdalla EK, Vauthey JN, Ellis LM et al. Recurrence and outcomes following hepatic resection, radiofrequency ablation, and combined resection/ablation for colorectal liver metastases. Ann Surg 2004; 239: $818-825$
78 Wang Y, Luo Q Li Y et al. Radiofrequency ablation versus hepatic resection for small hepatocellular carcinomas: a meta-analysis of randomized and nonrandomized controlled trials. PLoS One 2014; 9: e84484

79 Chen MS, Li JQ Zheng Y et al. A prospective randomized trial comparing percutaneous local ablative therapy and partial hepatectomy for small hepatocellular carcinoma. Ann Surg 2006; 243: 321 - 328

80 Huang J, Yan L, Cheng $Z$ et al. A randomized trial comparing radiofrequency ablation and surgical resection for HCC conforming to the Milan criteria. Ann Surg 2010; 252: 903 - 912

81 Feng $K$, Yan J, Li X et al. A randomized controlled trial of radiofrequency ablation and surgical resection in the treatment of small hepatocellular carcinoma. J Hepatol 2012; 57: 794-802

82 Livraghi T, Meloni F, Di Stasi M et al. Sustained complete response and complications rates after radiofrequency ablation of very early hepatocellular carcinoma in cirrhosis: Is resection still the treatment of choice? Hepatology 2008; 47: $82-89$

83 Arii S, Yamaoka Y, Futagawa S et al. Results of surgical and nonsurgical treatment for small-sized hepatocellular carcinomas: a retrospective and nationwide survey in Japan. The Liver Cancer Study Group of Japan. Hepatology 2000; 32: 1224-1229

84 Castells A, Bruix J, Bru C et al. Treatment of small hepatocellular carcinoma in cirrhotic patients: a cohort study comparing surgical resection and percutaneous ethanol injection. Hepatology 1993; 18: 1121 -1126

85 Livraghi T, Bolondi L, Buscarini L et al. No treatment, resection and ethanol injection in hepatocellular carcinoma: a retrospective analysis of survival in 391 patients with cirrhosis. Italian Cooperative HCC Study Group. J Hepatol 1995; 22: 522 - 526

86 Ryu M, Shimamura Y, Kinoshita T et al. Therapeutic results of resection, transcatheter arterial embolization and percutaneous transhepatic ethanol injection in 3225 patients with hepatocellular carcinoma: a retrospective multicenter study. Jpn J Clin Oncol 1997; 27: 251 - 257

87 Guglielmi A, Ruzzenente A, Valdegamberi A et al. Radiofrequency ablation versus surgical resection for the treatment of hepatocellular carcinoma in cirrhosis. J Gastrointest Surg 2008; 12: 192-198

88 Weis S, Franke A, Mossner J et al. Radiofrequency (thermal) ablation versus no intervention or other interventions for hepatocellular carcinoma. Cochrane Database Syst Rev 2013; 12: CD003046

89 Cucchetti A, Piscaglia F, Cescon M et al. An explorative data-analysis to support the choice between hepatic resection and radiofrequency ablation in the treatment of hepatocellular carcinoma. Dig Liver Dis 2014; 46: 257-263

90 Machi J, Bueno RS, Wong LL. Long-term follow-up outcome of patients undergoing radiofrequency ablation for unresectable hepatocellular carcinoma. World J Surg 2005; 29: 1364-1373

91 Lencioni R, Cioni D, Crocetti L et al. Early-stage hepatocellular carcinoma in patients with cirrhosis: long-term results of percutaneous image-guided radiofrequency ablation. Radiology 2005; 234: 961 - 967

92 Cabassa P, Donato F, Simeone F et al. Radiofrequency ablation of hepatocellular carcinoma: long-term experience with expandable needle electrodes. Am J Roentgenol 2006; 186: S316-S321

93 Yan $K$, Chen $M H$, Yang $W$ et al. Radiofrequency ablation of hepatocellular carcinoma: long-term outcome and prognostic factors. Eur J Radiol 2008; 67: 336 - 347

94 Kasugai H, Osaki Y, Oka H et al. Severe complications of radiofrequency ablation therapy for hepatocellular carcinoma: an analysis of $3891 \mathrm{ab}$ lations in 2614 patients. Oncology 2007; 72: 72 - 75

95 Shiina S, Tagawa K, Unuma T et al. Percutaneous ethanol injection therapy for hepatocellular carcinoma. A histopathologic study. Cancer 1991; 68: $1524-1530$

96 Fujimoto $T$. The experimental and clinical studies of percutaneous ethanol injection therapy (PEIT) under ultrasonography for small hepatocellular carcinoma. Acta Hepato JPN 1988; 29: 52

97 Lin DY, Lin SM, Liaw YF. Non-surgical treatment of hepatocellular carcinoma. J Gastroenterol Hepatol 1997; 12: S319-S328

98 Hasegawa S, Yamasaki N, Hiwaki T et al. Factors that predict intrahepatic recurrence of hepatocellular carcinoma in 81 patients initially treated by percutaneous ethanol injection. Cancer 1999; 86: $1682-$ 1690

99 Livraghi T, Benedini V, Lazzaroni S et al. Long term results of single session percutaneous ethanol injection in patients with large hepatocellular carcinoma. Cancer 1998; 83: 48 - 57

100 Pompili M, Rapaccini GL, Covino $M$ et al. Prognostic factors for survival in patients with compensated cirrhosis and small hepatocellular carcinoma after percutaneous ethanol injection therapy. Cancer 2001; 92: $126-135$ 
101 Sung YM, Choi D, Lim HK et al. Long-term results of percutaneous ethanol injection for the treatment of hepatocellular carcinoma in Korea. Korean J Radiol 2006; 7: 187-192

102 Livraghi T, Giorgio A, Marin G et al. Hepatocellular carcinoma and cirrhosis in 746 patients: long-term results of percutaneous ethanol injection. Radiology 1995; 197: $101-108$

103 Dietrich CF, Hocke M, Jenssen C. Ultrasound for abdominal lymphadenopathy. Dtsch Med Wochenschr 2013; 138: 1001-1018

104 Brunello F, Veltri A, Carucci P et al. Radiofrequency ablation versus ethanol injection for early hepatocellular carcinoma: A randomized controlled trial. Scand J Gastroenterol 2008; 43: 727 - 735

105 Lencioni RA, Allgaier HP, Cioni D et al. Small hepatocellular carcinoma in cirrhosis: randomized comparison of radio-frequency thermal ablation versus percutaneous ethanol injection. Radiology 2003; 228: $235-240$

106 Yin XY, Lu MD. Percutaneous ablation for small hepatocellular carcinoma. Expert Rev Gastroenterol Hepatol 2009; 3: 121-130

107 Huo TI, Huang YH, Wu JC et al. Comparison of percutaneous acetic acid injection and percutaneous ethanol injection for hepatocellular carcinoma in cirrhotic patients: a prospective study. Scand J Gastroenterol 2003; 38: $770-778$

108 Lin SM, Lin CJ, Lin CC et al. Randomised controlled trial comparing percutaneous radiofrequency thermal ablation, percutaneous ethanol injection, and percutaneous acetic acid injection to treat hepatocellular carcinoma of $3 \mathrm{~cm}$ or less. Gut 2005; 54: 1151-1156

109 Shiina S, Teratani T, Obi S et al. A randomized controlled trial of radiofrequency ablation with ethanol injection for small hepatocellular carcinoma. Gastroenterology 2005; 129: 122 - 130

110 Lin SM, Lin CJ, Lin CC et al. Radiofrequency ablation improves prognosis compared with ethanol injection for hepatocellular carcinoma $<$ or $=4 \mathrm{~cm}$. Gastroenterology 2004; 127: 1714-1723

111 Orlando A, Leandro G, Olivo $M$ et al. Radiofrequency thermal ablation vs. percutaneous ethanol injection for small hepatocellular carcinoma in cirrhosis: meta-analysis of randomized controlled trials. Am J Gastroenterol 2009; 104: 514-524

112 Yang B, Zan RY, Wang SY et al. Radiofrequency ablation versus percutaneous ethanol injection for hepatocellular carcinoma: a meta-analysis of randomized controlled trials. World J Surg Oncol 2015; 13: 96

113 Cho YK, Kim JK, Kim MY et al. Systematic review of randomized trials for hepatocellular carcinoma treated with percutaneous ablation therapies. Hepatology 2009; 49: 453-459

114 Giorgio A, Di Sarno A, De Stefano G et al. Percutaneous radiofrequency ablation of hepatocellular carcinoma compared to percutaneous ethanol injection in treatment of cirrhotic patients: an Italian randomized controlled trial. Anticancer Res 2011; 31: 2291 -2295

115 Germani G, Pleguezuelo M, Gurusamy K et al. Clinical outcomes of radiofrequency ablation, percutaneous alcohol and acetic acid injection for hepatocelullar carcinoma: a meta-analysis. J Hepatol 2010; 52: $380-388$

116 Bouza C, Lopez-Cuadrado T, Alcazar R et al. Meta-analysis of percutaneous radiofrequency ablation versus ethanol injection in hepatocellular carcinoma. BMC Gastroenterol 2009; 9: 31

117 Omata $M$, Tateishi $R$, Yoshida $H$ et al. Treatment of hepatocellular carcinoma by percutaneous tumor ablation methods: Ethanol injection therapy and radiofrequency ablation. Gastroenterology 2004; 127: S159-S166

118 Sala M, Llovet JM, Vilana R et al. Initial response to percutaneous ablation predicts survival in patients with hepatocellular carcinoma. Hepatology 2004; 40: 1352-1360

119 Lencioni R, Llovet JM. Percutaneous ethanol injection for hepatocellular carcinoma: alive or dead? J Hepatol 2005; 43: 377-380

120 Liang $P$, Dong $B, Y u X$ et al. Prognostic factors for survival in patients with hepatocellular carcinoma after percutaneous microwave ablation. Radiology 2005; 235: 299-307

121 Liang $P$, Wang $Y$. Microwave ablation of hepatocellular carcinoma. Oncology 2007; 72: 124-131

122 Liang $P$, Wang $Y, Y u$ X et al. Malignant liver tumors: treatment with percutaneous microwave ablation-complications among cohort of 1136 patients. Radiology 2009; 251: 933-940

$123 \mathrm{Lu} M D, X u \mathrm{HX}$, Xie XY et al. Percutaneous microwave and radiofrequency ablation for hepatocellular carcinoma: a retrospective comparative study. J Gastroenterol 2005; 40: 1054-1060

124 Ohmoto K, Miyake I, Tsuduki M et al. Percutaneous microwave coagulation therapy for unresectable hepatocellular carcinoma. Hepatogastroenterology 1999; 46: 2894-2900
125 Sato M, Watanabe Y, Ueda S et al. Microwave coagulation therapy for hepatocellular carcinoma. Gastroenterology 1996; 110: 1507-1514

126 Dong B, Liang $P, Y u$ X et al. Percutaneous sonographically guided microwave coagulation therapy for hepatocellular carcinoma: results in 234 patients. Am J Roentgenol 2003; 180: 1547-1555

127 Martin RC, Scoggins CR, McMasters KM. Safety and efficacy of microwave ablation of hepatic tumors: a prospective review of a 5-year experience. Ann Surg Oncol 2010; 17: 171-178

128 Yamashiki N, Kato T, Bejarano PA et al. Histopathological changes after microwave coagulation therapy for patients with hepatocellular carcinoma: review of 15 explanted livers. Am J Gastroenterol 2003; 98: $2052-2059$

129 Shibata T, Iimuro Y, Yamamoto Y et al. Small hepatocellular carcinoma: comparison of radio-frequency ablation and percutaneous microwave coagulation therapy. Radiology 2002; 223: 331-337

130 Livraghi T, Meloni F, Solbiati L et al. Complications of microwave ablation for liver tumors: results of a multicenter study. Cardiovasc Intervent Radiol 2012; 35: 868-874

131 Brunello F, Cantamessa A, Gaia S et al. Radiofrequency ablation: technical and clinical long-term outcomes for single hepatocellular carcinoma up to $30 \mathrm{~mm}$. Eur J Gastroenterol Hepatol 2013; 25: 842 - 849

132 Ferrari FS, Megliola A, Scorzelli A et al. Treatment of small HCC through radiofrequency ablation and laser ablation. Comparison of techniques and long-term results. Radiol Med 2007; 112: 377-393

133 Pacella CM, Bizzarri G, Magnolfi F et al. Laser thermal ablation in the treatment of small hepatocellular carcinoma: results in 74 patients. Radiology 2001; 221: $712-720$

134 Pacella CM, Bizzarri G, Francica G et al. Percutaneous laser ablation in the treatment of hepatocellular carcinoma with small tumors: analysis of factors affecting the achievement of tumor necrosis. J Vasc Interv Radiol 2005; 16: 1447 - 1457

$135 \mathrm{Lu}$ ZH, Shen F, Yan ZL et al. Treatment of portal vein tumor thrombus of hepatocellular carcinoma with percutaneous laser ablation. J Cancer Res Clin Oncol 2009; 135: 783-789

$136 \mathrm{El}$-Serag HB, Marrero JA, Rudolph L et al. Diagnosis and treatment of hepatocellular carcinoma. Gastroenterology 2008; 134: 1752-1763

137 Ebara M, Okabe S, Kita $\mathrm{K}$ et al. Percutaneous ethanol injection for small hepatocellular carcinoma: therapeutic efficacy based on 20year observation. J Hepatol 2005; 43: 458-464

138 Khan KN, Yatsuhashi H, Yamasaki K et al. Prospective analysis of risk factors for early intrahepatic recurrence of hepatocellular carcinoma following ethanol injection. J Hepatol 2000; 32: 269-278

139 Koda M, Murawaki Y, Mitsuda A et al. Predictive factors for intrahepatic recurrence after percutaneous ethanol injection therapy for small hepatocellular carcinoma. Cancer 2000; 88: 529-537

140 Kim YJ, Lee MW, Park HS. Small hepatocellular carcinomas: ultrasonography guided percutaneous radiofrequency ablation. Abdom Imaging 2013; 38: $98-111$

141 Rajesh S, Mukund A, Arora A et al. Contrast-enhanced US-guided radiofrequency ablation of hepatocellular carcinoma. J Vasc Interv Radiol 2013; 24: 1235-1240

142 Choi D, Lim HK, Lee WJ et al. Early assessment of the therapeutic response to radio frequency ablation for hepatocellular carcinoma: utility of gray scale harmonic ultrasonography with a microbubble contrast agent. J Ultrasound Med 2003; 22: 1163-1172

143 Minami Y, Kudo M, Chung $H$ et al. Contrast harmonic sonographyguided radiofrequency ablation therapy versus B-mode sonography in hepatocellular carcinoma: prospective randomized controlled trial. Am J Roentgenol 2007; 188: 489-494

144 van Duijnhoven FH, Jansen MC, Junggeburt JM et al. Factors influencing the local failure rate of radiofrequency ablation of colorectal liver metastases. Ann Surg Oncol 2006; 13: 651 -658

145 Alvarez-Sanchez MV, Jenssen C, Faiss S et al. Interventional endoscopic ultrasonography: an overview of safety and complications. Surg Endosc 2014; 28: $712-734$

146 Jenssen C, Dietrich CF. Kontraindikationen, Komplikationen, Komplikationsmanagment. In: Dietrich $\mathrm{CF}$, Nuernberg D eds. Interventionelle Sonographie. Thieme Verlag; 2011: 127-160

147 Takaki H, Yamakado K, Nakatsuka A et al. Frequency of and risk factors for complications after liver radiofrequency ablation under CT fluoroscopic guidance in 1500 sessions: single-center experience. Am J Roentgenol 2013; 200: 658-664

148 Evrard S, Brouste V, McKelvie-Sebileau P et al. Liver metastases in close contact to hepatic veins ablated under vascular exclusion. Eur J Surg Oncol 2013; 39: 1400-1406 
149 Desolneux G, Vara J, Razafindratsira T et al. Patterns of complications following intraoperative radiofrequency ablation for liver metastases. HPB (Oxford) 2014; 16: 1002 - 1008

150 Schwartz A, Desolneux G, Desjardin $M$ et al. Symptomatic diaphragmatic hernia after pulmonary radiofrequency ablation. J Visc Surg 2013; 150: $157-158$

151 Curley SA. Radiofrequency ablation of malignant liver tumors. Oncologist 2001; 6: 14-23

152 Livraghi T, Solbiati L, Meloni MF et al. Treatment of focal liver tumors with percutaneous radio-frequency ablation: complications encountered in a multicenter study. Radiology 2003; 226: 441 - 451

153 de Baère $T$, Risse 0, Kuoch $V$ et al. Adverse events during radiofrequency treatment of 582 hepatic tumors. Am J Roentgenol 2003; 181: $695-700$

154 Stigliano R, Marelli L, Yu D et al. Seeding following percutaneous diagnostic and therapeutic approaches for hepatocellular carcinoma. What is the risk and the outcome? Seeding risk for percutaneous approach of HCC. Cancer Treat Rev 2007; 33: 437 - 447

155 Di Stasi M, Buscarini L, Livraghi T et al. Percutaneous ethanol injection in the treatment of hepatocellular carcinoma. A multicenter survey of evaluation practices and complication rates. Scand J Gastroenterol 1997; 32: $1168-1173$

156 Livraghi T, Lazzaroni S, Meloni F et al. Risk of tumour seeding after percutaneous radiofrequency ablation for hepatocellular carcinoma. Br J Surg 2005; 92: $856-858$

157 Arienti V, Pretolani S, Goldberg SN et al. How to report and compare complications of image-guided ablation therapies: comments on seeding and the use of a sole common denominator for liver tumors. Radiology 2006; 241: 625 - 626

158 Chang S, Kim SH, Lim HK et al. Needle tract implantation after percutaneous interventional procedures in hepatocellular carcinomas: lessons learned from a 10-year experience. Korean J Radiol 2008; 9: $268-274$

159 Ozdil B, Akkiz H, Sandikci M et al. Giant subcutaneous HCC case occurring after percutaneous ethanol injection. Turk J Gastroenterol 2009; 20: $301-302$

160 Cedrone A, Rapaccini GL, Pompili M et al. Neoplastic seeding complicating percutaneous ethanol injection for treatment of hepatocellular carcinoma. Radiology 1992; 183: 787 - 788

161 EASL-EORTC clinical practice guidelines: management of hepatocellular carcinoma. J Hepatol 2012; 56: 908 - 943

162 Llovet JM, Bru C, Bruix J. Prognosis of hepatocellular carcinoma: the BCLC staging classification. Semin Liver Dis 1999; 19: 329-338

163 Llovet JM, Di Bisceglie AM, Bruix J et al. Design and endpoints of clinical trials in hepatocellular carcinoma. J Natl Cancer Inst 2008; 100 : $698-711$

164 Verslype C, Rosmorduc O, Rougier P et al. Hepatocellular carcinoma: ESMO-ESDO Clinical Practice Guidelines for diagnosis, treatment and follow-up. Ann Oncol 2012; 23: vii41 - vii48

165 Bruix J, Sherman M. Management of hepatocellular carcinoma: an update. Hepatology 2011; 53: 1020-1022

166 Lei JY, Wang WT, Yan LN et al. Radiofrequency ablation versus surgical resection for small unifocal hepatocellular carcinomas. Medicine (Baltimore) 2014; 93: e271

167 Garavoglia M, Oldani A, Gentilli S et al. Percutaneous radiofrequency ablation versus surgical radiofrequency-assisted nodulectomy in treatment of small single nodes of hepatocellular carcinoma: our experience. Minerva Chir 2013; 68: 367 - 375

168 Forner A, Llovet JM, Bruix J. Hepatocellular carcinoma. Lancet 2012; 379: 1245 - 1255

169 Akamatsu M, Yoshida H, Obi S et al. Evaluation of transcatheter arterial embolization prior to percutaneous tumor ablation in patients with hepatocellular carcinoma: a randomized controlled trial. Liver Int 2004; 24: 625 - 629

170 Iezzi R, Pompili M, La Torre MF et al. Radiofrequency ablation plus drug-eluting beads transcatheter arterial chemoembolization for the treatment of single large hepatocellular carcinoma. Dig Liver Dis 2014

171 Yan $S, X u$ D, Sun B. Combination of radiofrequency ablation with transarterial chemoembolization for hepatocellular carcinoma: a meta-analysis. Dig Dis Sci 2012; 57: 3026-3031

172 Ni JY, Liu SS, Xu LF et al. Transarterial chemoembolization combined with percutaneous radiofrequency ablation versus TACE and PRFA monotherapy in the treatment for hepatocellular carcinoma: a meta-analysis. J Cancer Res Clin Oncol 2013; 139: 653 - 659
$173 \mathrm{Ni} J Y$, Liu SS, Xu LF et al. Meta-analysis of radiofrequency ablation in combination with transarterial chemoembolization for hepatocellular carcinoma. World J Gastroenterol 2013; 19: 3872 - 3882

174 Wang JH, Wang CC, Hung $\mathrm{CH}$ et al. Survival comparison between surgical resection and radiofrequency ablation for patients in BCLC very early/early stage hepatocellular carcinoma. J Hepatol 2012; 56: 412 418

175 Hasegawa K, Makuuchi M, Takayama T et al. Surgical resection vs. percutaneous ablation for hepatocellular carcinoma: a preliminary report of the Japanese nationwide survey. J Hepatol 2008; 49: 589-594

176 Cucchetti A, Piscaglia F, Cescon M et al. Cost-effectiveness of hepatic resection versus percutaneous radiofrequency ablation for early hepatocellular carcinoma. J Hepatol 2013; 59: 300 - 307

177 Lu MD, Kuang M, Liang LJ et al. Surgical resection versus percutaneous thermal ablation for early-stage hepatocellular carcinoma: a randomized clinical trial. Zhonghua Yi Xue Za Zhi 2006; 86: 801 - 805

178 Kuang M, Lu MD, Xie XY et al. Ethanol ablation of hepatocellular carcinoma Up to $5.0 \mathrm{~cm}$ by using a multipronged injection needle with high-dose strategy. Radiology 2009; 253: 552 - 561

179 Kudo M. Radiofrequency ablation for hepatocellular carcinoma: up dated review in 2010. Oncology 2010; 78: 113-124

180 Zhou Y, Zhao Y, Li B et al. Meta-analysis of radiofrequency ablation versus hepatic resection for small hepatocellular carcinoma. BMC Gastroenterol 2010; 10: 78

181 Ishii $\mathrm{H}$, Okada S, Nose $\mathrm{H}$ et al. Local recurrence of hepatocellular carcinoma after percutaneous ethanol injection. Cancer 1996; 77: 1792 1796

182 Cheng BQ Jia CQ Liu CT et al. Chemoembolization combined with radiofrequency ablation for patients with hepatocellular carcinoma larger than $3 \mathrm{~cm}$ : a randomized controlled trial. JAMA 2008; 299: $1669-1677$

183 Kobayashi M, Ikeda K, Kawamura Y et al. Randomized controlled trial for the efficacy of hepatic arterial occlusion during radiofrequency ablation for small hepatocellular carcinoma-direct ablative effects and a long-term outcome. Liver Int 2007; 27: 353-359

184 Poon RT, Fan ST, Ng IO et al. Different risk factors and prognosis for early and late intrahepatic recurrence after resection of hepatocellular carcinoma. Cancer 2000; 89: 500-507

185 Poon RT, Fan ST, Lo CM et al. Improving survival results after resection of hepatocellular carcinoma: a prospective study of 377 patients over 10 years. Ann Surg 2001; 234: $63-70$

186 Poon RT, Fan ST, Tsang FH et al. Locoregional therapies for hepatocellular carcinoma: a critical review from the surgeon's perspective. Ann Surg 2002; 235: 466 - 486

187 Hakime A, Hines-Peralta A, Peddi $H$ et al. Combination of radiofrequency ablation with antiangiogenic therapy for tumor ablation efficacy: study in mice. Radiology 2007; 244: 464-470

188 Mertens JC, Martin IV, Schmitt J et al. Multikinase inhibitor sorafenib transiently promotes necrosis after radiofrequency ablation in rat liver but activates growth signals. Eur J Radiol 2012; 81: 1601 - 1606

189 Bruix J, Takayama T, Mazzaferro V et al. STORM: A phase III randomized, double-blind, placebo-controlled trial of adjuvant sorafenib after resection or ablation to prevent recurrence of hepatocellular carcinoma (HCC). ASCO Meeting Abstracts 2014; 32: 4006

190 Kanas GP, Taylor A, Primrose JN et al. Survival after liver resection in metastatic colorectal cancer: review and meta-analysis of prognostic factors. Clin Epidemiol 2012; 4: 283 - 301

191 Bradley AL, Chapman WC, Wright JK et al. Surgical experience with hepatic colorectal metastasis. Am Surg 1999; 65: 560-566

192 Doci R, Gennari L, Bignami P et al. One hundred patients with hepatic metastases from colorectal cancer treated by resection: analysis of prognostic determinants. Br J Surg 1991; 78: 797 - 801

193 Fong Y, Fortner J, Sun RL et al. Clinical score for predicting recurrence after hepatic resection for metastatic colorectal cancer: analysis of 1001 consecutive cases. Ann Surg 1999; 230: 309-318

194 Ohlsson B, Stenram U, Tranberg KG. Resection of colorectal liver metastases: 25-year experience. World J Surg 1998; 22: 268 -276

195 Scheele J, Stangl R, Altendorf-Hofmann A et al. Indicators of prognosis after hepatic resection for colorectal secondaries. Surgery 1991; 110 : $13-29$

196 Wagner JS, Adson MA, Van Heerden JA et al. The natural history of hepatic metastases from colorectal cancer. A comparison with resective treatment. Ann Surg 1984; 199: 502 - 508 
197 Neumann UP, Seehofer D, Neuhaus $P$. The surgical treatment of hepatic metastases in colorectal carcinoma. Dtsch Arztebl Int 2010; 107: $335-342$

198 Schmiegel W, Pox C, Reinacher-Schick A et al. S3 guidelines for colorectal carcinoma: results of an evidence-based consensus conference on February 6/7, 2004 and June 8/9, 2007 (for the topics IV, VI and VII). Z Gastroenterol 2010; 48: 65-136

199 Park IJ, Kim HC, Yu CS et al. Radiofrequency ablation for metachronous liver metastasis from colorectal cancer after curative surgery. Ann Surg Oncol 2008; 15: $227-232$

200 Lorentzen T, Skjoldbye BO, Nolsoe CP. Microwave ablation of liver metastases guided by contrast-enhanced ultrasound: experience with 125 metastases in 39 patients. Ultraschall in Med 2011; 32: 492 - 496

201 Cho YK, Kim JK, Kim WT et al. Hepatic resection versus radiofrequency ablation for very early stage hepatocellular carcinoma: a Markov model analysis. Hepatology 2010; 51: 1284-1290

202 Lee WS, Yun SH, Chun HK et al. Clinical outcomes of hepatic resection and radiofrequency ablation in patients with solitary colorectal liver metastasis. J Clin Gastroenterol 2008; 42: 945 - 949

203 Gillams AR, Lees WR. Five-year survival in 309 patients with colorectal liver metastases treated with radiofrequency ablation. Eur Radiol 2009; 19: $1206-1213$

204 Gillams AR, Lees WR. Radio-frequency ablation of colorectal liver metastases in 167 patients. Eur Radiol 2004; 14: 2261 - 2267

205 Knudsen AR, Kannerup AS, Mortensen FV et al. Radiofrequency ablation of colorectal liver metastases downstaged by chemotherapy. Acta Radiol 2009; 50: 716-721

206 Tanis E, Nordlinger B, Mauer $M$ et al. Local recurrence rates after radiofrequency ablation or resection of colorectal liver metastases. Analysis of the European Organisation for Research and Treatment of Cancer \#40004 and \#40983. Eur J Cancer 2014; 50: 912 -919

207 Kim KH, Yoon YS, Yu CS et al. Comparative analysis of radiofrequency ablation and surgical resection for colorectal liver metastases. J Korean Surg Soc 2011; 81: 25 - 34

208 Weng $M$, Zhang Y, Zhou D et al. Radiofrequency ablation versus resection for colorectal cancer liver metastases: a meta-analysis. PLoS One 2012; 7: e45493

209 Bai H, Huangz X, Jing L et al. The effect of radiofrequency ablation vs. liver resection on survival outcome of colorectal liver metastases (CRLM): a meta-analysis. Hepatogastroenterology 2015; 62: 373 377

210 Cirocchi $R$, Trastulli $S$, Boselli $C$ et al. Radiofrequency ablation in the treatment of liver metastases from colorectal cancer. Cochrane Database Syst Rev 2012; 6: CD006317

211 Ruers T, Punt C, van Coevorden $F$ et al. Radiofrequency ablation combined with systemic treatment versus systemic treatment alone in patients with non-resectable colorectal liver metastases: a randomized EORTC Intergroup phase II study (EORTC 40004). Ann Oncol 2012; 23: 2619-2626

212 Curry NS. Small renal masses (lesions smaller than $3 \mathrm{~cm}$ ): imaging evaluation and management. Am J Roentgenol 1995; 164: 355 - 362

213 Smith SJ, Bosniak MA, Megibow AJ et al. Renal cell carcinoma: earlier discovery and increased detection. Radiology 1989; 170: 699-703

214 Jamis-Dow CA, Choyke PL, Jennings SB et al. Small $(<$ or $=3-\mathrm{cm}$ ) renal masses: detection with CT versus US and pathologic correlation. Radiology 1996; 198: 785-788

215 Amendola MA, Bree RL, Pollack HM et al. Small renal cell carcinomas: resolving a diagnostic dilemma. Radiology 1988; 166: 637-641

216 Warshauer DM, McCarthy SM, Street L et al. Detection of renal masses: sensitivities and specificities of excretory urography/linear tomography, US, and CT. Radiology 1988; 169: 363-365

217 Robbin ML, Lockhart ME, Barr RG. Renal imaging with ultrasound contrast: current status. Radiol Clin North Am 2003; 41: 963 -978

218 Provet J, Tessler A, Brown J et al. Partial nephrectomy for renal cell carcinoma: indications, results and implications. J Urol 1991; 145: 472 476

219 Curti BD. Renal cell carcinoma. JAMA 2004; 292: 97 - 100

220 Jayson $M$, Sanders $H$. Increased incidence of serendipitously discovered renal cell carcinoma. Urology 1998; 51: 203 - 205

221 Remzi M, Javadli E, Ozsoy M. Management of small renal masses: a review. World J Urol 2010; 28: 275 - 281

222 Aron M, Gill IS. Minimally invasive nephron-sparing surgery (MINSS) for renal tumours. Part II: probe ablative therapy. Eur Urol 2007; 51 : $348-357$
223 Chawla SN, Crispen PL, Hanlon AL et al. The natural history of observed enhancing renal masses: meta-analysis and review of the world literature. J Urol 2006; 175: 425 -431

224 Nahum GS, Dupuy DE. Image-guided radiofrequency tumor ablation: challenges and opportunities-part I. J Vasc Interv Radiol 2001; 12: $1021-1032$

225 Gervais DA, McGovern FJ, Arellano RS et al. Radiofrequency ablation of renal cell carcinoma: part 1 , Indications, results, and role in patient management over a 6-year period and ablation of 100 tumors. Am J Roentgenol 2005; 185: 64-71

226 Gervais DA, Arellano RS, McGovern FJ et al. Radiofrequency ablation of renal cell carcinoma: part 2, Lessons learned with ablation of 100 tumors. Am J Roentgenol 2005; 185: 72 -80

227 Tracy CR, Raman JD, Donnally C et al. Durable oncologic outcomes after radiofrequency ablation: experience from treating 243 small renal masses over 7.5 years. Cancer 2010; 116: 3135 - 3142

228 Zagoria RJ, Traver MA, Werle DM et al. Oncologic efficacy of CT-guided percutaneous radiofrequency ablation of renal cell carcinomas. Am J Roentgenol 2007; 189: 429-436

229 Breen DJ, Rutherford EE, Stedman B et al. Management of renal tumors by image-guided radiofrequency ablation: experience in 105 tumors. Cardiovasc Intervent Radiol 2007; 30: 936-942

230 Levinson AW, Su LM, Agarwal D et al. Long-term oncological and overall outcomes of percutaneous radio frequency ablation in high risk surgical patients with a solitary small renal mass. J Urol 2008; 180: 499- 504

231 Stein RJ, KaoukJH. Renal cryotherapy: a detailed review including a 5year follow-up. BJU Int 2007; 99: 1265-1270

232 Atwell TD, Callstrom MR, Farrell MA et al. Percutaneous renal cryoablation: local control at mean 26 months of followup. J Urol 2010; 184: $1291-1295$

233 Atwell TD, Farrell MA, Callstrom MR et al. Percutaneous cryoablation of large renal masses: technical feasibility and short-term outcome. Am J Roentgenol 2007; 188: 1195-1200

234 Klatte T, Kroeger N, Zimmermann U et al. The contemporary role of ablative treatment approaches in the management of renal cell carcinoma (RCC): focus on radiofrequency ablation (RFA), high-intensity focused ultrasound (HIFU), and cryoablation. World J Urol 2014; 32 : 597-605

235 El Dib R, Touma NJ, Kapoor A. Cryoablation vs radiofrequency ablation for the treatment of renal cell carcinoma: a meta-analysis of case series studies. BJU Int 2012; 110: 510-516

236 Goel RK, Kaouk JH. Probe ablative treatment for small renal masses: cryoablation vs. radio frequency ablation. Curr Opin Urol 2008; 18 : $467-473$

237 Wah TM, Irving HC, Gregory W et al. Radiofrequency ablation (RFA) of renal cell carcinoma (RCC): experience in 200 tumours. BJU Int 2014; 113: $416-428$

238 Weight CJ, KaoukJH, Hegarty NJ et al. Correlation of radiographic imaging and histopathology following cryoablation and radio frequency ablation for renal tumors. J Urol 2008; 179: 1277-1281

239 Raman JD, Stern JM, Zeltser I et al. Absence of viable renal carcinoma in biopsies performed more than 1 year following radio frequency ablation confirms reliability of axial imaging. J Urol 2008; 179: $2142-2145$

240 Hui GC, Tuncali K, Tatli S et al. Comparison of percutaneous and surgical approaches to renal tumor ablation: metaanalysis of effectiveness and complication rates. J Vasc Interv Radiol 2008; 19: 1311 -1320

241 Goldberg SN, Grassi CJ, Cardella JF et al. Image-guided tumor ablation: standardization of terminology and reporting criteria. J Vasc Interv Radiol 2009; 20: S377-S390

242 Campbell SC, Novick AC, Belldegrun A et al. Guideline for management of the clinical T1 renal mass. J Urol 2009; 182: 1271 -1279

243 Psutka SP, Feldman AS, McDougal WS et al. Long-term oncologic outcomes after radiofrequency ablation for T1 renal cell carcinoma. Eur Urol 2013; 63: 486-492

244 Kunkle DA, Egleston BL, Uzzo RG. Excise, ablate or observe: the small renal mass dilemma-a meta-analysis and review. J Urol 2008; 179: $1227-1233$

245 Ljungberg B, Cowan NC, Hanbury DC et al. EAU guidelines on renal cell carcinoma: the 2010 update. Eur Urol 2010; 58: 398-406

246 Volpe A, Kachura JR, Geddie WR et al. Techniques, safety and accuracy of sampling of renal tumors by fine needle aspiration and core biopsy. J Urol 2007; 178: 379 - 386 
247 Kyle CC, Wingo MS, Carey RI et al. Diagnostic yield of renal biopsy immediately prior to laparoscopic radiofrequency ablation: a multicenter study. J Endourol 2008; 22: 2291 - 2293

248 Kunkle DA, Uzzo RG. Cryoablation or radiofrequency ablation of the small renal mass: a meta-analysis. Cancer 2008; 113: 2671 - 2680

249 Meloni MF, Bertolotto M, Alberzoni C et al. Follow-up after percutaneous radiofrequency ablation of renal cell carcinoma: contrast-enhanced sonography versus contrast-enhanced CT or MRI. Am J Roentgenol 2008; 191: 1233-1238

250 Kong WT, Zhang WW, Guo HQ et al. Application of contrast-enhanced ultrasonography after radiofrequency ablation for renal cell carcinoma: is it sufficient for assessment of therapeutic response? Abdom Imaging 2011; 36: $342-347$

251 Ignee A, Straub B, Brix D et al. The value of contrast enhanced ultrasound (CEUS) in the characterisation of patients with renal masses. Clin Hemorheol Microcirc 2010; 46: 275-290

252 Ignee A, Straub B, Schuessler G et al. Contrast enhanced ultrasound of renal masses. World J Radiol 2010; 2: 15-31

253 Neoptolemos JP, Stocken DD, Friess $H$ et al. A randomized trial of chemoradiotherapy and chemotherapy after resection of pancreatic cancer. N Engl J Med 2004; 350: 1200 - 1210

254 McWilliams JP, Lee EW, Yamamoto S et al. Image-guided tumor ablation: emerging technologies and future directions. Semin Intervent Radiol 2010; 27: 302-313

255 Girelli $R$, Frigerio I, Salvia $R$ et al. Feasibility and safety of radiofrequency ablation for locally advanced pancreatic cancer. Br J Surg 2010; 97: 220-225

$256 \mathrm{Wu}$ Y, Tang $Z$, Fang $\mathrm{H}$ et al. High operative risk of cool-tip radiofrequency ablation for unresectable pancreatic head cancer.J Surg Oncol 2006; 94: $392-395$

257 Spiliotis JD, Datsis AC, Michalopoulos NV et al. Radiofrequency ablation combined with palliative surgery may prolong survival of patients with advanced cancer of the pancreas. Langenbecks Arch Surg 2007; 392: $55-60$

258 D'Onofrio M, Barbi E, Girelli R et al. Radiofrequency ablation of locally advanced pancreatic adenocarcinoma: an overview. World J Gastroenterol 2010; 16: 3478-3483

259 Fegrachi S, Besselink MG, van Santvoort HC et al. Radiofrequency ablation for unresectable locally advanced pancreatic cancer: a systematic review. HPB (Oxford) 2014; 16: 119-123

260 Casadei R, Ricci C, Pezzilli R et al. A prospective study on radiofrequency ablation locally advanced pancreatic cancer. Hepatobiliary Pancreat Dis Int 2010; 9: 306-311

261 Ikuta S, Kurimoto A, Iida $\mathrm{H}$ et al. Optimal combination of radiofrequency ablation with chemoradiotherapy for locally advanced pancreatic cancer. World J Clin Oncol 2012; 3: 12 - 14

262 Smith EH, Bartrum RJ Jr. Ultrasonically guided percutaneous aspiration of abscesses. Am J Roentgenol Radium Ther Nucl Med 1974; 122: $308-312$

263 Wittmann DH, Schein M, Condon RE. Management of secondary peritonitis. Ann Surg 1996; 224: $10-18$

264 Schein M, Wittmann DH, Wise L et al. Abdominal contamination, infection and sepsis: a continuum. Br J Surg 1997; 84: 269-272

265 Holzheimer RG, Mannick JA. Surgical Treatment: Evidence-Based and Problem-Oriented. Munic: 2001

266 Kishina M, Koda M, Tokunaga S et al. Usefulness of contrast-enhanced ultrasound with Sonazoid for evaluating liver abscess in comparison with conventional B-mode ultrasound. Hepatol Res 2014

267 Liu GJ, Lu MD, Xie XY et al. Real-time contrast-enhanced ultrasound imaging of infected focal liver lesions. J Ultrasound Med 2008; 27 : 657-666

268 Dietrich $C F$, Nuernberg $D$. Interventional Ultrasound: A Practical Guide and Atlas. Stuttgart, New York, Delhi, Rio: Thieme publisher; 2014

269 Cai YL, Xiong XZ, Lu J et al. Percutaneous needle aspiration versus catheter drainage in the management of liver abscess: a systematic review and meta-analysis. Oxford: HPB; 2014

270 Zerem E, Hadzic A. Sonographically guided percutaneous catheter drainage versus needle aspiration in the management of pyogenic liver abscess. Am J Roentgenol 2007; 189: W138 -W142

271 Zerem E, Bergsland J. Ultrasound guided percutaneous treatment for splenic abscesses: the significance in treatment of critically ill patients. World J Gastroenterol 2006; 12: 7341 - 7345

272 Lorentzen T, Nolsoe C, Skjoldbye B. Ultrasound-guided drainage of deep pelvic abscesses: experience with 33 cases. Ultrasound Med Biol 2011; 37: 723-728
273 Schwerk WB, Gorg C, Gorg K et al. Percutaneous drainage of liver and splenic abscess. Z Gastroenterol 1991; 29: $146-152$

274 Schwerk WB, Gorg C, Gorg K et al. Ultrasound-guided percutaneous drainage of pyogenic splenic abscesses. J Clin Ultrasound 1994; 22: $161-166$

275 Singh O, Gupta S, Moses S et al. Comparative study of catheter drainage and needle aspiration in management of large liver abscesses. Indian J Gastroenterol 2009; 28: 88-92

276 Mueller PR, vanSonnenberg E, Ferrucci JT et al. Percutaneous drainage of 250 abdominal abscesses and fluid collections. Part II: Current procedural concepts. Radiology 1984; 151: 343 - 347

277 Rothlin MA, Schob O, Klotz H et al. Percutaneous drainage of abdominal abscesses: are large-bore catheters necessary? Eur J Surg 1998; 164: 419-424

278 Cui XW, Ignee A, Dietrich CF. Ultrasound-guided percutaneous abscess drainage. In. http://www.efsumb.org/asp/detail06.asp?ref=373\&url=/ intro/home.asp?ref=1: European Federation of Societies for Ultrasound in Medicine and Biology; 2011

279 Ignee A, Schuessler G, Cui XW et al. Intracavitary contrast medium ultrasound - different applications, a review of the literature ad future prospects. Ultraschall in Med 2013; 34: 504-525; quiz 526-508

280 Ignee A, Jenssen C, Cui XW et al. Intracavitary contrast-enhanced ultrasound in abscess drainage - feasibility and clinical value. Scand J Gastroenterol 2015: 1-7

281 Pham Van L, Duong Manh H, Pham Nhu H. Amebic abscess of the liver: ultrasound guided puncture. Ann Chir 1996; 50: 340-343

282 Ooi LL, Leong SS. Splenic abscesses from 1987 to 1995. Am J Surg 1997; 174: $87-93$

283 Chou YH, Tiu CM, Chiou HJ et al. Ultrasound-guided interventional procedures in splenic abscesses. Eur J Radiol 1998; 28: 167-170

284 Green BT. Splenic abscess: report of six cases and review of the literature. Am Surg 2001; 67: 80-85

285 Kang $M$, Kalra N, Gulati $M$ et al. Image guided percutaneous splenic interventions. Eur J Radiol 2007; 64: 140-146

286 Lucey BC, Boland GW, Maher MM et al. Percutaneous nonvascular splenic intervention: a 10-year review. Am J Roentgenol 2002; 179: $1591-1596$

287 Ng KK, Lee TY, Wan YL et al. Splenic abscess: diagnosis and management. Hepatogastroenterology 2002; 49: $567-571$

288 Thanos L, Dailiana T, Papaioannou G et al. Percutaneous CT-guided drainage of splenic abscess. Am J Roentgenol 2002; 179: 629-632

289 Ferraioli G, Brunetti E, Gulizia R et al. Management of splenic abscess: report on 16 cases from a single center. Int J Infect Dis 2009; 13: 524 530

290 McInnes MD, Kielar AZ, Macdonald DB. Percutaneous image-guided biopsy of the spleen: systematic review and meta-analysis of the complication rate and diagnostic accuracy. Radiology 2011; 260: 699-708

291 vanSonnenberg E, Wittich GR, Chon KS et al. Percutaneous radiologic drainage of pancreatic abscesses. Am J Roentgenol 1997; 168: 979984

292 vanSonnenberg E, Wittich GR, Goodacre BW et al. Percutaneous abscess drainage: update. World J Surg 2001; 25: 362 - 369; discussion 370-362

293 Fusaroli P, Jenssen C, Hocke $M$ et al. EFSUMB guidelines on interventional ultrasound, part V. EUS-guided therapeutic interventions. Ultraschall in Med 2015; 36

294 Will $U$, Wanzar C, Gerlach $R$ et al. Interventional ultrasound-guided procedures in pancreatic pseudocysts, abscesses and infected necroses - treatment algorithm in a large single-center study. Ultraschall in Med 2011; 32: 176-183

295 Feagins LA, Holubar SD, Kane SV et al. Current strategies in the management of intra-abdominal abscesses in Crohn's disease. Clin Gastroenterol Hepatol 2011; 9: 842-850

296 Gervais DA, Hahn PF, O'Neill MJ et al. Percutaneous abscess drainage in Crohn disease: technical success and short- and long-term outcomes during 14 years. Radiology 2002; 222: 645-651

297 Golfieri R, Cappelli A, Giampalma E et al. CT-guided percutaneous pelvic abscess drainage in Crohn's disease. Tech Coloproctol 2006; 10 : $99-105$

298 Sahai A, Belair M, Gianfelice D et al. Percutaneous drainage of intraabdominal abscesses in Crohn's disease: short and long-term outcome. Am J Gastroenterol 1997; 92: 275 - 278

299 da Luz Moreira A, Stocchi L, Tan E et al. Outcomes of Crohn's disease presenting with abdominopelvic abscess. Dis Colon Rectum 2009; 52: $906-912$ 
300 Rypens F, Dubois J, Garel L et al. Percutaneous drainage of abdominal abscesses in pediatric Crohn's disease. Am J Roentgenol 2007; 188: $579-585$

301 Bahadursingh AM, Virgo KS, Kaminski DL et al. Spectrum of disease and outcome of complicated diverticular disease. Am J Surg 2003; 186: $696-701$

302 Siewert B, Tye G, Kruskal J et al. Impact of CT-guided drainage in the treatment of diverticular abscesses: size matters. Am J Roentgenol 2006; 186: 680-686

303 Brandt D, Gervaz P, Durmishi $Y$ et al. Percutaneous CT scan-guided drainage vs. antibiotherapy alone for Hinchey II diverticulitis: a casecontrol study. Dis Colon Rectum 2006; 49: 1533-1538

304 Kumar RR, Kim JT, Haukoos JS et al. Factors affecting the successful management of intra-abdominal abscesses with antibiotics and the need for percutaneous drainage. Dis Colon Rectum 2006; 49: 183 - 189

305 Kaiser AM, Jiang JK, Lake JP et al. The management of complicated diverticulitis and the role of computed tomography. Am J Gastroenterol 2005; 100: $910-917$

306 Durmishi Y, Gervaz P, Brandt D et al. Results from percutaneous drainage of Hinchey stage II diverticulitis guided by computed tomography scan. Surg Endosc 2006; 20: 1129-1133

307 Kuligowska E, Keller E, Ferrucci JT. Treatment of pelvic abscesses: value of one-step sonographically guided transrectal needle aspiration and lavage. Am J Roentgenol 1995; 164: 201 - 206

308 Wroblicka JT, Kuligowska E. One-step needle aspiration and lavage for the treatment of abdominal and pelvic abscesses. Am J Roentgenol 1998; 170: 1197 - 1203

309 Cheng D, Nagata KT, Yoon HC. Randomized prospective comparison of alteplase versus saline solution for the percutaneous treatment of loculated abdominopelvic abscesses. J Vasc Interv Radiol 2008; 19 : 906-911

310 Laborda A, De Gregorio MA, Miguelena JM et al. Percutaneous treatment of intrabdominal abscess: urokinase versus saline serum in 100 cases using two surgical scoring systems in a randomized trial. Eur Radiol 2009; 19: 1772 - 1779

311 Maskell NA, Davies CW, Nunn AJ et al. U.K. Controlled trial of intrapleural streptokinase for pleural infection. N Engl J Med 2005; 352: $865-874$

312 McDermott VG, Schuster MG, Smith TP. Antibiotic prophylaxis in vascular and interventional radiology. Am J Roentgenol 1997; 169: 31 - 38

313 Venkatesan AM, Kundu S, Sacks D et al. Practice guidelines for adult antibiotic prophylaxis during vascular and interventional radiology procedures. Written by the Standards of Practice Committee for the Society of Interventional Radiology and Endorsed by the Cardiovascular Interventional Radiological Society of Europe and Canadian Interventional Radiology Association [corrected]. J Vasc Interv Radiol 2010; 21: 1611 - 1630; quiz 1631

314 Lorber B, Swenson RM. The bacteriology of intraabdominal infections. Surg Clin North Am 1975; 55: 1349 - 1354

315 Galandiuk S, Lamos J, Montgomery Wet al. Antibiotic penetration of experimental intra-abdominal abscesses. Am Surg 1995; 61: 521 - 525

316 Dravid VS, Gupta A, Zegel HG et al. Investigation of antibiotic prophylaxis usage for vascular and nonvascular interventional procedures. J Vasc Interv Radiol 1998; 9: 401 - 406

317 Mercaldi CJ, Lanes SF. Ultrasound guidance decreases complications and improves the cost of care among patients undergoing thoracentesis and paracentesis. Chest 2013; 143: $532-538$

318 Nicolaou S, Talsky A, Khashoggi K et al. Ultrasound-guided interventional radiology in critical care. Crit Care Med 2007; 35: S186-S197

319 Sharzehi K, Jain V, Naveed A et al. Hemorrhagic complications of paracentesis: a systematic review of the literature. Gastroenterol Res Pract 2014; 2014: 985141

320 Cervini P, Hesley GK, Thompson RL et al. Incidence of infectious complications after an ultrasound-guided intervention. Am J Roentgenol 2010; 195: $846-850$

321 Cavanna L, Mordenti P, Berte $R$ et al. Ultrasound guidance reduces pneumothorax rate and improves safety of thoracentesis in malignant pleural effusion: report on 445 consecutive patients with advanced cancer. World J Surg Oncol 2014; 12: 139

322 Brooling J, Ghaoui R, Lindenauer PK et al. Use of paracentesis in hospitalized patients with decompensated cirrhosis and ascites: Opportunities for quality improvement. J Hosp Med 2014; 9: 797 - 799

323 Bernardi M, Caraceni P, Navickis RJ et al. Albumin infusion in patients undergoing large-volume paracentesis: a meta-analysis of randomized trials. Hepatology 2012; 55: $1172-1181$
324 Katz MJ, Peters MN, Wysocki JD et al. Diagnosis and management of delayed hemoperitoneum following therapeutic paracentesis. Proc (Bayl Univ Med Cent) 2013; 26: 185-186

325 Sangisetty SL, Miner TJ. Malignant ascites: A review of prognostic factors, pathophysiology and therapeutic measures. World J Gastrointest Surg 2012; 4: 87-95

326 Becker G, Galandi D, Blum HE. Malignant ascites: systematic review and guideline for treatment. Eur J Cancer 2006; 42: 589-597

327 Lee A, Lau TN, Yeong KY. Indwelling catheters for the management of malignant ascites. Support Care Cancer 2000; 8: 493-499

328 Sartori S, Nielsen I, Trevisani L et al. Sonographically guided peritoneal catheter placement in the palliation of malignant ascites in end-stage malignancies. Am J Roentgenol 2002; 179: 1618-1620

329 Narayanan G, Pezeshkmehr A, Venkat S et al. Safety and efficacy of the PleurX catheter for the treatment of malignant ascites. J Palliat Med 2014; 17: $906-912$

330 Tapping CR, Ling L, Razack A. PleurX drain use in the management of malignant ascites: safety, complications, long-term patency and factors predictive of success. Br J Radiol 2012; 85: 623 - 628

331 Lungren MP, Kim CY, Stewart JK et al. Tunneled peritoneal drainage catheter placement for refractory ascites: single-center experience in 188 patients. J Vasc Interv Radiol 2013; 24: 1303-1308

332 Fleming ND, Alvarez-Secord A, Von Gruenigen V et al. Indwelling catheters for the management of refractory malignant ascites: a systematic literature overview and retrospective chart review. J Pain Symptom Manage 2009; 38: 341 - 349

333 Richard HM 3rd, Coldwell DM, Boyd-Kranis RL et al. Pleurx tunneled catheter in the management of malignant ascites. J Vasc Interv Radiol 2001; 12: $373-375$

334 Barnett TD, Rubins J. Placement of a permanent tunneled peritoneal drainage catheter for palliation of malignant ascites: a simplified percutaneous approach. J Vasc Interv Radiol 2002; 13: 379-383

335 O'Neill MJ, Weissleder R, Gervais DA et al. Tunneled peritoneal catheter placement under sonographic and fluoroscopic guidance in the palliative treatment of malignant ascites. Am J Roentgenol 2001; 177: $615-618$

336 Rosenberg S, Courtney A, Nemcek AA et al. Comparison of percutaneous management techniques for recurrent malignant ascites. J Vasc Interv Radiol 2004; 15: 1129-1131

337 White J, Carolan-Rees G. PleurX peritoneal catheter drainage system for vacuum-assisted drainage of treatment-resistant, recurrent malignant ascites: a NICE Medical Technology Guidance. Appl Health Econ Health Policy 2012; 10: 299 - 308

338 Zerem E, Imamovic G, Omerovic S. Percutaneous treatment of symptomatic non-parasitic benign liver cysts: single-session alcohol sclerotherapy versus prolonged catheter drainage with negative pressure. Eur Radiol 2008; 18: 400-406

339 Dietrich CF, Braden B. Percutaneous Sclerotherapy of Cysts. In: Dietrich CF, Nuernberg D eds. Interventional ultrasound. Stuttgart: Georg Thieme Verlag /Thieme Publisher; 2014: 165-166

340 Garber S, Mathieson J, Cooperberg PL. Percutaneous sclerosis of hepatic cysts to treat obstructive jaundice in a patient with polycystic liver disease. Am J Roentgenol 1993; 161: 77-78

341 Erdogan D, van Delden OM, Rauws EA et al. Results of percutaneous sclerotherapy and surgical treatment in patients with symptomatic simple liver cysts and polycystic liver disease. World J Gastroenterol 2007; 13: 3095 - 3100

342 Benzimra J, Ronot M, Fuks D et al. Hepatic cysts treated with percutaneous ethanol sclerotherapy: time to extend the indications to haemorrhagic cysts and polycystic liver disease. Eur Radiol 2014; 24: $1030-1038$

343 Gevers TJ, Drenth JP. Diagnosis and management of polycystic liver disease. Nat Rev Gastroenterol Hepatol 2013; 10: 101 -108

344 Temmerman F, Missiaen L, Bammens B et al. Systematic review: the pathophysiology and management of polycystic liver disease. Aliment Pharmacol Ther 2011; 34: $702-713$

345 Macutkiewicz C, Plastow R, Chrispijn M et al. Complications arising in simple and polycystic liver cysts. World J Hepatol 2012; 4: 406-411

346 Fong ZV, Wolf AM, Doria C et al. Hemorrhagic hepatic cyst: report of a case and review of the literature with emphasis on clinical approach and management. J Gastrointest Surg 2012; 16: 1782 - 1789

347 Sparchez Z, Radu P, Zaharie F et al. Percutaneous treatment of symptomatic non-parasitic hepatic cysts. Initial experience with single-session sclerotherapy with polidocanol. Med Ultrason 2014; 16: 222 - 228 
348 Nakaoka R, Das K, Kudo M et al. Percutaneous aspiration and ethanolamine oleate sclerotherapy for sustained resolution of symptomatic polycystic liver disease: an initial experience. Am J Roentgenol 2009; 193: $1540-1545$

349 Furuta T, Yoshida Y, Saku M et al. Treatment of symptomatic nonparasitic liver cysts-surgical treatment versus alcohol injection therapy. HPB Surg 1990; 2: 269-277; discussion 277-269

350 Drenth JP, Chrispijn M, Nagorney DM et al. Medical and surgical treatment options for polycystic liver disease. Hepatology 2010; 52: $2223-2230$

351 Moorthy K, Mihssin N, Houghton PW. The management of simple hepatic cysts: sclerotherapy or laparoscopic fenestration. Ann R Coll Surg Engl 2001; 83: 409-414

352 Yang CF, Liang HL, Pan HB et al. Single-session prolonged alcohol-retention sclerotherapy for large hepatic cysts. Am J Roentgenol 2006; 187: $940-943$

353 Fabrizzi G, Lanza C, Bolli V et al. Symptomatic hepatic cyst in a child: treatment with single-shot injection of tetracycline hydrochloride. Pediatr Radiol 2009; 39: 1091 - 1094

354 Yoshida H, Onda M, Tajiri T et al. Long-term results of multiple minocycline hydrochloride injections for the treatment of symptomatic solitary hepatic cyst. J Gastroenterol Hepatol 2003; 18: 595-598

355 Jusufovic R, Zerem E. Percutaneous treatment of symptomatic nonparasitic benign liver cysts with $20 \% \mathrm{NaCl}$ solution. Med Arh 2011 ; 65: $35-37$

356 Yamamoto K, Sakaguchi H, Anai H et al. Sclerotherapy for simple cysts with use of ethanolamine oleate: preliminary experience. Cardiovasc Intervent Radiol 2005; 28: 751 - 755

357 vanSonnenberg E, Wroblicka JT, D'Agostino HB et al. Symptomatic hepatic cysts: percutaneous drainage and sclerosis. Radiology 1994; 190: $387-392$

358 Tikkakoski T, Makela JT, Leinonen S et al. Treatment of symptomatic congenital hepatic cysts with single-session percutaneous drainage and ethanol sclerosis: technique and outcome. J Vasc Interv Radiol 1996; $7: 235-239$

359 Larssen TB, Jensen DK, Viste A et al. Single-session alcohol sclerotherapy in symptomatic benign hepatic cysts. Long-term results. Acta Radiol 1999; 40: 636-638

360 Larssen TB, Rosendahl K, Horn A et al. Single-session alcohol sclerotherapy in symptomatic benign hepatic cysts performed with a time of exposure to alcohol of 10 min: initial results. Eur Radiol 2003; 13: $2627-2632$

361 Itou C, Koizumi J, Hashimoto T et al. Foam sclerotherapy for a symptomatic hepatic cyst: a preliminary report. Cardiovasc Intervent Radiol 2014; 37: $800-804$

362 Skolarikos A, Laguna MP, de la Rosette JJ. Conservative and radiological management of simple renal cysts: a comprehensive review. BJU Int 2012; 110: $170-178$

363 Okeke AA, Mitchelmore AE, Keeley FX et al. A comparison of aspiration and sclerotherapy with laparoscopic de-roofing in the management of symptomatic simple renal cysts. BJU Int 2003; 92: 610-613

364 Agarwal M, Agrawal MS, Mittal R et al. A randomized study of aspiration and sclerotherapy versus laparoscopic deroofing in management of symptomatic simple renal cysts. J Endourol 2012; 26: 561 - 565

365 Shao Q Xu J, Adams $T$ et al. Comparison of aspiration-sclerotherapy versus laparoscopic decortication in management of symptomatic simple renal cysts. J Xray Sci Technol 2013; 21: 419-428

366 Egilmez H, Gok V, Oztoprak I et al. Comparison of CT-guided sclerotherapy with using $95 \%$ ethanol and $20 \%$ hypertonic saline for managing simple renal cyst. Korean J Radiol 2007; 8: 512 - 519

367 Ohta S, Fujishiro Y, Fuse H. Polidocanol sclerotherapy for simple renal cysts. Urol Int 1997; 58: $145-147$

368 Yoo KH, Lee SJ, Jeon SH. Simple renal cyst sclerotherapy with acetic acid: our 10-year experience. J Endourol 2008; 22: 2559-2563

369 Madeb R, Feldman PA, Knopf J et al. Povidone-iodine sclerotherapy is ineffective in the treatment of symptomatic renal cysts. J Endourol 2006; 20: $402-404$

370 Kilinc M, Tufan O, Guven S et al. Percutaneous injection sclerotherapy with tetracycline hydrochloride in simple renal cysts. Int Urol Nephrol 2008; 40: 609-613

371 Ohkawa M, Tokunaga S, Orito $M$ et al. Percutaneous injection sclerotherapy with minocycline hydrochloride for simple renal cysts. Int Urol Nephrol 1993; 25: $37-43$

372 Zerem E, Imamovic G, Omerovic S. Symptomatic simple renal cyst: comparison of continuous negative-pressure catheter drainage and single-session alcohol sclerotherapy. Am J Roentgenol 2008; 190 $1193-1197$

373 Mohsen T, Gomha MA. Treatment of symptomatic simple renal cysts by percutaneous aspiration and ethanol sclerotherapy. BJU Int 2005; 96: $1369-1372$

374 Delakas D, Karyotis I, Loumbakis Pet al. Long-term results after percutaneous minimally invasive procedure treatment of symptomatic simple renal cysts. Int Urol Nephrol 2001; 32: 321 - 326

375 Chung BH, Kim JH, Hong $\mathrm{CH}$ et al. Comparison of single and multiple sessions of percutaneous sclerotherapy for simple renal cyst. BJU Int 2000; 85: 626-627

376 Fontana D, Porpiglia F, Morra I et al. Treatment of simple renal cysts by percutaneous drainage with three repeated alcohol injection. Urology 1999; 53: $904-907$

377 Hanna RM, Dahniya MH. Aspiration and sclerotherapy of symptomatic simple renal cysts: value of two injections of a sclerosing agent. Am J Roentgenol 1996; 167: 781 - 783

378 Lin YH, Pan HB, Liang HL et al. Single-session alcohol-retention sclerotherapy for simple renal cysts: comparison of 2- and 4-hr retention techniques. Am J Roentgenol 2005; 185: 860 - 866

379 Gasparini D, Sponza M, Valotto $C$ et al. Renal cysts: can percutaneous ethanol injections be considered an alternative to surgery? Urol Int 2003; 71: 197 - 200

380 Touloupidis S, Fatles G, Rombis $V$ et al. Percutaneous drainage of simple cysts of the kidney: a new method. Urol Int 2004; 73: 169-172

381 Falci-Junior R, Lucon AM, Cerri LM et al. Treatment of simple renal cysts with single-session percutaneous ethanol sclerotherapy without drainage of the sclerosing agent. J Endourol 2005; 19: 834-838

382 McManus DP, Zhang W, Li J et al. Echinococcosis. Lancet 2003; 362 $1295-1304$

383 Stojkovic M, Rosenberger K, Kauczor HU et al. Diagnosing and staging of cystic echinococcosis: how do CT and MRI perform in comparison to ultrasound? PLoS Negl Trop Dis 2012; 6: e1880

384 Brunetti E, Kern P, Vuitton DA et al. Expert consensus for the diagnosis and treatment of cystic and alveolar echinococcosis in humans. Acta Trop 2010; 114: 1 - 16

385 Guidelines for treatment of cystic and alveolar echinococcosis in humans. WHO Informal Working Group on Echinococcosis. Bull World Health Organ 1996; 74: $231-242$

386 Group WHOIW. International classification of ultrasound images in cystic echinococcosis for application in clinical and field epidemiological settings. Acta Trop 2003; 85: 253-261

387 Khuroo MS, Wani NA, Javid G et al. Percutaneous drainage compared with surgery for hepatic hydatid cysts. N Engl J Med 1997; 337: 881 887

388 Gharbi HA, Hassine W, Brauner MW et al. Ultrasound examination of the hydatic liver. Radiology 1981; 139: 459 - 463

389 Tamarozzi F, Nicoletti GJ, Neumayr A et al. Acceptance of standardized ultrasound classification, use of albendazole, and long-term followup in clinical management of cystic echinococcosis: a systematic review. Curr Opin Infect Dis 2014; 27: 425-431

390 Ben Amor N, Gargouri M, Gharbi HA et al. Trial therapy of inoperable abdominal hydatid cysts by puncture. Ann Parasitol Hum Comp 1986; 61: 689-692

391 Gargouri M, Ben Amor N, Ben Chehida F et al. Percutaneous treatment of hydatid cysts (Echinococcus granulosus). Cardiovasc Intervent Radiol 1990; 13: 169-173

392 Richter J, Hatz C, Haussinger D. Ultrasound in tropical and parasitic diseases. Lancet 2003; 362: 900 - 902

393 Hosch W, Stojkovic M, Janisch T et al. MR imaging for diagnosing cysto-biliary fistulas in cystic echinococcosis. Eur J Radiol 2008; 66: $262-267$

394 Hosch W, Junghanss T, Stojkovic $M$ et al. Metabolic viability assessment of cystic echinococcosis using high-field 1H MRS of cyst contents. NMR Biomed 2008; 21: 734-754

395 Zhang W, Li J, McManus DP. Concepts in immunology and diagnosis of hydatid disease. Clin Microbiol Rev 2003; 16: 18-36

396 Rinaldi F, Brunetti E, Neumayr A et al. Cystic echinococcosis of the liver: A primer for hepatologists. World J Hepatol 2014; 6: 293 - 305

397 Junghanss T, da Silva AM, Horton J et al. Clinical management of cystic echinococcosis: state of the art, problems, and perspectives. Am J Trop Med Hyg 2008; 79: 301 - 311

398 Giorgio A, de Stefano G, Esposito $V$ et al. Long-term results of percutaneous treatment of hydatid liver cysts: a single center 17 years experience. Infection 2008; 36: $256-261$ 
399 Akhan O, Yildiz AE, Akinci D et al. Is the adjuvant albendazole treatment really needed with PAIR in the management of liver hydatid cysts? A prospective, randomized trial with short-term follow-up results. Cardiovasc Intervent Radiol 2014; 37: 1568 - 1574

400 Brunetti E, Junghanss T. Update on cystic hydatid disease. Curr Opin Infect Dis 2009; 22: $497-502$

401 Kabaalioglu A, Ceken K, Alimoglu E et al. Percutaneous imaging-guided treatment of hydatid liver cysts: do long-term results make it a first choice? Eur J Radiol 2006; 59: 65 - 73

402 Giorgio A, Tarantino L, de Stefano G et al. Hydatid liver cyst: an 11-year experience of treatment with percutaneous aspiration and ethanol injection. J Ultrasound Med 2001; 20: 729-738

403 Giorgio A, Di Sarno A, de Stefano G et al. Sonography and clinical outcome of viable hydatid liver cysts treated with double percutaneous aspiration and ethanol injection as first-line therapy: efficacy and long-term follow-up. Am J Roentgenol 2009; 193: W186-W192

404 Giorgio A, de Stefano G, Di Sarno A et al. Clinical and sonographic management of viable hydatid liver cysts. J Ultrasound 2008; 11: 107-112

405 Tappeh KH, Einshaei A, Mahmudloo R et al. Effect of different concentrations of hypertonic saline at different times on protoscoleces of hydatid cyst isolated from liver and lung. Turkiye Parazitol Derg 2011; 35: $148-150$

406 Giorgio A, Calisti G, de Stefano G et al. Percutaneous treatment of hydatid liver cysts: an update. Recent Pat Antiinfect Drug Discov 2012; 7: $231-236$

407 Smego RA Jr, Bhatti S, Khaliq AA et al. Percutaneous aspiration-injection-reaspiration drainage plus albendazole or mebendazole for hepatic cystic echinococcosis: a meta-analysis. Clin Infect Dis 2003; 37 : $1073-1083$

408 Khuroo MS, Dar MY, Yattoo GN et al. Percutaneous drainage versus albendazole therapy in hepatic hydatidosis: a prospective, randomized study. Gastroenterology 1993; 104: 1452-1459

409 Nasseri-Moghaddam S, Abrishami A, Taefi A et al. Percutaneous needle aspiration, injection, and re-aspiration with or without benzimidazole coverage for uncomplicated hepatic hydatid cysts. Cochrane Database Syst Rev 2011: CD003623

410 Gupta N, Javed A, Puri S et al. Hepatic hydatid: PAIR, drain or resect? J Gastrointest Surg 2011; 15: 1829-1836

411 Cozzi G, Severini A, Civelli E et al. Percutaneous transhepatic biliary drainage in the management of postsurgical biliary leaks in patients with nondilated intrahepatic bile ducts. Cardiovasc Intervent Radiol 2006; 29: $380-388$

412 Nagino M, Takada T, Miyazaki $M$ et al. Preoperative biliary drainage for biliary tract and ampullary carcinomas. J Hepatobiliary Pancreat Surg 2008; 15: $25-30$

413 Kavanagh PV, vanSonnenberg E, Wittich GR et al. Interventional radiology of the biliary tract. Endoscopy 1997; 29: 570-576

414 Adler DG, Baron TH, Davila RE et al. ASGE guideline: the role of ERCP in diseases of the biliary tract and the pancreas. Gastrointest Endosc 2005; 62: $1-8$

415 Itoi T, Tsuyuguchi T, Takada T et al. TG13 indications and techniques for biliary drainage in acute cholangitis (with videos). J Hepatobiliary Pancreat Sci 2013; 20: $71-80$

416 Skinner M, Popa D, Neumann H et al. ERCP with the overtube-assisted enteroscopy technique: a systematic review. Endoscopy 2014; 46: $560-572$

417 Will $U$, Meyer F. Endoscopic ultrasonography (EUS)-guided transluminal cholangiodrainage (EUCD) - a novel option of interventional endoscopy in the interdiciplinary management of obstructive jaundice. Zentralbl Chir 2012; 137: 20-31

418 Dumonceau JM, Tringali A, Blero D et al. Biliary stenting: indications, choice of stents and results: European Society of Gastrointestinal Endoscopy (ESGE) clinical guideline. Endoscopy 2012; 44: 277-298

419 Anderson MA, Appalaneni V, Ben-Menachem T. American Society for Gastrointestinal Endoscopy Standards of Practice C. et al. The role of endoscopy in the evaluation and treatment of patients with biliary neoplasia. Gastrointest Endosc 2013; 77: 167-174

420 Hayashi N, Sakai T, Kitagawa $M$ et al. US-guided left-sided biliary drainage: nine-year experience. Radiology 1997; 204: 119-122

421 Rivera-Sanfeliz GM, Assar OS, LaBerge JM et al. Incidence of important hemobilia following transhepatic biliary drainage: left-sided versus right-sided approaches. Cardiovasc Intervent Radiol 2004; 27: 137 139

422 Kuhn JP, Busemann A, Lerch MM et al. Percutaneous biliary drainage in patients with nondilated intrahepatic bile ducts compared with pa- tients with dilated intrahepatic bile ducts. Am J Roentgenol 2010; 195: $851-857$

423 Weber A, Gaa J, Rosca B et al. Complications of percutaneous transhepatic biliary drainage in patients with dilated and nondilated intrahepatic bile ducts. Eur J Radiol 2009; 72: 412-417

424 Lee W, Kim GC, Kim JY et al. Ultrasound and fluoroscopy guided percutaneous transhepatic biliary drainage in patients with nondilated bile ducts. Abdom Imaging 2008; 33: 555-559

425 Miyazaki M, Shibuya K, Tokue H et al. Percutaneous transhepatic biliary drainage assisted by real-time virtual sonography: a retrospective study. BMC Gastroenterol 2013; 13: 127

426 Feigenbaum K, Ellett ML, Miller R et al. ALARA study of teaching effectiveness on reducing radiation exposure. Gastroenterol Nurs 1998; 21: $234-238$

427 Kozlov AV, Polikarpov AA, Oleshchuk NV et al. Comparative assessment of percutaneous transhepatic cholangio drainage under roentgenoscopy and ultrasound guidance. Vestn Rentgenol Radiol 2002; 4: $30-33$

428 Saad WE, Wallace MJ, Wojak JC et al. Quality improvement guidelines for percutaneous transhepatic cholangiography, biliary drainage, and percutaneous cholecystostomy. J Vasc Interv Radiol 2010; 21: 789 795

429 Choi S, McCartney CJ. Evidence Base for the Use of Ultrasound for Upper Extremity Blocks: 2014 Update. Reg Anesth Pain Med 2014

430 Atkinson P, Boyle A, Robinson S et al. Should ultrasound guidance be used for central venous catheterisation in the emergency department? Emerg Med J 2005; 22: 158-164

431 Ignee A, Baum U, Schuessler $G$ et al. Contrast-enhanced ultrasoundguided percutaneous cholangiography and cholangiodrainage (CEUSPTCD). Endoscopy 2009; 41: 725 - 726

432 Ignee A, Cui X, Schuessler G et al. Percutaneous transhepatic cholangiography and drainage using extravascular contrast enhanced ultrasound. Z Gastroenterol 2015; 53: 385 - 390

433 Luyao Z, Xiaoyan X, Huixiong X et al. Percutaneous ultrasound-guided cholangiography using microbubbles to evaluate the dilated biliary tract: initial experience. Eur Radiol 2012; 22: 371-378

$434 \mathrm{Xu}$ EJ, Zheng RQ Su ZZ et al. Intra-biliary contrast-enhanced ultrasound for evaluating biliary obstruction during percutaneous transhepatic biliary drainage: a preliminary study. Eur J Radiol 2012; 81: $3846-3850$

435 Gurusamy K, Junnarkar S, Farouk $M$ et al. Meta-analysis of randomized controlled trials on the safety and effectiveness of day-case laparoscopic cholecystectomy. Br J Surg 2008; 95: 161 - 168

436 Gurusamy K, Samraj K, Gluud C et al. Meta-analysis of randomized controlled trials on the safety and effectiveness of early versus delayed laparoscopic cholecystectomy for acute cholecystitis. Br J Surg 2010; 97: 141 - 150

437 Houghton PW, Jenkinson LR, Donaldson LA. Cholecystectomy in the elderly: a prospective study. Br J Surg 1985; 72: 220-222

438 Sanjay P, Mittapalli D, Marioud A et al. Clinical outcomes of a percutaneous cholecystostomy for acute cholecystitis: a multicentre analysis. HPB (Oxford) 2013; 15: $511-516$

439 Elyaderani M, Gabriele OF. Percutaneous cholecystostomy and cholangiography in patients with obstructive jaundice. Radiology 1979; 130: $601-602$

440 Shaver RW, Hawkins IF Jr, Soong J. Percutaneous cholecystostomy. Am J Roentgenol 1982; 138: 1133 - 1136

441 Winbladh A, Gullstrand P, Svanvik J et al. Systematic review of cholecystostomy as a treatment option in acute cholecystitis. HPB (Oxford) 2009; 11: $183-193$

442 Venara A, Carretier V, Lebigot J et al. Technique and indications of percutaneous cholecystostomy in the management of cholecystitis in 2014. J Visc Surg 2014; 151: 435 - 439

443 Miura F, Takada T, Kawarada Y et al. Flowcharts for the diagnosis and treatment of acute cholangitis and cholecystitis: Tokyo Guidelines. J Hepatobiliary Pancreat Surg 2007; 14: 27 - 34

444 Chung YH, Choi ER, Kim KM et al. Can percutaneous cholecystostomy be a definitive management for acute acalculous cholecystitis? J Clin Gastroenterol 2012; 46: 216-219

445 Kirkegard J, Horn T, Christensen SD et al. Percutaneous Cholecystostomy is an Effective Definitive Treatment Option for Acute Acalculous Cholecystitis. Scand J Surg 2015

446 Horn T, Christensen SD, Kirkegard J et al. Percutaneous cholecystostomy is an effective treatment option for acute calculous cholecystitis: a 10-year experience. HPB (Oxford) 2015; 17: 326-331 
447 Gurusamy KS, Rossi M, Davidson BR. Percutaneous cholecystostomy for high-risk surgical patients with acute calculous cholecystitis. Cochrane Database Syst Rev 2013; 8: CD007088

$448 \mathrm{Hu}$ YR, Pan JH, Tong XC et al. Efficacy and safety of B-mode ultrasound-guided percutaneous transhepatic gallbladder drainage combined with laparoscopic cholecystectomy for acute cholecystitis in elderly and high-risk patients. BMC Gastroenterol 2015; 15: 81

449 Na BG, Yoo YS, Mun SP et al. The safety and efficacy of percutaneous transhepatic gallbladder drainage in elderly patients with acute cholecystitis before laparoscopic cholecystectomy. Ann Surg Treat Res 2015; 89: $68-73$

450 Anderson JE, Chang DC, Talamini MA. A nationwide examination of outcomes of percutaneous cholecystostomy compared with cholecystectomy for acute cholecystitis, 1998-2010. Surg Endosc 2013; 27: $3406-3411$

451 Takada T, Strasberg SM, Solomkin JS et al. TG13: Updated Tokyo Guidelines for the management of acute cholangitis and cholecystitis. J Hepatobiliary Pancreat Sci 2013; 20: 1 -7

452 Chiappetta Porras LT, Napoli ED, Canullan CM et al. Minimally invasive management of acute biliary tract disease during pregnancy. HPB Surg 2009; 2009: 829020

453 Gunay Y, Bircan HY, Emek E et al. The management of acute cholecystitis in chronic hemodialysis patients: percutaneous cholecystostomy versus cholecystectomy. J Gastrointest Surg 2013; 17: 319-325

454 Hatzidakis AA, Prassopoulos P, Petinarakis I et al. Acute cholecystitis in high-risk patients: percutaneous cholecystostomy vs conservative treatment. Eur Radiol 2002; 12: 1778 - 1784

455 Johanning JM, Gruenberg JC. The changing face of cholecystectomy. Am Surg 1998; 64: 643-647; discussion 647-648

456 Barie PS, Eachempati SR. Acute acalculous cholecystitis. Curr Gastroenterol Rep 2003; 5: 302 - 309

457 Simorov A, Ranade A, Parcells J et al. Emergent cholecystostomy is superior to open cholecystectomy in extremely ill patients with acalculous cholecystitis: a large multicenter outcome study. Am J Surg 2013; 206: 935 - 940; discussion 940-931

458 Ito K, Fujita N, Noda $Y$ et al. Percutaneous cholecystostomy versus gallbladder aspiration for acute cholecystitis: a prospective randomized controlled trial. Am J Roentgenol 2004; 183: 193-196

459 Chopra S, Dodd GD 3rd, Mumbower AL et al. Treatment of acute cholecystitis in non-critically ill patients at high surgical risk: comparison of clinical outcomes after gallbladder aspiration and after percutaneous cholecystostomy. Am J Roentgenol 2001; 176: 1025-1031

460 Melloul E, Denys A, Demartines $N$ et al. Percutaneous drainage versus emergency cholecystectomy for the treatment of acute cholecystitis in critically ill patients: does it matter? World J Surg 2011; 35: 826 833

461 Hatjidakis AA, Karampekios S, Prassopoulos P et al. Maturation of the tract after percutaneous cholecystostomy with regard to the access route. Cardiovasc Intervent Radiol 1998; 21: 36-40

462 van Overhagen $H$, Meyers H, Tilanus HW et al. Percutaneous cholecystectomy for patients with acute cholecystitis and an increased surgical risk. Cardiovasc Intervent Radiol 1996; 19: 72 - 76

463 Loberant $N$, Notes $Y$, Eitan A et al. Comparison of early outcome from transperitoneal versus transhepatic percutaneous cholecystostomy. Hepatogastroenterology 2010; 57: $12-17$

464 Gang MH, Kim JY. Short-Term Complications of Percutaneous Endoscopic Gastrostomy according to the Type of Technique. Pediatr Gastroenterol Hepatol Nutr 2014; 17: 214-222

465 Campoli PM, de Paula AA, Alves LG et al. Effect of the introducer technique compared with the pull technique on the peristomal infection rate in PEG: a meta-analysis. Gastrointest Endosc 2012; 75: 988 - 996

466 Lowe AS, Laasch HU, Stephenson S et al. Multicentre survey of radiologically inserted gastrostomy feeding tube (RIG) in the UK. Clin Radiol 2012; 67: 843 - 854

467 Blomberg J, Lagergren J, Martin L et al. Complications after percutaneous endoscopic gastrostomy in a prospective study. Scand J Gastroenterol 2012; 47: 737 - 742

468 Laskaratos FM, Walker M, Walker $M$ et al. Predictive factors for early mortality after percutaneous endoscopic and radiologically-inserted gastrostomy. Dig Dis Sci 2013; 58: 3558 - 3565

469 Schlottmann K, Klebl F, Wiest R et al. Ultrasound-guided percutaneous endoscopic gastrostomy in patients with negative diaphanoscopy. Endoscopy 2007; 39: 686-691

470 Lorentzen T, Skjoldbye B, Nolsoe C et al. Percutaneous gastrostomy guided by ultrasound and fluoroscopy. Acta Radiol 1995; 36: 159-162
471 Lorentzen T, Nolsoe CP, Adamsen S. Percutaneous radiologic gastrostomy with a simplified gastropexy technique under ultrasonographic and fluoroscopic guidance: experience in 154 patients. Acta Radiol 2007; 48: $13-19$

472 Klek S, Hermanowicz A, Salowka J et al. Ultrasound-guided percutaneous 'push-introducer' gastrostomy is a valuable method for accessing the gastrointestinal tract. Nutr Hosp 2014; 29: 365 - 369

473 Pugash RA, Brady AP, Isaacson S. Ultrasound guidance in percutaneous gastrostomy and gastrojejunostomy. Can Assoc Radiol J 1995; 46: $196-198$

474 Quadri A, Umapathy N, Orme R. Percutaneous gastrostomy in patients with complete obstruction of the upper digestive tract. Eur J Radiol 2005; 56: 74-77

475 Lipp A, Lusardi G. Systemic antimicrobial prophylaxis for percutaneous endoscopic gastrostomy. Cochrane Database Syst Rev 2013; 11: CD005571

476 Wah TM, Weston MJ, Irving HC. Percutaneous nephrostomy insertion: outcome data from a prospective multi-operator study at a UK training centre. Clin Radiol 2004; 59: 255 - 261

477 Hausegger KA, Portugaller HR. Percutaneous nephrostomy and antegrade ureteral stenting: technique-indications-complications. Eur Radiol 2006; 16: 2016-2030

478 Dagli M, Ramchandani P. Percutaneous nephrostomy: technical aspects and indications. Semin Intervent Radiol 2011; 28: 424-437

479 Hopper KD, Sherman JL, Luethke JM et al. The retrorenal colon in the supine and prone patient. Radiology 1987; 162: $443-446$

480 Hopper $K D$, Yakes WF. The posterior intercostal approach for percutaneous renal procedures: risk of puncturing the lung, spleen, and liver as determined by CT. Am J Roentgenol 1990; 154: 115-117

481 Mahmood RD, Yizhi L, Tan MLM. Percutaneous Nephrostomy. In Goeoz M ed. Chronic Kidney Disease. InTech; 2012: 297-314

482 Ramchandani P, Cardella JF, Grassi CJ et al. Quality improvement guidelines for percutaneous nephrostomy. J Vasc Interv Radiol 2003; 14: S277 - S281

483 Png JC, Chapple CR. Principles of ureteric reconstruction. Curr Opin Urol 2000; 10: 207-212

484 Lapitan MC, Buckley BS. Impact of palliative urinary diversion by percutaneous nephrostomy drainage and ureteral stenting among patients with advanced cervical cancer and obstructive uropathy: a prospective cohort. J Obstet Gynaecol Res 2011; 37: 1061 - 1070

485 Ahmad I, Saeed Pansota M, Tariq M et al. Comparison between Double J (DJ) Ureteral Stenting and Percutaneous Nephrostomy (PCN) in Obstructive Uropathy. Pak J Med Sci 2013; 29: 725-729

486 Wyatt J, Kolettis PN, Burns JR. Treatment outcomes for percutaneous nephrolithotomy in renal allografts. J Endourol 2009; 23: 1821 - 1824

487 Mahdavi $R$, Tavakkoli M, Taghavi $R$ et al. Minimally invasive procedures for treatment of urolithiasis in transplanted kidneys. Exp Clin Transplant 2014; 12: 200-204

488 Farrell TA, Hicks ME. A review of radiologically guided percutaneous nephrostomies in 303 patients. J Vasc Interv Radiol 1997; 8: 769 - 774

489 Skolarikos A, Alivizatos G, Papatsoris A et al. Ultrasound-guided percutaneous nephrostomy performed by urologists: 10-year experience. Urology 2006; 68: 495 - 499

490 Kariniemi J, Sequeiros RB, Ojala $R$ et al. MRI-guided percutaneous nephrostomy: a feasibility study. Eur Radiol 2009; 19: 1296-1301

491 Barbaric ZL, Hall T, Cochran ST et al. Percutaneous nephrostomy: placement under CT and fluoroscopy guidance. Am J Roentgenol 1997; 169: 151 - 155

492 Cui XW, Ignee A, Maros T et al. The use of ultrasound contrast agent in ultrasound guided percutaneous nephrostomy. Lepzig: Z Gastroenterol; 2014: KG264

493 Nielsen OS, Grossmann E. Ultrasonically guided percutaneous nephrostomy. Scand J Urol Nephrol 1990; 24: 219-221

494 Ray CE Jr, Brown AC, Smith MT et al. Percutaneous access of nondilated renal collecting systems. Semin Intervent Radiol 2014; 31: $98-100$

495 Patel U, Hussain FF. Percutaneous nephrostomy of nondilated renal collecting systems with fluoroscopic guidance: technique and results. Radiology 2004; 233: 226 - 233

496 Fischbach $F$, Porsch M, Krenzien $F$ et al. MR imaging guided percutaneous nephrostomy using a 1.0 Tesla open MR scanner. Cardiovasc Intervent Radiol 2011; 34: 857-863

497 Mariappan P, Smith G, Moussa SA et al. One week of ciprofloxacin before percutaneous nephrolithotomy significantly reduces upper tract infection and urosepsis: a prospective controlled study. BJU Int 2006; 98: $1075-1079$ 
498 Karim R, Sengupta S, Samanta $S$ et al. Percutaneous nephrostomy by direct puncture technique: An observational study. Indian J Nephrol 2010; 20: 84-88

499 Regalado SP. Emergency percutaneous nephrostomy. Semin Intervent Radiol 2006; 23: 287-294

500 Cangüven O, Göktafl C, Kafkasl A et al. Comparison of direct and Seldinger percutaneous nephrostomy insertion techniques. BTDMJB 2009; 5: $103-105$

501 Li CC, Li JR, Huang LH et al. Metallic stent in the treatment of ureteral obstruction: experience of single institute. J Chin Med Assoc 2011; 74: $460-463$

502 Dyer RB, Regan JD, Kavanagh PV et al. Percutaneous nephrostomy with extensions of the technique: step by step. Radiographics 2002; 22: $503-525$

503 von der Recke P, Nielsen MB, Pedersen JF. Complications of ultrasoundguided nephrostomy. A 5-year experience. Acta Radiol 1994; 35: $452-454$

504 Lee WJ, Smith $A D$, Cubelli V et al. Complications of percutaneous nephrolithotomy. Am J Roentgenol 1987; 148: 177-180

505 Carey RI, Siddiq FM, Guerra J et al. Conservative management of a splenic injury related to percutaneous nephrostolithotomy. JSLS 2006; 10: 504-506

506 Lewis S, Patel U. Major complications after percutaneous nephrostomy-lessons from a department audit. Clin Radiol 2004; 59: 171 - 179

507 Lee WJ, Patel U, Patel S et al. Emergency percutaneous nephrostomy: results and complications. J Vasc Interv Radiol 1994; 5: 135-139

508 Radecka E, Magnusson A. Complications associated with percutaneous nephrostomies. A retrospective study. Acta Radiol 2004; 45: $184-188$

509 LeMaitre L, Mestdagh P, Marecaux-Delomez J et al. Percutaneous nephrostomy: placement under laser guidance and real-time CT fluoroscopy. Eur Radiol 2000; 10: $892-895$

510 Lee MJ, Papanicolaou N, Nocks BN et al. Fluoroscopically guided percutaneous suprapubic cystostomy for long-term bladder drainage: an alternative to surgical cystostomy. Radiology 1993; 188: 787-789
511 Gochman RF, Karasic RB, Heller MB. Use of portable ultrasound to assist urine collection by suprapubic aspiration. Ann Emerg Med 1991; 20: $631-635$

512 Chu RW, Wong YC, Luk SH et al. Comparing suprapubic urine aspiration under real-time ultrasound guidance with conventional blind aspiration. Acta Paediatr 2002; 91: 512-516

513 Kiernan SC, Pinckert TL, Keszler M. Ultrasound guidance of suprapubic bladder aspiration in neonates. J Pediatr 1993; 123: 789-791

514 Cronin CG, Prakash P, Gervais DA et al. Imaging-guided suprapubic bladder tube insertion: experience in the care of 549 patients. Am J Roentgenol 2011; 196: $182-188$

515 Rohl L. On the etiology of bladder cancer. Urologe 1963; 2: 57-61

516 Harrison SC, Lawrence WT, Morley R et al. British Association of Urological Surgeons' suprapubic catheter practice guidelines. BJU Int 2011; 107: 77-85

517 Jacob P, Rai BP, Todd AW. Suprapubic catheter insertion using an ultrasound-guided technique and literature review. BJU Int 2012; 110: $779-784$

518 Lawrentschuk N, Lee D, Marriott P et al. Suprapubic stab cystostomy: a safer technique. Urology 2003; 62: 932-934

519 Aguilera PA, Choi T, Durham BA. Ultrasound-guided suprapubic cystostomy catheter placement in the emergency department. J Emerg Med 2004; 26: 319-321

520 Lamont T, Harrison S, Panesar S et al. Safer insertion of suprapubic catheters: summary of a safety report from the National Patient Safety Agency. BMJ 2011; 342: d924

521 Johnson S, Fiscus G, Sudakoff GS et al. The utility of abdominal ultrasound during percutaneous suprapubic catheter placement. Can J Urol 2013; 20: 6840-6843

522 Requarth J. Image-guided palliative care procedures. Surg Clin North Am 2011; 91: 367-402, ix

523 Mariani PJ, Setla JA. Palliative ultrasound for home care hospice patients. Acad Emerg Med 2010; 17: 293-296 